\title{
ACTIVIDAD TURÍSTICA Y CAMBIO CLIMÁTICO EN LA COMUNIDAD VALENCIANA
}

Diagnóstico y propuestas

Estudio elaborado por la Universidad de Alicante en colaboración con la Agència Valenciana del Turisme.

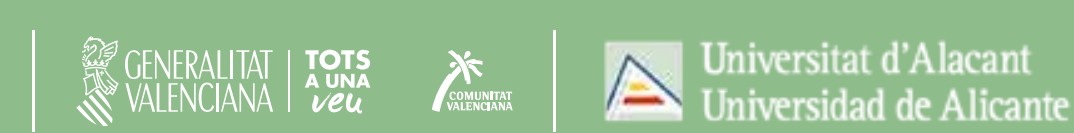

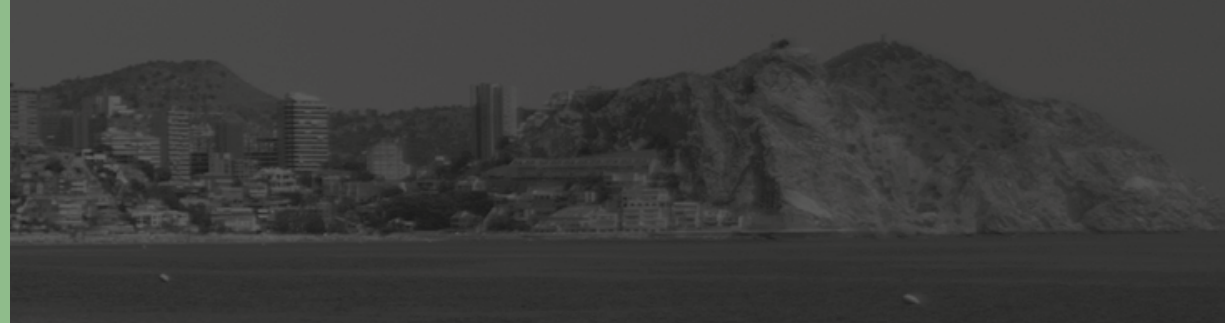




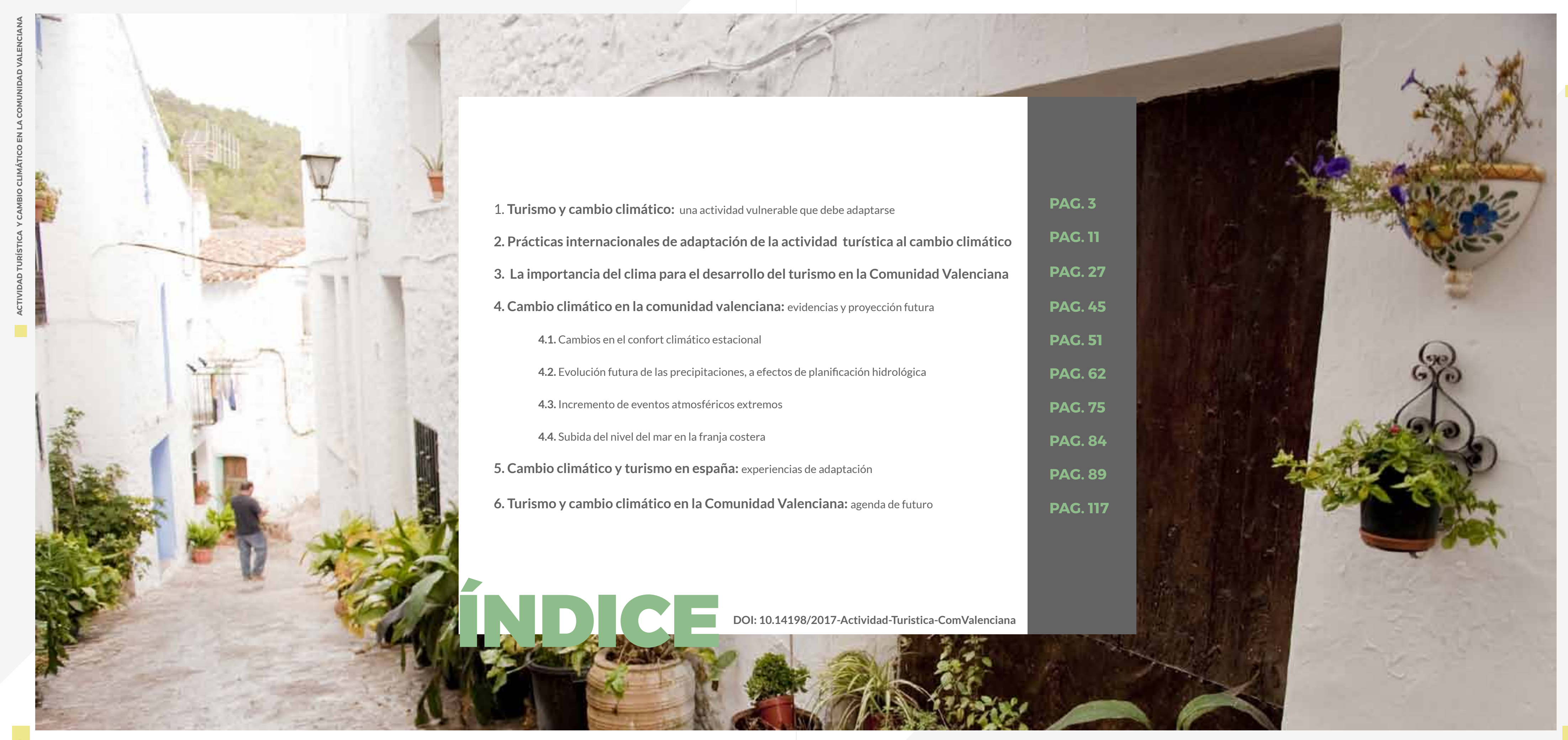


El turismo es, junto a la agricultura, la actividad económica con más alto grado de exposición a los efectos del calentamiento climático. En términos de análisis de riesgo la agricultura es una actividad más expuesta pero menos vulnerable, mientras que el turismo es una actividad más vulnerable con una exposicín variable según la modalidad que se practique en el espacio geográfico: muy elevada, por ejemplo, en el caso del turismo de sol y playa, del turismo de nieve o en el turismo urbano de grandes ciudades. El análisis de los factores espaciales que permiten el desarrollo de a actividad turística en un territorio ha cobrado creciente protagonismo en la

investigación científica del turismo En el contexto actula de globalización, de cambios económicos acelerados, cualquier alteración en los elementos del medio físico pueden afectar a la actividad económica de un territorio El mantenimiento de los recursos territoriales que favorecen la actividad turística en los principales destinos mundiales

Ienod inceridumbes debidoalas nodfcaiones

que, de forma manifiesta, experimentan las condiciones climáticas terrestres.

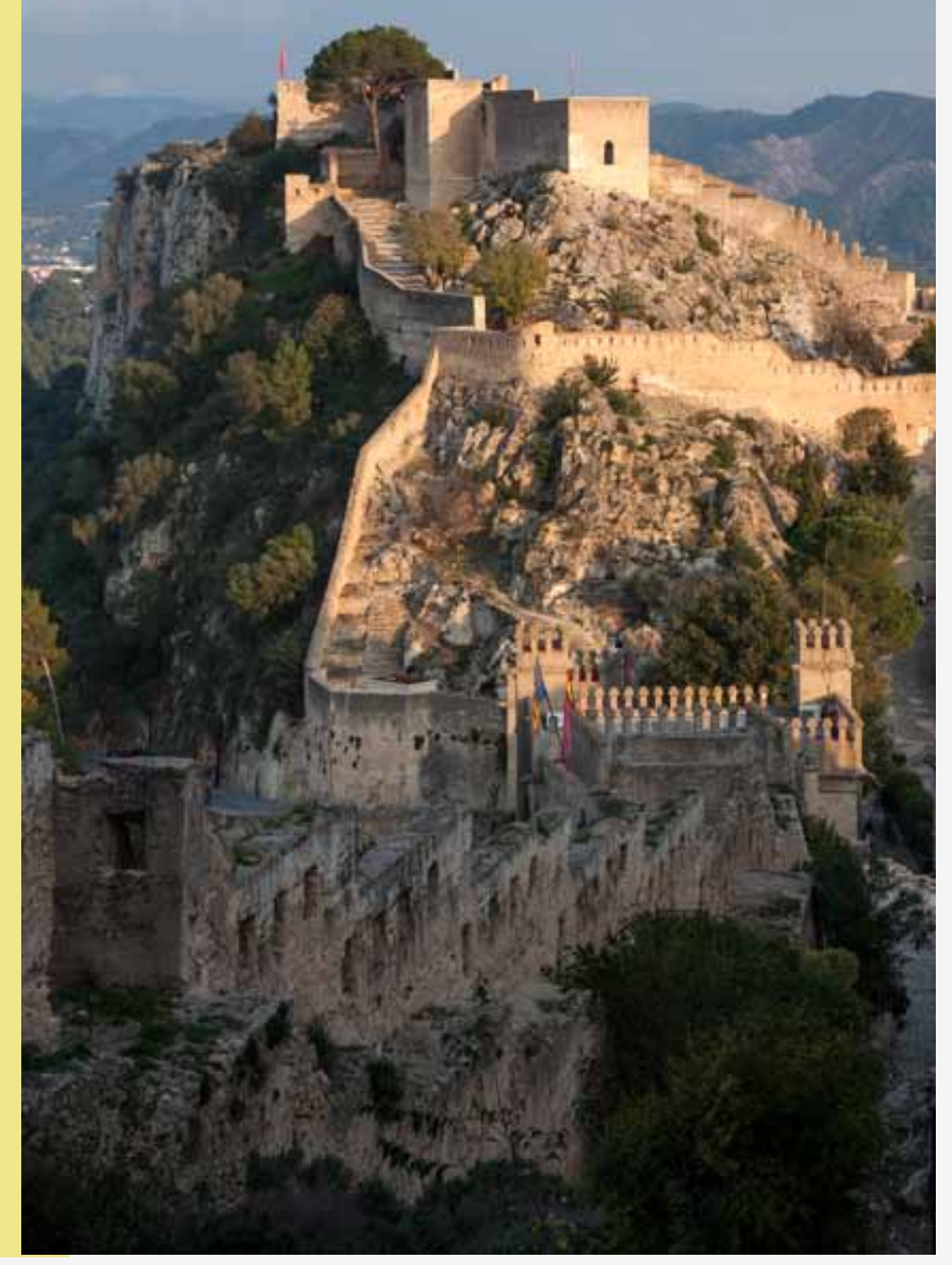



de se desarrolla. Otra cuestión es el grado real de preparación existen-
Los efectos posibles del cambio climático son conocidos, desde hace años, por el sector turístico. A la celebración regular, desde 2003, de conferencias internacionales sobre la cuestión, bajo los auspicios de la Organización Mundial del Turismo (Djerba, Davos, Copenhague, Cancún, Durban, Doha, Kenia) y de congresos mundiales sobre aspectos concretos de la relación entre cambio climático y turismo, asimismo organizados por la OMT, (turismo de montaña y nieve; turismo y transporte aéreo), se une la lucha contra el cambio climático en los planes elaborados por los gobiernos en los países desarrollados y las medidas puestas en marcha, desde el ámbito privado del propio sector turístico. Hay, por tanto, un nivel de conocimiento elevado de esta cuestión en consonancia con la importancia de los efectos que puede suponer e cambio climático en esta actividad económica y en los territorios donte y la efectividad de las medidas desarrolladas. Sirva como muestra la aplicación de la tasa de emisiones de $\mathrm{CO} 2$ para las compañías aéreas puesta en marcha en la Unión Europea y que ha desatado serias reacciones en contra por parte de compañías de países exteriores (EE.UU. China, India), lo que está impidiendo su cumplimiento.

En el informe sobre adaptación de la economía al cambio climático (KPMG, 2008) $)^{1}$ se manifiesta el escaso grado de preparación de turismo ante el cambio climático, frente al elevado nivel de percepción del riesgo que este proceso supone para el sector. En España, informe sobre la respuesta de la sociedad ante el cambio climático

(Meira Cartea, dir., 2013) ${ }^{2}$ señala que apenas el $43 \%$ de la muestra encuestada considera probable que se experimente una disminución de la actividad turística en nuestro país a medio plazo (horizonte 2030) por efecto del cambio climático, frente a un $51 \%$ que lo estima poco o nada probable. Es un resultado 25 puntos porcentuales inferior a la probabilidad estimada para el siguiente enunciado menos valorado entre las cuestiones analizadas en la muestra (la "extinción acelerad de especies de plantas y animales", 69,5\%). Por contra, el que más

valoración de probabilidad real de desarrollo presenta en la muestra analizada $(86,3 \%)$ es el relativo a la génesis más frecuente de períodos de sequía. Es significativo comprobar, asimismo, que dentro de la división en áreas climáticas que se ha realizado en este informe, la zona "mediterránea" (litoral) es la que estima menos probable (sólo un $48 \%$ lo considera probable) el desarrollo de disminución significativa de la actividad turística a medio plazo (2030), frente a otras zonas climáticas donde la actividad turística es menos destacada (montaña, $52 \%$; interior, $67 \%$ )

Una valoración actualizada del impacto económico del cambio climático y, de manera específica, de sus efectos en áreas geográficas de litoral con vocación turística, como el litoral mediterráneo español, ha sido realizada en la revisión del informe JRC Peseta l| (2014) A partir de manejo de 4 modelos climáticos se ha calculado el efecto en diversos sectores económicos del calentamiento planetario. En efecto, se han manejado tres escenarios de emisiones medio-altas: uno sin medidas

VVid. KPMG (2008) Climate changes your bussines. KPMG Global Sustainable Services, The Netherlands, 85 p. disponible en

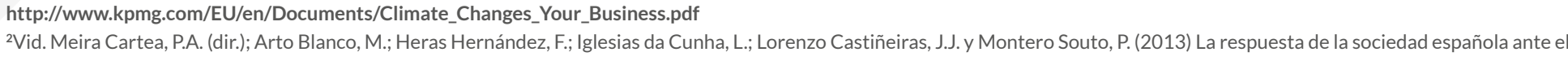
cambio climático, Fundación Mapfre, Madrid, 223 de mitigación (SRES A1B) o business as usual, que conduce a un aumento global de $3,5^{\circ} \mathrm{C}$ de temperatura en 2100 , en comparación con el nivel preindustrial: un segundo escenario a partir también del SRES A1B más cálido y más seco: un tercer escenario por el contrario más frio y húmedo que el de referencia SRES A1B Por último un cuarto escenario que tiene en cuenta el objetivo climático de la UE de incremento ta sólo de $2^{\circ} \mathrm{C}$ en 2100, con reducción de emisiones, a partir del modelo ENSEMBLES E1. España se ha incluido en la región de Europa meridiona dentro de este informe, para la cual se presenta una evolución poco favorable en los registros de temperatura y de $2^{\circ} \mathrm{C}$ en 2100 , con reducció de emisiones, a partir del modelo ENSEMBLES E1. España se ha incluido en la región de Europa meridional dentro de este informe, para la cual se presenta una evolución poco favorable en los registros de temperatura y de precipitación para el último tercio del presente siglo, incluso en respecto al período 1961-1990.

\begin{tabular}{|c|c|c|c|c|}
\hline & $\begin{array}{c}\text { MODELO BUSINESS } \\
\text { AS USUAL }\end{array}$ & $\begin{array}{c}\text { MODELO BUSINESS } \\
\text { AS USUAL } \\
\text { (Variante de cálida) }\end{array}$ & $\begin{array}{l}\text { MODELO BUSINESS } \\
\text { AS USUAL } \\
\text { (variante fría) }\end{array}$ & MODELO $2^{\circ}$ \\
\hline $\begin{array}{l}\text { TEMPERATURA } \\
\left({ }^{\circ} \mathrm{C}\right)\end{array}$ & +3.2 & +3.7 & +2.4 & +2.3 \\
\hline $\begin{array}{l}\text { PRECIPITACIONES } \\
(\%)\end{array}$ & -19 & -14 & -14 & -14 \\
\hline
\end{tabular}

En la investigación científica del cambio climático y sus efectos para la fundamentalmente la parte social y económica del cambio climático actividad turistica se ha pasado, en la última década, de la descripción en relación con la actividad turistica, mientras siguen las investigaciofisica del fenómeno y de los efectos estimados por la modelización climática en los territorios, al análisis del impacto de las proyecciones de clima futuro sobre la actividad económica (economía), al estudio y elaboración de propuestas de adaptación (administración), al análisis de los efectos sobre recursos esenciales para la actividad turística (geografía) y, asimismo, a la valoración de la percepción del cambio clmático en espacios turísticos (sociología, geografía). Preocupa ahora al aumento de la peligrosidad climática y, en algunas regiones del nes de la componente física del proceso (actualización de informes por parte del IPCC).

El cambio climático puede afectar, por tanto, a los espacios y a la actividad turística. En términos territoriales (espacio turístico) el cambio climático supone, entre otros aspectos, la transformación de destinos (nieve, sol y playa) el incremento de territorios de riesgo debido el modelo con reducción de emisiones $\left(2^{\circ} \mathrm{C}\right.$ model) (vid. tabla 1).

Tabla 1. Evolución de las temperaturas y las precipitaciones en Europa meridional, horizonte 2070-2100, 
mundo - -p.e. en latitudes mediterráneas- la aparición de problemas de abastecimiento de agua potable por descenso de volúmenes de agu disponible. Por su parte, en términos económicos (actividad turística) el cambio climático puede ser uno de los factores que propicien la pérdida de cuota turística (visitantes) en algunos destinos y el cambio en la estacionalidad y la determinación cronológica de la temporada alta. Aunque en estos procesos influyen otros aspectos tan determinantes como el cambio en las condiciones climáticas de un destino turístico (precios, modas y preferencias de los turistas, política turística).

Los recursos territoriales turísticos, en un escenario de cambio climàtico, experimentan alteraciones significativas. Pasan de ser una base "estable" del producto turistico, donde el turista ve cubiertas las exigencias de disfrute, seguridad y confort, $y$ donde la competitividad con otros espacios turísticos se basa en el aprovechamiento y promoción de los recursos existentes a ser territorios que experimentan cambos ambientales rápidos, donde se pierde el control sobre la seguridady confort y en los que la competitividad con otros destinos turísticos supone necesidad de adaptación al nuevo escenario definido por las nuevas condiciones climáticas (vid. figura 1).

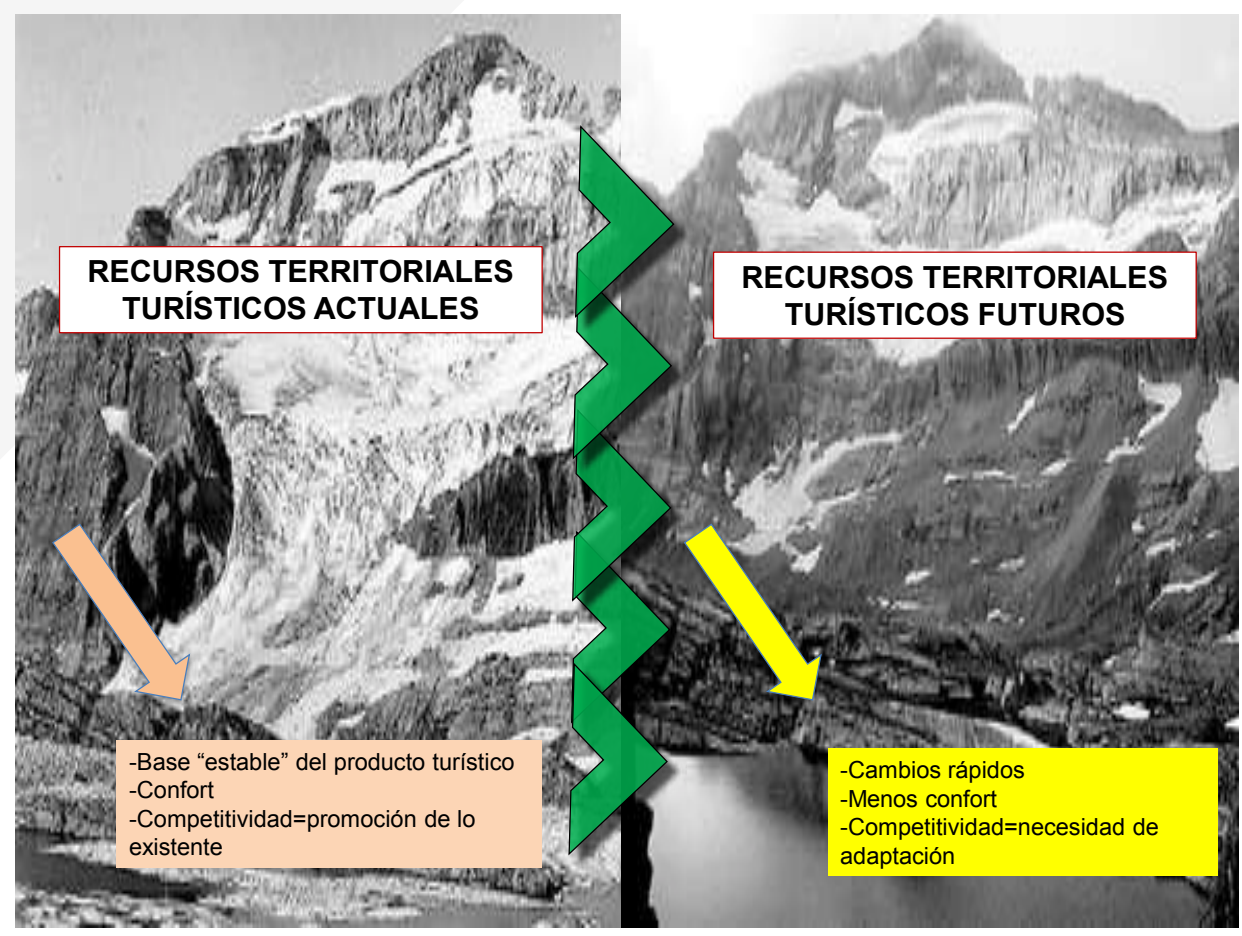

En su conjunto, España es un territorio especialmente expuesto a las posibles alteraciones climáticas debido a su misma posición geográfica en latitudes medias. La actividad turística, de enorme importancia para la economía nacional, con 65 millones de llegadas internaciona (2014) y un movimiento económico total cifrado en el 10\% del PIB español (Roselló, 2011), se muestra especialmente vulnerable ante el cambio climático. Algunos estudios predicen una pérdida de la cuota del mercado internacional próxima al $5 \%$ a finales del presente siglo ${ }^{3}$ consecuencia del cambio en las condiciones térmicas y pluviométricas. De forma que la realización de aproximaciones científicas al proceso del cambio climático y sus efectos en las actividades económicas es, desde el momento presente, una necesidad. Es preciso conocer, con el mayor grado de aproximación posible, los efectos reales del calentamiento planetario en nuestras latitudes, comprender cómo puede afectar ello a los espacios turísticos y qué medidas pueden implementarse, a diversa escala, para mitigar sus consecuencias.

Hay tres procesos principales que pueden desarrollarse en nuestro país por efecto del cambio climático con implicaciones directas en la actividad turística: a) un aumento de los extremos atmosféricos (mayor peligrosidad climática); b) una reducción de precipitaciones en el sur y este peninsular por aumento térmico en los meses centrales de verano.

Algunos estudios han señalado una serie de efectos, a medio y largo plazo, en la actividad turística española a consecuencia del proceso planetario de calentamiento térmico que, en esencia, se resumen $\mathrm{a}^{4}$

- Pérdida de cuota de mercado a nivel mundial, que pasará del $6 \%$ al $4,8 \%$ en 2030 .

- Reducción a largo plazo en el número de llegadas de turistas, estima da en un $20 \%$ para el año 2080

- Pérdida relativa de importancia del turismo de sol y playa como producto turístico debido a la falta de confort climático en verano

- Posibles cambios en los destinos turísticos interiores, con péd da de importancia del litoral mediterráneo como mercado turístico y aumento de la cuota de mercado en el litoral cantábrico, que se percibira ya en 2030

3Para valorar lo que puede suponer una pérdida de cuota de mercado turistico internacional en España, el informe de UNWTO Panorama del turismo internacional (2012) señala que España a cupa el c cuartol lugar del mundo por llegada de turistas internacionales, con 56,7 millones de llegadas en 2011 yel segundo por nivel de ingresos (59,9 millones de \$, 2011). "Vid. entre otros Bigano, A. Hamilton, J.M. and Richard, S.J.TTl (2008) "Climate change and tourism in the Mediterranean", Working Paper FNU-157. Research Unit Sustainable and Global Change. Hamburg University. Disponible en http:///www.fnu.zmaw.de/HTM.5681.0.htm!.

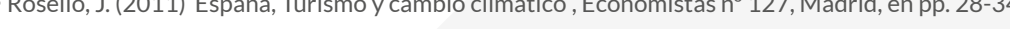


Lamodelización climática en latitudes medis y especifcamente en mbito mediterráneo, señala una serie de alteraciones para las próxmas décadas que ponen en duda el cumplimiento de las exigencias climáticas en los destinos turísticos (Besancenot, 1991)

- El aumento de días sin lluvia que, en principio, aumentaría las posibilidades de disfrute se verá contrarrestado por la reducción de volúmenes de agua disponible que puede poner en peligro los abastecimientos de espacios turísticos.

- Temperaturas más altas en verano y calor húmedo, poco soportable en zonas litorales. Pérdida, por tanto, de confort climático. - Incremento de extremos atmosféricos; por tanto, nivel de riesgo mayor.

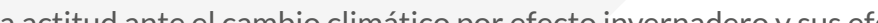
os en las actividades económicas, debe ser la de la mejora constante de sus procesos físicos y la adaptación sensata frente a sus posibles consecuencias. Dada la enorme importancia económica del turismo en los territorios donde se desarrolla la transmisión de lo qu

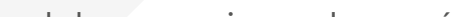
bio climático previstos y de las ventajas que supone la puesta en marcha, desde ahora, de medidas de mitigación y adaptación es la medida más eficaz frente a los "miedos" que este proceso puede generar en el propio sector turístico. Scott (2008) ha establecido una interesante relación entre el transcurso cronológico de la vida de un ser humano que hubiera nacido en el año 2000 y la manifestación progresiva de una modalidad de producto turístico que se hubiera iniciado ese mismo año (p.e. resort hotelero) y el funcionamiento de los diferentes

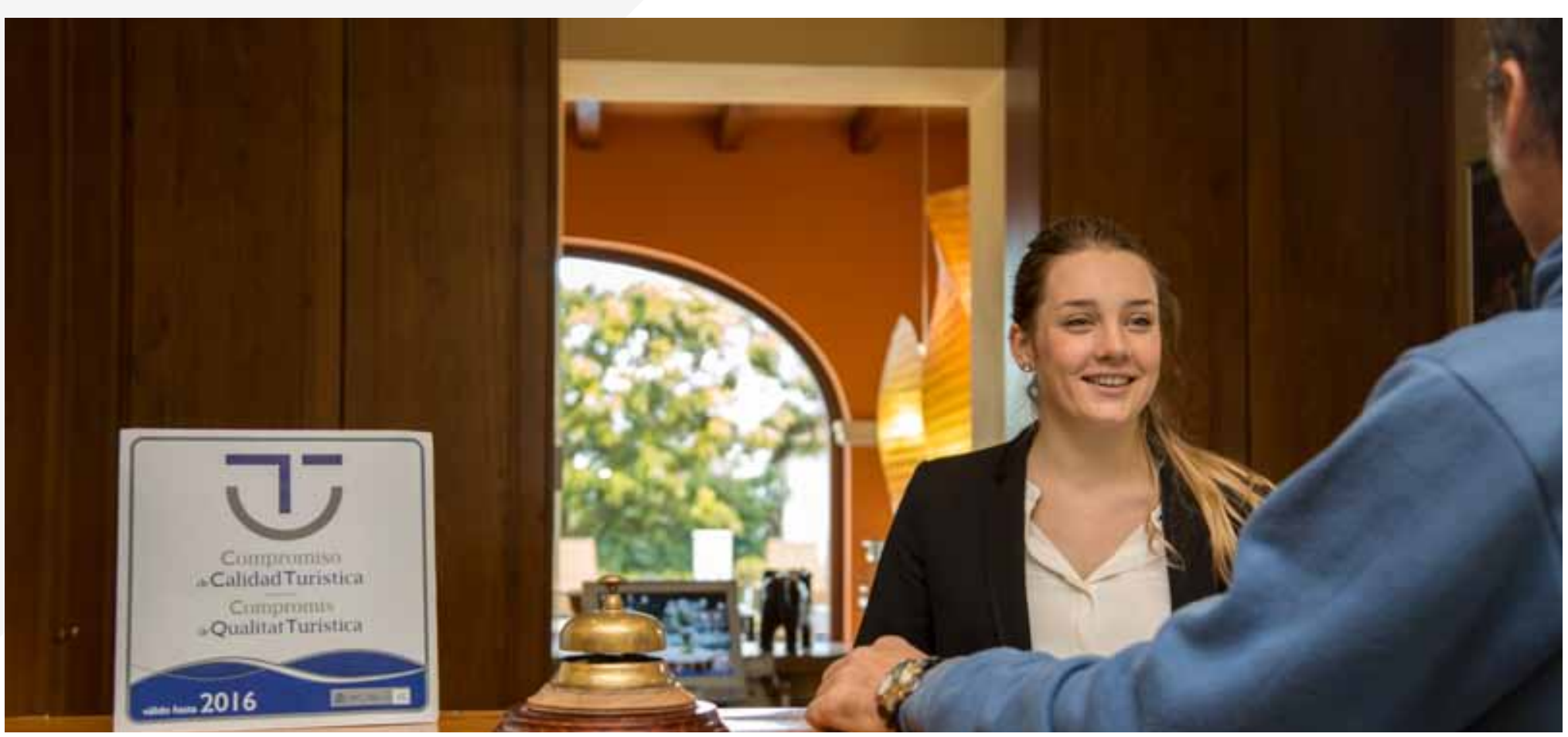

efectos del cambio climático previstos enta modelización climática. La reducción de la nieve (estaciones de esqui) y de las precipitaciones (volúmenes de agua disponible) serán, para Scott, los primeros efectos visibles del cambio climático (hacia 2030) con implicaciones importantes en la actividad turistica. Una persona que en 2000 tuviera 35 años de edad apenas notará las consecuencias del cambio global a lo largo de su vida; sin embargo, una persona nacida ese mismo año 2000 experimentara mbientales previstos hasta finales de presente siglo. Por ello, las medidas de mitigación o adaptación no pueden esperar a las decisiones políticas de ritmo casi siempre lento; deben activarse inapelablemente ahora que se ha iniciado la segunda década del siglo XXI puesto que, en caso contrario, la inacción en este asunto convierte el problema en irreversible hacia 2060-70

SVid. Scott, D. (2008) Climate Change and Touriss: Responmarco del CTO / CRSTDP Pegional Workshop The Bahamas $18-19$ March 2008. Disponible enhttp://www.onecaribbea orgtcontentilies/DavosReportoverview Danscott.pdr

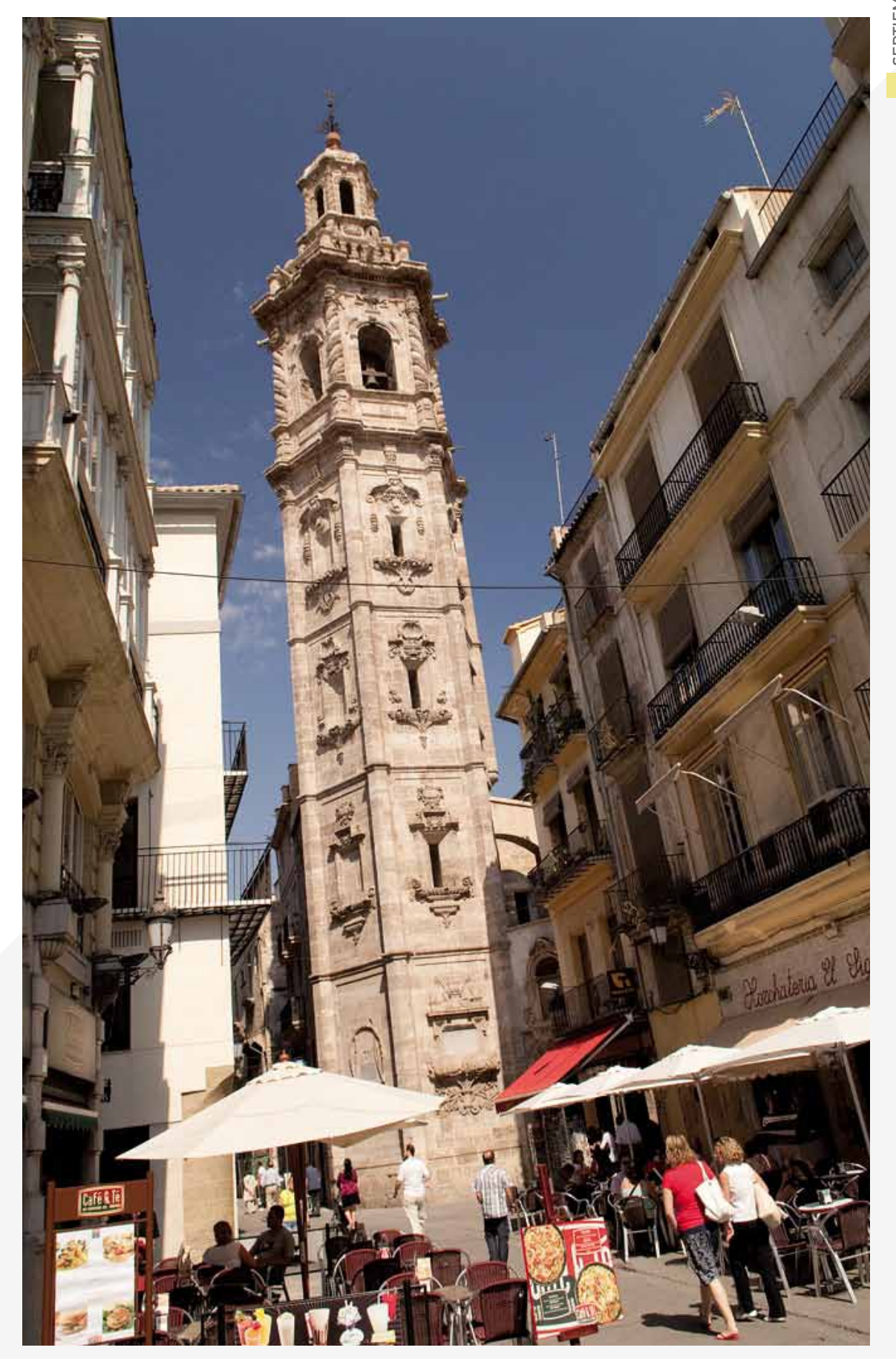


PRÁCTICAS INTERNACIONALES DE 2 ADAPTACIÓN DE LA ACTIVIDAD TURÍSTICA AL CAMBIO CLIMÁTICO
La adaptación al cambio climático debe entenderse como el conjunto de actuaciones puestas en marcha para adecuar los territorios y las actividades que en para las próximas décadas. Si, como se ha señalado, se iones de la modelización climática llevada a cabo por or snismos internacionales y centros de investigación climática, los territorios y las sociedades que en ellos viven experimentarán alteraciones en sus modos de vida actuales, positivas en algunos casos $y$ ara las que resulta conveniente tener previstos mecanismos de adaptación que deben ir planteándose desc este momento, debido al rasgo de proceso de medio y largo plazo del propio cambio climático.

Es interesante destacar que en materia de prevención. mitigación, del cambio climático se ha pasado de las acciones de "lucha" contra el proceso, basadas, casi e exclusiva en aspectos energéticos (cambio de modelo, apuesta por energías limpias) a concepciones más integrales donde, además de los aspectos energéticos, cuenta el territorio y sus actividades como principio motor de las actuaciones a llevar a cabo. En este contexto es donde la adaptación cobra protagonismo como mecanismo multidisciplinar y multitarea para el planteamiento de soluciones integrales ante un problema global.

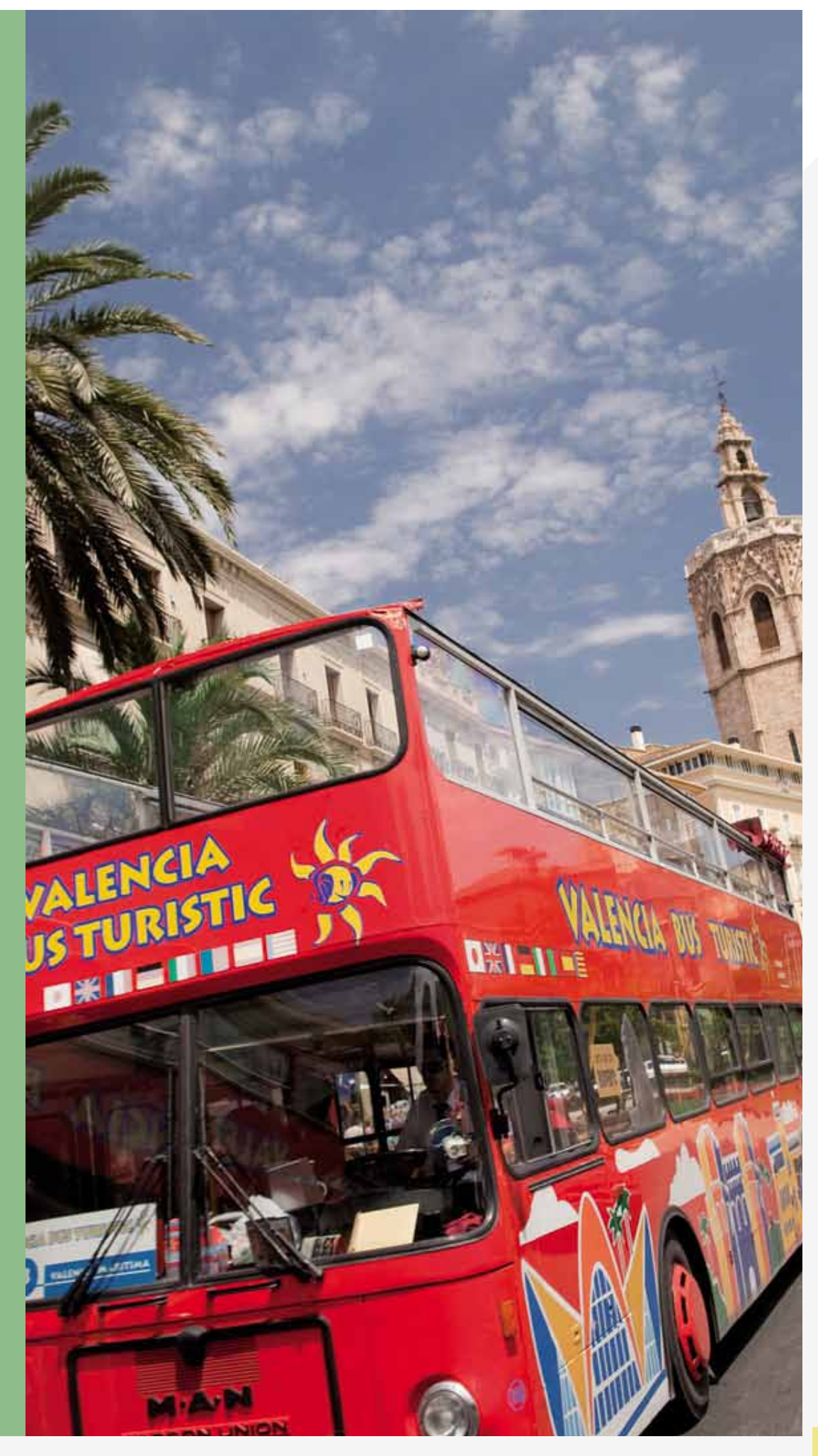


Como se ha señalado, hay actividades económicas con un grado de exposición alto a los efectos del cambio climático como la agricultura y e turismo; en este segundo caso y para algunas modalidades de gran uso social (sol y playa, nieve) se une, además, una vulnerabilidad elevad debido al volumen elevado de personas que lo practican. El turismo es pues una actividad vulnerable que debe adaptarse a la nueva realidad climática que se proyecta (Olcina, 2012).

El escenario de cambio climático futuro obliga a los destinos turisticos y a sus agentes implicados (administración pública, empresas y usuarios) a adaptarse a la nueva realidad si se quiere mantener la actual competitividad. Se trata de un proceso de medio y largo plazo que debe comenzar a planificarse ahora para evitar mayores costes económicos, sociales y territoriales dentro de unas décadas. En los ultimos años se han desarrollado acciones de mitigación y adaptación de la actividad turística ante el cambio climático en diversos países de mundo y, entre ellos también en España y en alguna de sus Comunidades Autónomas. Por lo general, las actuaciones orientadas a la lucha contra el cambio climático se han orientado, sobre todo, a las cuestiones energéticas, $y$ han tenido menor protagonismo el desarrollo de medidas de tipo económico (tasas ambientales) y territorial (planificación sostenible).
Anivel internacional, el cumplimiento de los protocolos internacionales de reducción de gases de efecto invernadero es una obligación de los estados firmantes y de aquellos que nunca los han firmado -Chin India y EE.UU.- por la propia salubridad de la atmósfera terrestre. E desarrollo del Programa 2020 por parte de la Unión Europea representa la iniciativa más esperanzadora puesta en marcha por un grupo de países desarrollados con objeto de reducir emisiones, con compromiso firme. Japón, por su parte, ha aprobado en 2015 un importante plan de reducción de emisiones (20\% en 2030), después de unos años últimos donde este país ha aumentado estas emisiones debido a la sustitución con energía térmica clásica de una parte de su producción energética tras el desastre de Fukushima y el rechazo social que ello causó hacia la energía nuclear.

En los últimos años se han desarrollado políticas de reducción de los efectos del cambio climático en los espacios y la actividad turística, por parte de las diferentes administraciones en los países desarrollados. La adaptación al cambio climático en la escala local resulta de especia interés por la inmediatez de las acciones y la participación de actores sociales directamente implicados en la gestión de políticas turísticas o de empresas. Varias ciudades del mundo, entre ellas importantes destinos turísticos, han aprobado declaraciones de "neutralidad en sus emisiones de carbono" para 2020, lo que conlleva la puesta en marcha de acciones para asegurarse el autoabastecimiento de energía (plantas eólicas, paneles solares.
En Europa fue muy discutida la aprobación de la tasa europea sobre emisión de gases de efecto invernadero (Directiva 2009/29, de comercio de emisiones comunitarias, ETC Emissions Trading System) y la incorporación a este sistema, en 2012, de las compañías aéreas que operen en e espacio europeo. Este sistema establece que las plantas de generación de energía, las aerolíneas, y otras empresas puedan comprar o vender licencias de emisión o permisos para seguir contaminando. Para que la medida pueda tener éxito, el precio de la compra-venta de derechos de emisión se debería realizar a un precio que anime a las empresas a buscar alternativas para ahorrar energía y reducir sus emisiones. El ETS afecta a más de 11.000 centrales eléctricas y plantas de producción de los veintiocho Estados miembros de la UE, más Islandia, Liechtenstein y Noruega. En total, cubre alrededor del $45 \%$ del conjunto de las emisiones de la UE.

En el marco del sistema ETC si una empresa no entrega suficientes derechos para cubrir sus emisiones, se la penaliza. Tiene entonces que comprar derechos que compensen eldéciti, su nombre se publica en una ista que la señala como infractora y debe pagar una multa disuasoria por cada tonelada emitida de más. La multa en 2013 es de $100 €$ por tonelada de $\mathrm{CO}$. En la actualidad, el precio de mercado de estos permisos es muy bajo porque la crisis económica ha causado un desplome de la demanda al mismo tiempo que el suministro se ha mantenido constante: de ahi que la Unión Europea se haya planteado la reforma del sistema en 2015. El sistema ha sido criticado por las agrupaciones ecologistas europeas puesto que consideran que de este modo se permite el mantenimiento de un modelo energético que, por el contrario, debería cambiarse de ns ru relación con la actividad turística, es aplicable a obstante, como muestra de la dificultad de su aplicación, las compañías aéreas extracomunitarias han tachado la medida de intromisión en su soberanía y varios países se han negado a aplicarla (China, India, EE.UU) Como efecto positivo de este mecanismo en las compañías aéreas, al margen de las cuestiones impositivas, está el hecho de la incentivación de programas de investigación en reducción de consumo de combustible en los aviones con motores más eficientes (Airbus, Boeing, Embraer) o búsqueda de alternativas (bio-combustibles) que ya han puesto en marcha las aerolineas europeas KLM, Lufthansa. Air France e lberia.

En gran medida, como se ha señalado, las acciones de reducción del cambio climático puestas en marcha en los últimos años, por Estadosy empresas, han estado relacionadas con la cuestión energética (reducción de emisiones energías alternativas). En este campo $y$ dentro del sector turístico se han desarrollado algunas iniciativas dignas de mención. Es e caso de la red europea "Hotel Energy Solutions", creada en 2008 dentro de la mencionada iniciativa energética europea 2020 y auspiciada por la Organización Mundial del Turismo, que pretende aportar soluciones para la reducción de las emisiones y la huella de carbono en el sector turístico. Entre sus objetivos está la mejora de la eficiencia energética en un 20\% y el uso de energías alternativas en un $10 \%$ del consumo total en hoteles medianos y pequeños del territorio europeo. 
Por término medio, un hotel en Europa libera anualmente entre 160-200 kg. de C02 por m2. Mediante la reducción de las emisiones de $\mathrm{CO} 2$, los hoteles pueden hacer una contribución positiva al medio ambiente y, al mismo tiempo, reducir sus costes de operación. Para ello se ha desarrollado una herramienta en red (e-toolkit) que calcula la eficacia energética de un establecimiento hotelero en cualquier tipo de clima y proporciona soluciones para una mayor eficiencia. En este programa participan diversos destinos turísticos de Europa, entre ellos Palma de Mallorca, donde 23 hoteles se han incorporado, en la actualidad, al uso de la herramienta e-toolkit de eficiencia energética.

Un paso más en estas iniciativas de reducción de consumos energèticos $y$, por ende, de emisiones de gases de efecto invernadero en la empresa turística ha sido la puesta en marcha de la iniciativa "neZEH", que tiene como objetivo acelerar la tasa de renovación de hoteles existentes para transformarlos en edificios de consumo casi nulo (nZEB), en respuesta a la Directiva Europea sobre Eficiencia Energética en Edificios (Directiva 31/2010). Para ello se han seleccionado una serie de proyectos piloto en siete países europeos (Croacia, Grecia, Francia, Italia, Rumanía, Suecia y España), a los que se aplicará una serie de protocolos en la búsqueda de su eficiencia energética. Para el caso español, se han seleccionado 5 proyectos en hoteles de costa, de montaña y rural, de los cuales dos están ubicados en el litoral mediterráneo
(Hotel Corona del Mar en Benidorm y Hotel Cala Serena en Palma de Mallorca). Para poder formar parte de este programa los hoteles, $y$ tras una auditoría previa con la herramienta e-toolkit, deben reducir su consumo energético hasta un nivel de excelencia (94 kwh/m/2/año) y aumentar la cuota de energías limpias hasta el $50 \%$ del su consumo total

Juto a estas medidas de reducción del cambio climático en el turismo basadas en las cuestiones energéticas, se han desarrollado también acciones integrales de adaptación donde las actuaciones de planificación territorial cobran protagonismo. A escala mundial, destaca el plan de rrolladas por el gobierno de Australia, que ha creado un Departamento específico de cambio climático y eficacia energética ${ }^{8}$. En el apartado de adaptación, se han desarrollado acciones concretas en el sector turístico para la reducción del impacto futuro del cambio climático, tanto en el turismo de nieve, como en el de sol y playa. Así ante la previsión de descenso de nevadas, se señala el uso de cañones de producción de nueve artificial con empleo de agua residual depurada (Mount Buller Ski Resort, Victoria) y se dan pautas para la construcción de resorts turísticos resistentes a los vientos violentos de ciclones tropicales y oleajes de temporal marítimo

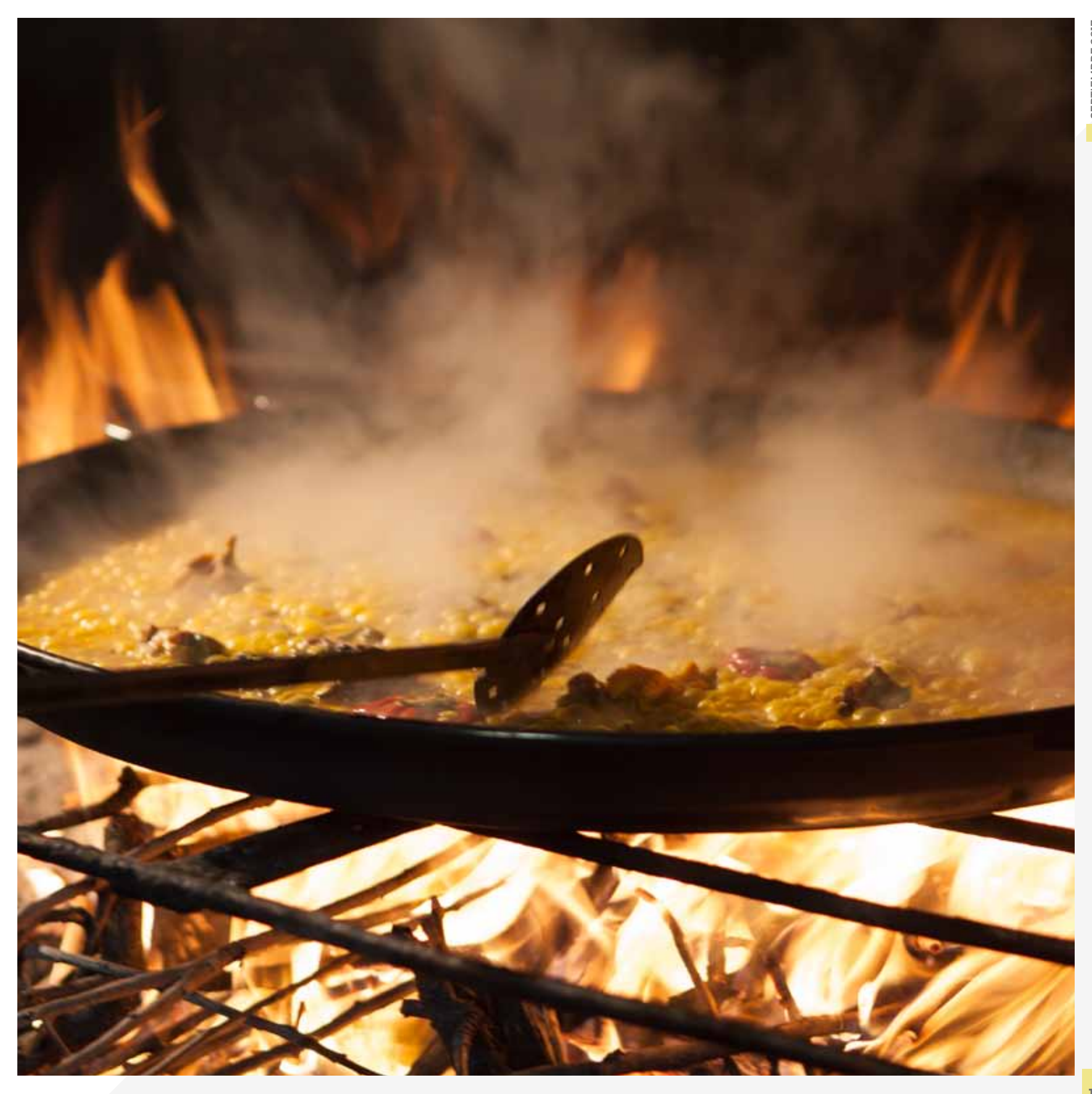


La ordenación del territorio a escalal regional y la planificación urbanistica a escala local, como herramienta de adaptación al cambio climático y a los episodios extremos asociados, ha tenido experiencias destacadas en algunos países y ciudades concretas que son destinos turísticos. bien de sol y playa o bien como turismo urbano, incluyendo megacidades. Algunos ejemplos son muy interesantes, como la aprobación de la "Ley de tejados verdes" en Copenhague o Amberes; la construcción de viviendas palafiticas en Nueva Orleans para evitar desastres como el ocasionado por el huracán "Katrina" en 2005; la construcción de un pabellón multiusos flotante en Rotterdam resistente a las crecidas fluviales y recrecimiento de polders potencialmente afectables por la acción combinada de inundación y oleajes intensos en áreas costeras en diversas áreas de Holanda ${ }^{10}$; edificaciones sobreelevadas en Helsinki, en el marco del proyecto "Baltcica" (vid. infra), puesto en marcha por los países ribereños del mar Báltico. Por su parte, Londres, uno de los destinos turísticos urbanos europeos más destacados, levantó, en 1982, el segundo dique móvil más largo del mundo sobre el río Támesis, en Woolwich Reach (Thames barriers) para evitar los efectos de las crecidas, presentes y futuras, del río en la ciudad. Desde 1990 ha sido preciso aumentar el número de cierres al año, alcanzado una media de cuatro al año. Los modelos de elevación del nivel del mar estiman que en 2030 la marea del mar exceda, sin embargo, la protección de este dique móvil. a puesta en marcha del Plan NYC "A Greener Greater Nueva York" al año (12 millones extranjeros), Nueva York es la séptima ciudad mundial más visitada anualmente. Ya ello hay que sumar la población censada en la ciudad (8,5 mill. 2016) y en el conjunto del área metropolitana (20,2 mill. en 2016). De manera que el nivel de vulnerabilidad frente al cambio climático y a los episodios atmosféricos extremos es muy elevado. El Plan NYC contiene 132 iniciativas y 400 objetivo concretos a desarrollar con dicho horizonte temporal. Junto a otros aspectos relativos a vivienda, espacios verdes, agua, residuos, calidad del aire y movilidad, el plan incluye un apartado especifico a la adaptación de la megalópolis al cambio climático. Además, las propuestas iniciales contenidas en el mismo, fueron reforzadas con una acción complementaria ("A stronger more resilient New York", 2012) tras los efectos que ocasionó en la ciudad el huracán Sandy, en 2008. La sección Cambio Climático incluye 13 iniciativas de mitigación y adaptación entre las que destacan la reducción del 30\% de emisiones de gases de efecto invernadero respecto al nivel de emisiones de 2005 en 2030, la actualización, junto a la FEMA, de los mapas de inundación de la ciudad para el período de retorno de 100 años, la actualización de las normas de construcción, el fomento de medidas de protección frente a las inundaciones en las viviendas en acción coordinada con las compañías de seguro, la reducción de la isla de calor urbano, la integración de las proyecciones del cambio climático en la planificación de la gestión de las emergencias y la comunicación del riesgo a las comunidades de la ciudad para aumentar su resistencia frente al cambio climático y sus peligros atmosféricos asociados. Un apartado detallado de este plan es el program de incremento de la resiliencia de la ciudad ante eventos atmosféricos extremos, especialmente huracanes, para lo que se ha llevado a cabo diversas acciones de reconstrucción de diques en el frente litoral, el diseño de una barrera de contención de ola de ciclón tropical en la costa sur de la ciudad, la aprobación de una ordenanza para la construcción de edificaciones en zonas de riesgo (inundación y oleaje costero) y elaboración de un mapa de riesgo de inundación de edificaciones sensibles (energía, sanitarias, educativas telecomunicaciones) sobre las que se deberá actuar en los próximos años para aminorar su nivel de exposición. Se ha diseñado, además, un sistema de indicadores para llevar a cabo el seguimiento anual del plan y, desde 2012, se elaboran informes anuales sobre el estado de cumplimiento del mismo.

En Europa, la apuesta por las políticas de adaptación al cambio climátco es una realidad, aunque con velocidades distintas según los países. Estas iniciativas complementan las acciones de lucha energética contra el cambio climático que la Unión Europea ha puesto en marcha desde 2009 (Plan 2020 COM (2011) 109 final Energy Effciency Plan 2011) que ha resultado pionero en el contexto internacional, al tratarse de un programa con objetivos concretos y mecanismos de sanción ${ }^{12}$. La Unión Europea aprobó en 2013 una Estrategia de Adaptación al cambio climatico, que a través de ocho acciones persigue convertir a los paises rritorios más resilientes ante los cambios previsto ido tres prioridades a desarrollar en los años inmediatos: implementar las actuaciones previstas en los Estados miembros; mejorar la información sobre el cambio climático para poder tomar decisiones fundadas; $y$ actuar de forma prioritaria sobre sectores especialmente vulnerables ta plataforma Climate-Adapt reúne, en este contexto, la información sobre los proyectos europeos de adaptación al cambio climático que se están desarrollando en diferentes países en los últimos años. En la actualidad, sesenta y ocho proyectos integran los estudios de caso de esta plataformay la tipología de acciones y medidas de adaptación es muy variad. Entre los proyectos que se incluyen en la plataforma Climate-Adapt. tan sólo uno está relacionado directamente con la actividad turística: la prevención de la erosión en la playa de la localidad sueca de Ystad. Aunque las que se llevan a cabo o están programadas para zonas costeras o grandes ciudades (Berlín, Venecia. Múnich) benefician de un modo otro, y así de indica en las memorias de proyecto correspondientes, este sector económico.

Por la importancia que tiene el turismo urbano, es interesante destacar los proyectos de adaptación al cambio climático que se están llevando a cabo en Berlín y Venecia. Con el objetivo de reducir el efecto de la isla de calor urbana, en la capital alemana se ha aprobado una ordenanza municipal para la aplicación de un indicador para el desarrollo de zonas 
verdes en manzanas y edificios, que tiene en cuenta el volumen construido y la antigüedad de los edificios. Es el llamado "Biotope Factor Area". Desarrollado para "verdear" los barrios del centro de la ciudad, el "Biotope Factor Area" (BAF) tiene como objetivo principal asegurar que una proporción determinada de un área edificada se deja sin desarrollar y se cubra de vegetación. El programa BAF pretende compatibilizar altas densidades de edificación en el centro de Berlín, con el desarrollo de la infraestructura verde de la ciudad. El indicador BAF es similar a otros parámetros manejados en planificación urbana para regular el desarrollo edificatorio de un municipio, y se expresa como relación entre el área (m2) de la superficie "ecológicamente eficaces" (área cubierta de vegetación) y el área total (m2) del espacio objeto de ordenación (parcela, manzana). dar en el área (vid. tabla 2).

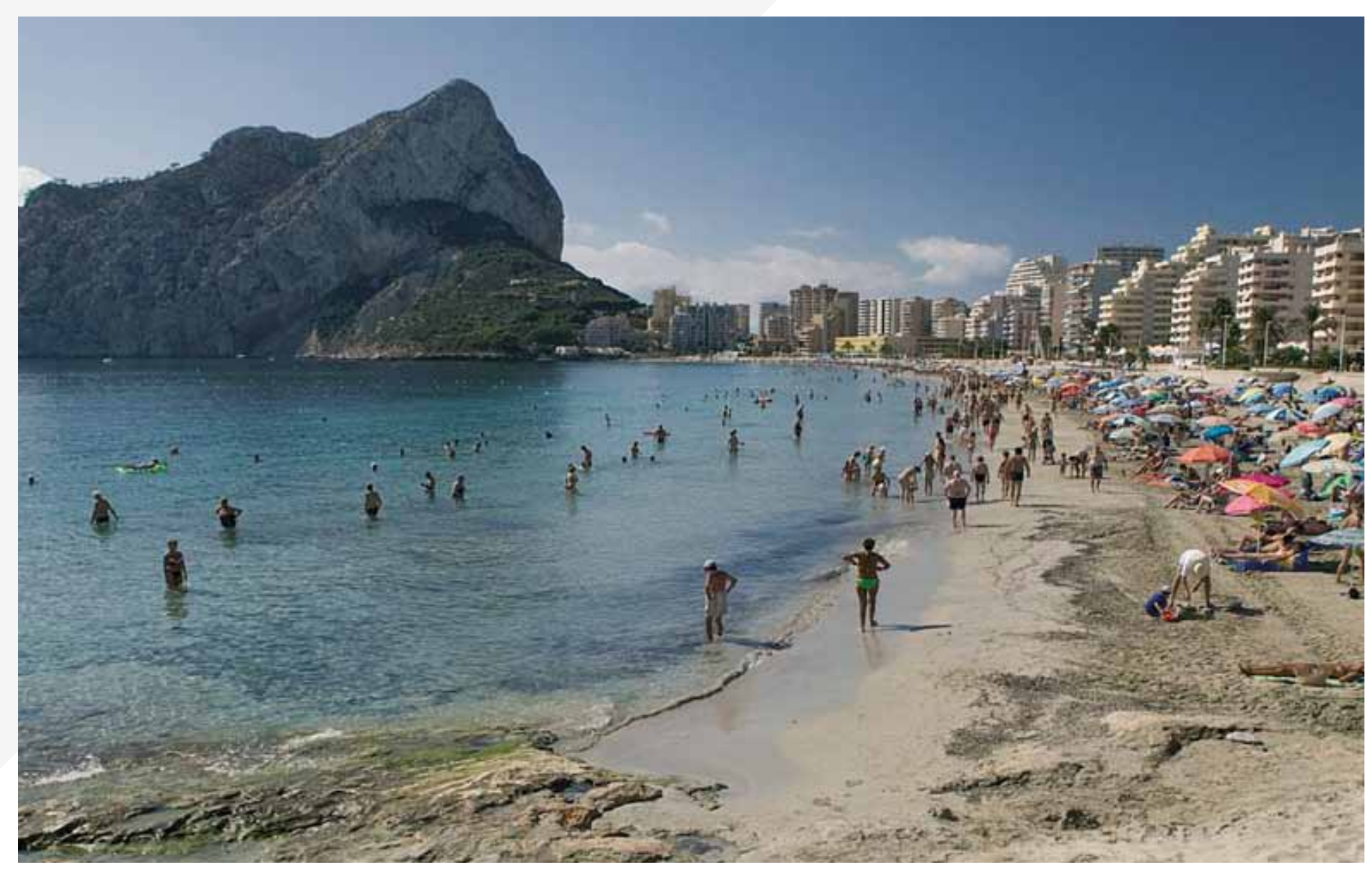

Tabla 2. Indicador BAF para diferentes tipos de desarrollo urbanístico en Berlín.

\begin{tabular}{|c|c|c|}
\hline \multicolumn{2}{|c|}{ CAMBIOS EN ÁREAS YA URBANIZADAS } & \multirow{2}{*}{$\begin{array}{l}\text { NUEVOS DESARROLLOS URBANOS } \\
\text { BAF }\end{array}$} \\
\hline GRADO DE OCUPACIÓN & BAF & \\
\hline \multicolumn{3}{|l|}{ USO RESIDENCIAL } \\
\hline $\begin{array}{c}\text { HASTA 0,37 } \\
0,38-0,49 \\
\text { MÁS DE 0,50 }\end{array}$ & $\begin{array}{l}0.60 \\
0.45 \\
0.30\end{array}$ & 0.60 \\
\hline \multicolumn{3}{|l|}{ USO COMERCIAL } \\
\hline N/A & 0.30 & 0.30 \\
\hline \multicolumn{3}{|c|}{$\begin{array}{l}\text { EMPRESAS } \\
\text { COMERCIALES,CENTRALES DE } \\
\text { NEGOCIO; USO ADMINISTRATIVO Y } \\
\text { GENERAL }\end{array}$} \\
\hline N/A & 0.30 & 0.30 \\
\hline \multicolumn{3}{|l|}{ INSTALACIONES PÚBLICAS } \\
\hline $\begin{array}{c}\text { HASTA } 0,37 \\
0,38-0,49 \\
\text { MÁS DE 0,50 }\end{array}$ & $\begin{array}{l}0.60 \\
0.45 \\
0.30\end{array}$ & 0.60 \\
\hline \multicolumn{3}{|c|}{$\begin{array}{l}\text { USO ESCOLAR Y COMPLEJOS EDUCA- } \\
\text { TIVOS }\end{array}$} \\
\hline N/A & 0.30 & 0.30 \\
\hline \multicolumn{3}{|l|}{$\begin{array}{l}\text { GUARDERÍAS Y CENTROS DE ATEN- } \\
\text { CIOON DIARIA }\end{array}$} \\
\hline $\begin{array}{c}\text { HASTA } 0,37 \\
0,38-0,49 \\
\text { MÁS DE } 0,50\end{array}$ & $\begin{array}{l}0.60 \\
0.45 \\
0.30\end{array}$ & 0.60 \\
\hline \multicolumn{3}{|l|}{ INFRAESTRUCTURAS TÉCNICAS } \\
\hline N/A & 0.30 & 0.30 \\
\hline
\end{tabular}


Aunque el programa se sigue desarrollando en la actualidad y constituye una de las iniciativas europeas de adaptación al cambio climático en la escala local, más interesantes, de las que se llevan a cabo en los últimos años, debe señalarse que el programa Biotope Factor Area fue una delas lineas de actuación del "Programa Paisajistico" del sector occidental de la ciudad de Berlín, puesto en marcha en 1984, antes de la unificación. En 1994 se probó como ordenanza municipal de aplicación en toda la ciudad (vid figura 2).

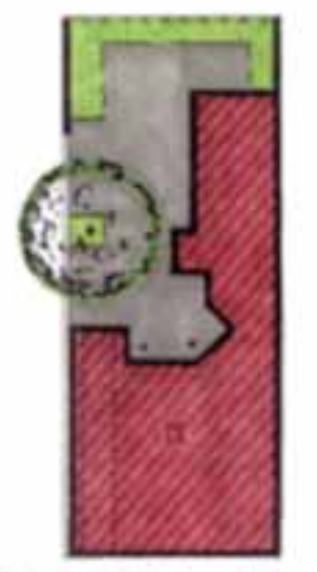

Current situation

BAF $=0.06$

Sealed surface $=140 \mathrm{~m}^{2}$ Semi-open surface $=59 \mathrm{~m}^{2}$ Open soil $=1 \mathrm{~m}^{2}$

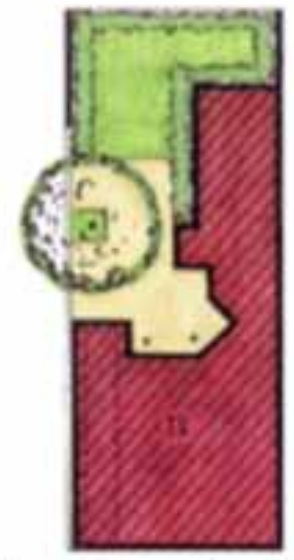

Planning variant $\mathrm{A}$ $\mathrm{BAF}=0.3$

Vegetation $=115 \mathrm{~m}^{2}$ Mosaic paving $=25.5 \mathrm{~m}^{2}$

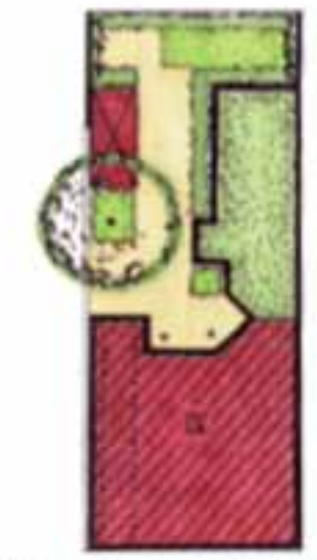

Planning variant $\mathrm{B}$ BAF $=0.3$

Concrete surface $=21 \mathrm{~m}^{2}$ Vegetation $=79 \mathrm{~m}^{2}$ Mosaic paving $=100 \mathrm{~m}^{2}$ Green walls $=10 \mathrm{~m}^{2}$ Green walls $=10 \mathrm{~m}^{2}$
Sobre la base de indicador BAF, se han desarrollado programas similares para el desarrollo urbano de Malmö, Suecia (2001) o de la ciudad de Seattle (2007). Kazmierczak y Carter (2010) han analizado diversas iniciativas mundiales desarrolladas en los últimos años y que tienen como principio de actuación la aplicación de indicadores de "verdeamiento" de áreas urbanas para limitar los efectos de la isla de calor o mejorar confortclimático general de la ciudad. Se trata de ejemplos de buenas prácticas de desarrollo urbanístico orientadas a la mitigación de efectos que puede originar el cambio en las condiciones climáticas futuras, que son las que mayores resultados están teniendo como acciones efectivas e adaptación al cambio climático en la escala local.

En esta línea de actuación, e incluida asimismo en las iniciativas de la plataforma Climate-Adapt, se está aplicando esta filosofía de incrementar las zonas verdes urbanas en Stuttgart, dentro del proyecto municipa de creación de un corredor de ventilación verde para reducir asimismo e impacto térmico de la isla de calor urbana.

Dtra actuación, en esta ocasión de carácter estructural, de gran calado gable, es el proyecto de defensa frente a las inundaciones en Venecia, originadas por el doble efecto de tormentas y aguas altass a partir de la construcción de una serie de barreras móviles (proyecto MOSE, Modulo Experimental Electromecánico) en cuatro puntos (Lido, Malamocco y Chioggia) del frente litoral, con un coste de 5.400 millones de euros. Las obras de construcción comenzaron en 2003 y en 2014 se completarán las dos primeras barreras de mareas de tempestad en la entrada del Lido. Está previsto que el conjunto del plan esté terminado en 2018. El proyecto está gestionado por el Consorcio Venezia Nuova ${ }^{13}$ que integra diferentes socios, bajo la dirección del Gobierno italiano a través de Miisterio.

El sistema se basa en la instalación, como se ha señalado, de una serie

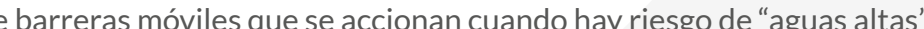
sobre la ciudad de Venecia. Se trata de un fenómeno cuya frecuencia de aparición ha aumentado en las últimas décadas como se comprueba en las estadísticas del Centro Previsioni e Segnalazioni Maree de la Ciudad de Venecia (vid. figura 3), originando elevadas pérdidas económicas en Ia actividad turistica de esta localidad italiana, que es la base fundamental de su economía. 
El programa de adaptación al cambio climático de la ciudad de Rotterdam reviste enorme interés por la concepción integral del fenómeno (subida nivel del mar, intrusión marina, incremento de eventos de

inundación, incremento de la isla de calor urbana y disconfort climático) y de la respuesta (medida estructural y de planificación territorial). As se ha diseñado una "Estrategia de Adaptación al Cambio Climático 14 para la ciudad, que es un documento de planificación territorialy redseño urbano para la adaptación a la subida de temperaturas (creación de jardines colectivos dentro de manzanas edificadas, tejados verdes, empleo de vegetación para cubrir los diques), a la subida del nivel de mar (recrecimiento de diques existentes y nuevos diques; elevación de cota de edificación) y y i incremento de inundaciones (depósitos pluviales colectores de agua pluvial, espacios de inundación natural en la ciudad. El plan de acompaña de la creación de un gran corredor "verde-azul", un canal desde el antiguo río Maas al 'Zuiderpark' en Rotterdam que, junto a los efectos ambientales (zona verde y azul) se plantea como línea de suministro de agua en épocas de aridez al provechar los lagos de este gran parque como depósitos de almacenamiento de agua para tal fin.

Por la magnitud territorial del proyecto y el efecto para la activida turística que está teniendo merece destacarse la iniciativa de creacón del gran corredor verde del Bajo Danubio (Lower Danube Gren Corridor), puesta en marcha en 2000 por iniciativa de los gobiernos de Bulgaria, Moldavia, Rumania y Ucrania y que cuenta con el partenariado de la organización de defensa ambiental WWF. Es un ambicioso plan de recuperación de riveras fluviales y acondicionamiento de la cuenca baja (n)

Desde comienzos del siglo XX un 70\% de la llanura de inundación se han erdido en esta región y la capacidad natural de retención de las crecidas fluviales se redujo drásticamente (Schneider, 2010). El potencial de restauración del Bajo Danubio Corredor Verde es de aproximadamente 500.000 hectáreas que, en caso de llevarse a cabo en toda esta extensión, podría suponer el almacenamiento de un volumen importante de agua para reducir los riesgos de inundación. Si se restaura un área de 100.000 hectáreas de antiguos humedales se puede almacenar un volumen de agua de 1,6 millones de $\mathrm{m}^{3}$ durante un proceso de crecida fluvial. En el "Acuerdo del Corredor Verde del Bajo Danubio" los gobiernos de Bulgaria, Rumania, Moldavia y Ucrania acordaron proteger 773.166 ha. ha. de nuevas áreas protegidas y la restauración 223.608 ha. de llanuras naturales de inundación, que forman parte del proyecto general del Corredor Verde del Bajo Danubio que integra 9000 km2. La restauración de estas zonas de inundación natural se realiza mediante la eliminación de diques, restauracín de humedales y de áreas arricolas situados en áreas inundable. Prueba de los resultados que el proyecto va obteniendo es el hecho de que durante la crecida del Danubio en junio de 2013 no a tico de la ciudad sea con energia verde al 100\% en el año 2025. El objetivo de producir suficiente electricidad verde en sus la primera ciudad en el mundo con más de un millón de habitantes se ejecute por completo de la energía renovable. Las medidas de adaptación al cambio climático en Munich se completan con una estrategia de paisaje urbano y de creación de espacios verdes y un plan de reducción del riesgo ante las inundaciones del río Isar. El plan para el autoabastecimiento energético con energía verde está desarrollado por la compañía SWM (Munich City Utilities) Renewable Energies que, en la actualidad, opera 21 plantas solares, 13 centrales hidroeléctricas, una planta de biogás, una planta de procesamiento de biogás, dos plantas geotérmicas y un parque eólico; además tiene en proyecto la construcción de nuevas centrales solar, eólica e hidroeléctricas en el río Isar. En 2015, la capacidad de producción de energía verde de la región metropolitana de Munich asciende al $50 \%$ de la demanda anual. 
hubo inundaciones en el bajo Danubio aunque el agua alanzó un nivel superior a la media. Además del beneficio ambiental que se obtiene (restauración de áreas húmedas y creación de zonas protegidas), el desarrollo de este programa ha favorecido la actividad turística (turismo de naturaleza ${ }^{15}$, turismo rural) del área afectada, para la que se estima un beneficio de 85 millones de $€$ anuales. Este Plan se desarrolla a través de Planes de Acción y se integra, además, en el conjunto de ciones desarrolladas por la Comisión Internacional para la protección del río Danubio (ICPDR).

Uno de los espacios europeos que ha desarrollado actuaciones de adaptación ante el cambio climático de forma más efectiva en los últimos años es la región del Mar Báltico. Aquís ha ha llevado a cabo el proyecto BaltCica (Climate Change in Baltic Sea Region). En este caso, la puesta en marcha de medidas ha tenido al municipio como escala principal de trabajo. Se han desarrollado fases de investigación con elaboración de informes $y$ cartografia sobre los riesgos naturales relacionados con el cambio en las condiciones del clima (inundaciones, litoral), se han abordado medidas de adaptación, con fases de consulta municipales para llevar a cabo las actuaciones programadas ${ }^{16}$. Filies y Schumacher (2013) han analizado el impacto del cambio climático para el turismo litoral de la región y señalan que la complejidad de adaptación de esta actividad que requiere medidas integradas en políticas globales de mitigación del problema (defensa estructural de la costa). No obstante, hay algunas acciones que debe llevar a cabo el propio sector: información, medidas de ahorro de agua, edificaciones turísticas diseñadas para la recogid (a) meteorologicos ("Experience the Wild Baltic Sea"). A partir de los resultados de del cambio climático en esta región europea se relaciona especiamente con el desarrollo de veranos cálidos y la presencia de aguas de mar más cálidas y de algas en las playas, al tiempo que la mitad de los Ca un problema importante el cambio climático en estos países ribereños del mar Báltico.

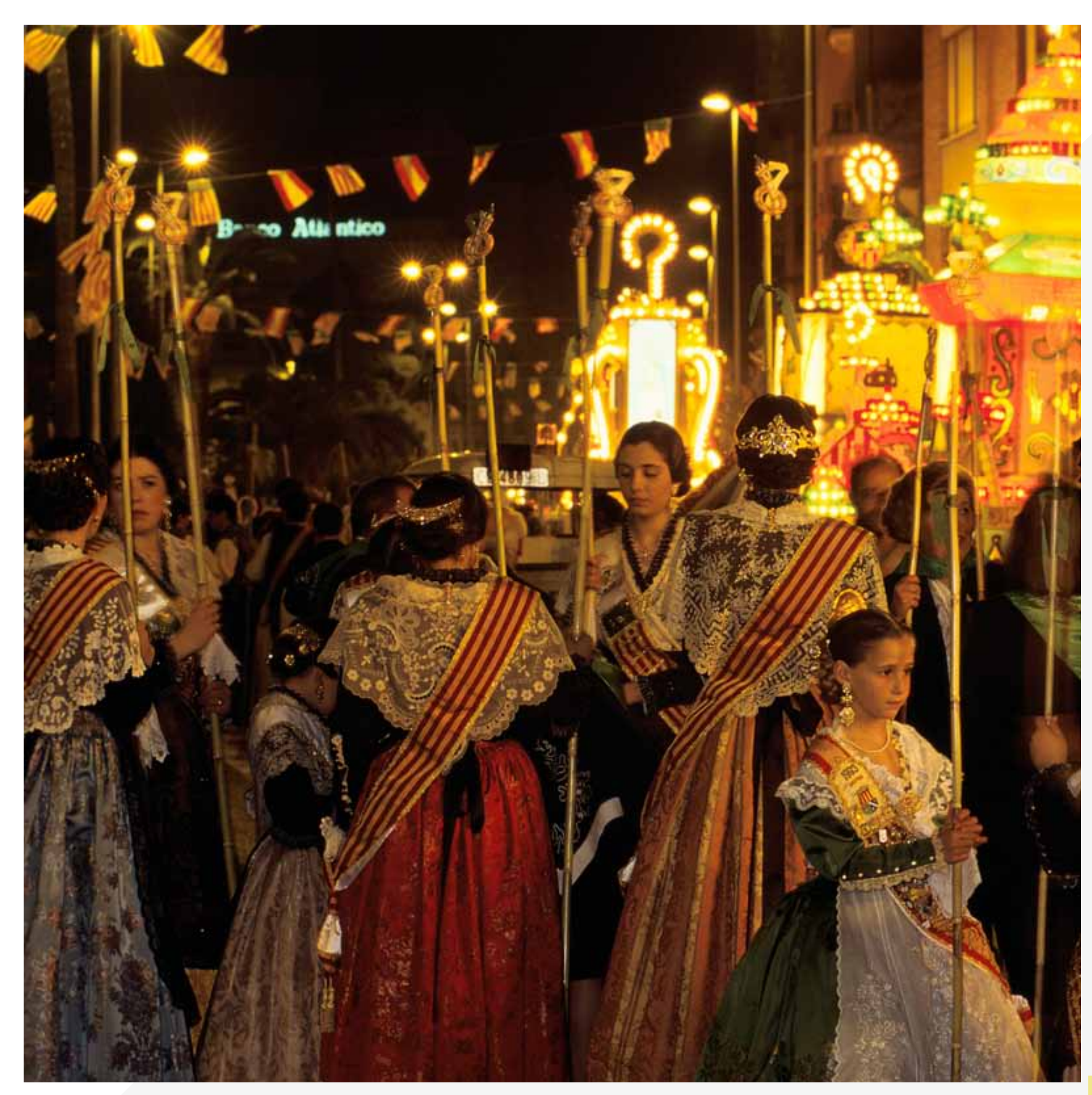




\section{LA IMPORTANCIA DEL CLIMA PARA EL DESARROLLO 3 DEL TURISMO EN LA COMUNIDAD VALENCIANA}

El espacio geográfico define su función a partir de unos factores que favorecen el desarrollo de actividades económicas. La existencia de dinamismo social, de capacidad emprendedora, las posibilidades de acceso a los recursos naturales, el desarrollo de redes de transporte y comunicación rápidas, la consolidación de mecanismos de

financiación o la puesta en marcha de políticas públicas

son básicas para entender el mayor o menor éxito de las iniciativas de desarrollo económico. Todos estos aspectos integran el conjunto de factores endógenos y exógenos

que, desde el siglo XIX, han permitido la consolidación las

diversas formas de organización económica del espacio

geográfico, con sus evidentes efectos socio-territoriales. Y junto a ellos, la existencia de un medio natural con rasgos geológicos geomorfológicos climáticos hidricos edáficos y biogeográficos favorecedores de las actividades puestas en marcha por las sociedades que en él se desarrollan, son una pieza básica, especialmente en aquellos sectores que dependen ampliamente de estos elementos del medio

físico. La actividad turística es una de estas actividades

cuyo desarrollo territorial está en estrecha relación con

las características fisicas del medio donde tiene lugar.

La Comunidad Valenciana, en la fachada mediterránea

española, dispone de unas excelencias del medio natural

muy idóneas para la implantación de actividades de ocio y

recreación que son la base del desarrollo turístico. Las tie-

rras valencianas acogen una serie de recursos con enorme potencialidad de transformación en producto turistico.

La tabla adjunta resumen los rasgos del medio natural que

son un recurso para la actividad turística (vid. tabla 3 ).

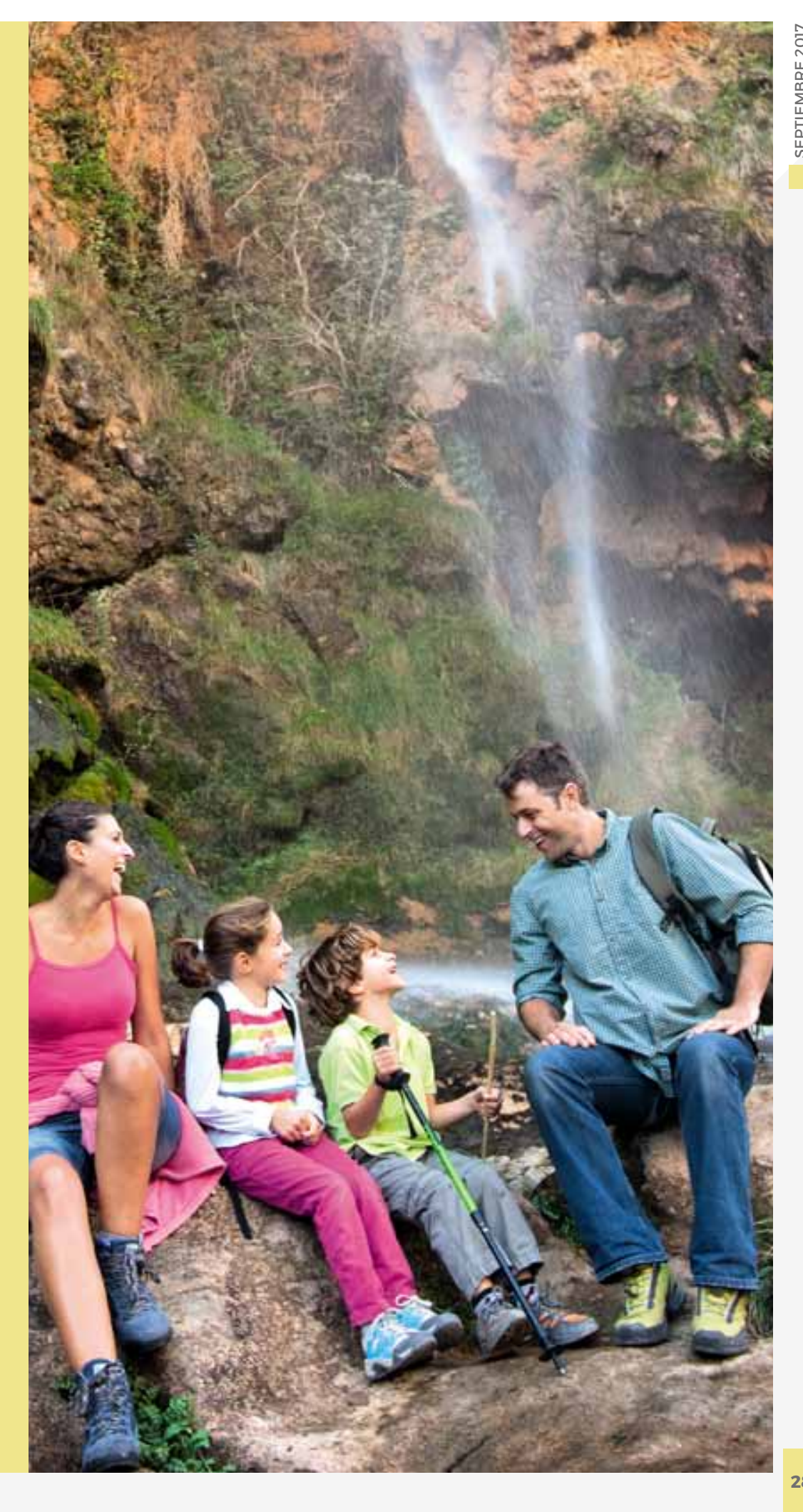


Tabla 3. Elementos del medio natural que son recurso para la actividad turística en la

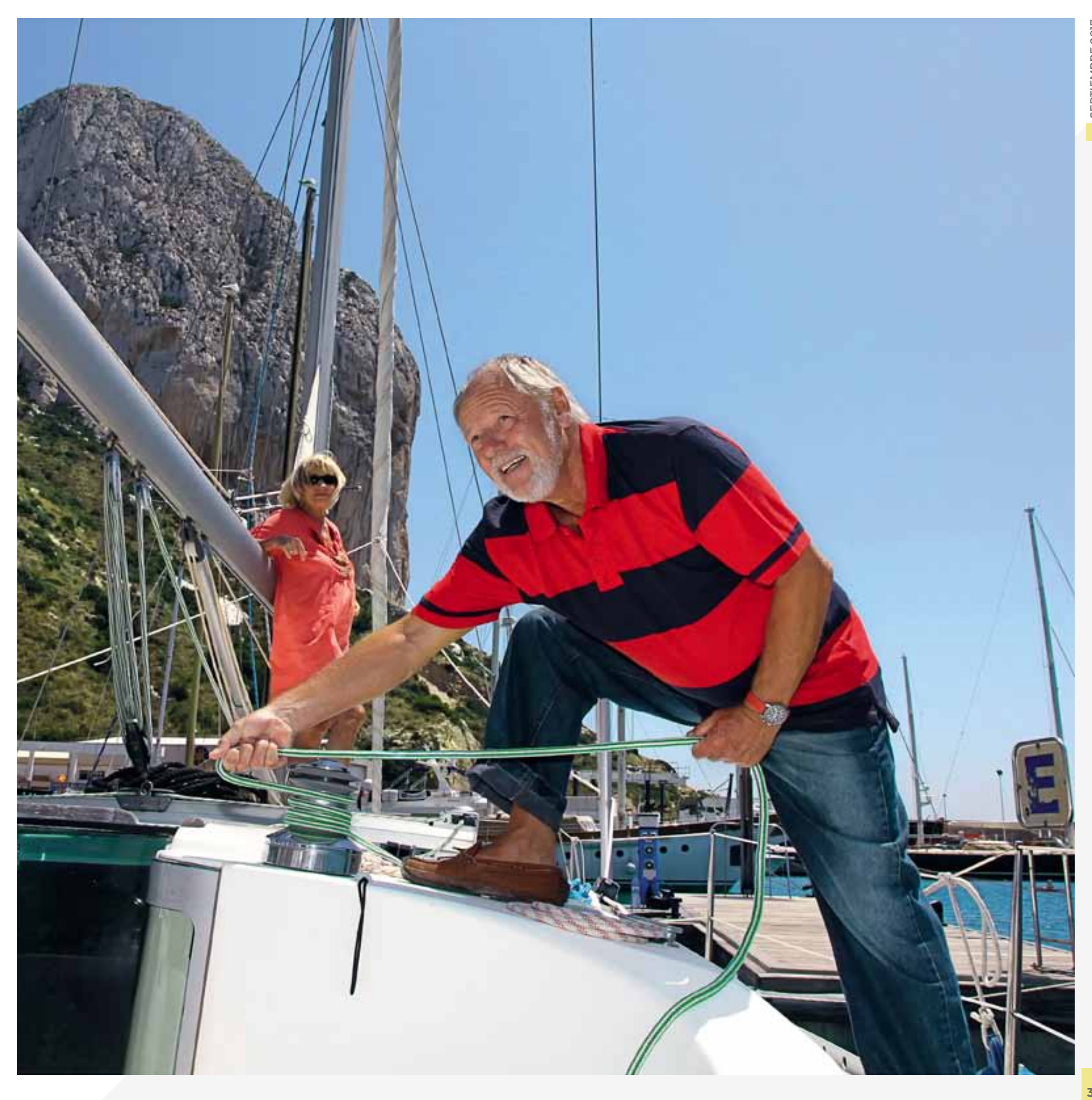

\begin{tabular}{|c|c|}
\hline RELIEVE & $\begin{array}{l}\text { - Ricos contrastes paisajisticos entre montaña y litoral } \\
\text { - Relieves interiores (Ibéricos y Béticos) con encanto } \\
\text { paisajístico } \\
\text { - Disposición de montañas que resguardan de vientos fríos } \\
\text { del norte. } \\
\text { - Abrigos montañosos y cuevas objeto de expresiones } \\
\text { artísticas desde época prehistórica }\end{array}$ \\
\hline LITORAL & $\begin{array}{l}\text { - Playas arenosas y suaves } \\
\text { - Playas acantiladas con encanto } \\
\text { - Restos de cordones dunares de alto valor ecológico } \\
\text { - Humedales litorales de enorme valor ecológico }\end{array}$ \\
\hline CLIMA & $\begin{array}{l}\text { - Temperaturas generalmente suaves } \\
\text { - Abundancia de días despejados } \\
\text { - Soplo de la brisa marina con efecto refrescante en verano }\end{array}$ \\
\hline VEGETACIÓN & $\begin{array}{l}\text { - Espacios interiores de rica vegetación mediterránea } \\
\text { - Especies endémicas protegidas en el interior y en la costa }\end{array}$ \\
\hline MAR & $\begin{array}{l}\text { - Temperaturas muy agradables para el baño entre junio y } \\
\text { septiembre } \\
\text { - Fondos marinos con gran riqueza de vegetación (prade- } \\
\text { ras de posidonia oceánica) y fauna. } \\
\text { - Escasas jornadas de oleaje fuerte }\end{array}$ \\
\hline AGUA & $\begin{array}{l}\text { - Recursos propios ajustados generalmente bien gestiona- } \\
\text { dos } \\
\text { - Cursos fluviales con ricos paisajes culturales }\end{array}$ \\
\hline
\end{tabular}


Entre estos valores del medio, destaca el clima como principal factor de atracción del turismo La existencia de un clima de fliación medterránea, con una temperie generalmente tranquila, temperaturas agradables, abundancia de días de sol, soplo de vientos generalmente suave, efecto refrescante de la brisa en verano, a lo que se une un área de aguas con temperaturas muy agradables para el baño entre la primavera y el otoño hacen del territorio valenciano un área privi giada para el desarrollo de la actividad turística. No en vano, desde los años sesenta del siglo pasado, las provincias de la Comunidad Valenciana se ha posicionado como uno de los destinos principales del litora mediterráneo español y uno de los destacados a escala europea en la modalidad de turismo de sol y playa.

Sin duda, el clima de la Comunidad Valenciana es un factor determinante de su elevado potencial turístico. Temperaturas generalmente benignas durante muchos meses al año, predominio de un ambiente soleado, aguas costeras propicias al baño etc. son elementos cha mente atractivos para el turismo, especialmente en el período estival. En efecto, la Comunidad Valenciana, en su conjunto, registra un número de horas de sol elevado, en comparación con otras regiones de la Península Ibérica. Si bien, nos notorios los contrastes entre el territorio meridional alicantino donde se registra un total de horas de sol acumuladas al año que supera las 2.700 horas y, en las comarcas más meridionales de Alicante se alcanzan las 3.000 horas anuales y el interior septentrional, en la provincia de Castellón (Maestrazgo y Els Ports) donde apenas se registran 2.400 horas al año po medio. La mayor presencia de nubosidad en este sector, así como en el espacio pluviométrico de La Safor, explican la menor insolación en estos territorios valencianos, frente al resto donde las horas de sol anuales son más elevadas. Sin olvidar estos contrastes territoriales, es cierto que la Comunidad Valenciana en su conjunto y muy especialmente la fachada litoral y las comarcas meridionales son áreas con enorme potencial climático para el desarrollo de la modalidad turística del sol y la playa (vid. figura 4).

.

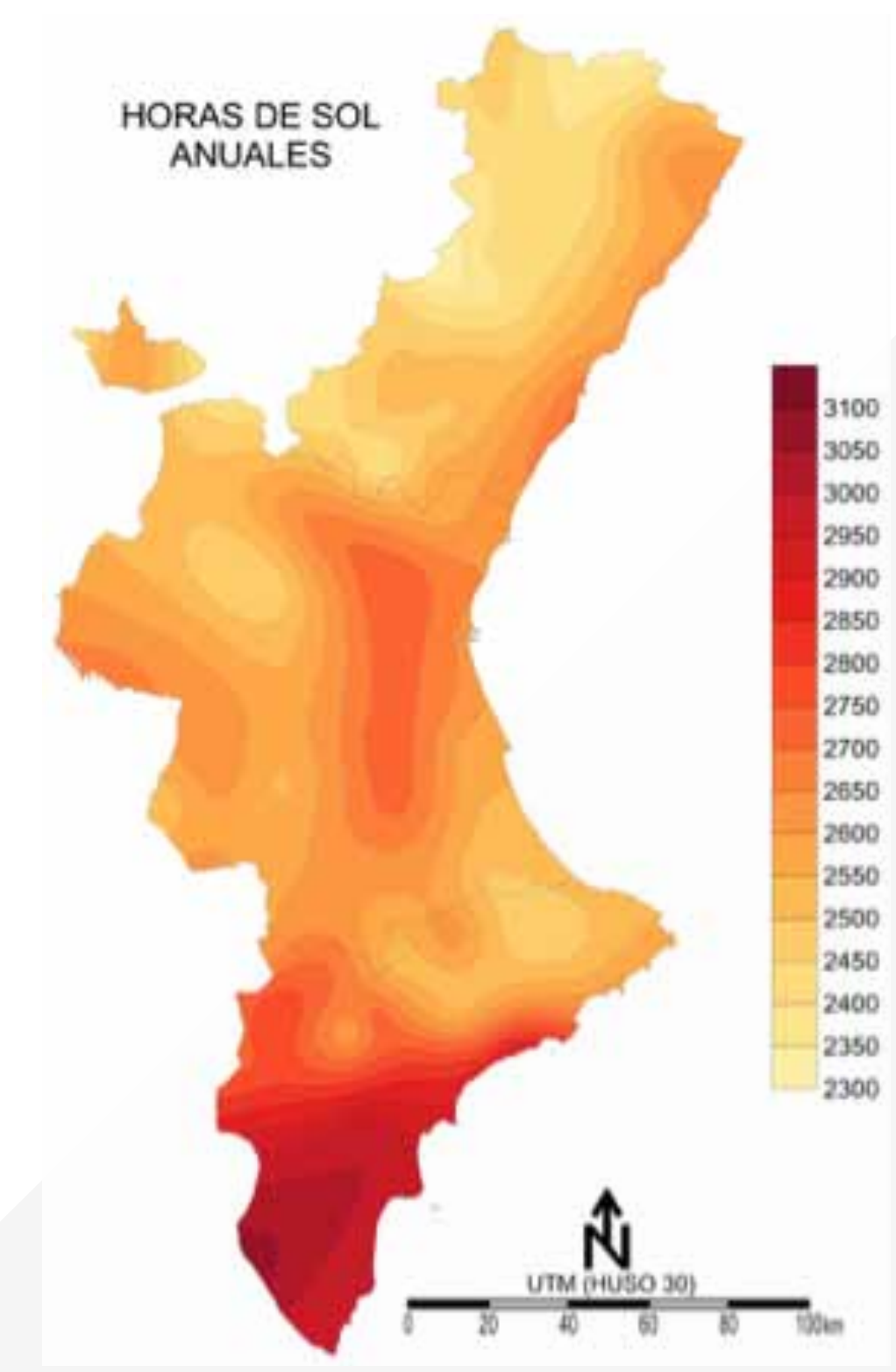


A ese ambiente soleado se suma el predominio de aguas cálidas en la orilla del Mediterráneo durante el semestre estival, especialmente en su segunda mitad, cuando son muy propicias al baño. Son al go menos propicias durante a primavera y bastante menos en invierno, aunque no inposibilitan el baño. Así, al analizar los valores normales de la temperatura del agua del mar en su superficie (SST) durante las estaciones del año encontramos una temperatura de $15^{\circ} \mathrm{C}$ en invierno, que asciende a unos $18^{\circ} \mathrm{C}$ en primavera. Durante el verano el agua alcanza sus mejores valores, de $26^{\circ} \mathrm{C}$ por término medio, manteniéndose aún en unos $21^{\circ} \mathrm{C}$ durante el otoño. Por meses, las temperaturas SST más elevadas se alcanzan en Agosto (por encima de $26^{\circ} \mathrm{C}$ ), y en segundo lugar estarían Julio y Septiembre (alrededor o por encima de $25^{\circ} \mathrm{C}$ ). Por contra, el mes con aguas más frías es Febrero $\left(14^{\circ} \mathrm{C}\right)$, quedando próximos Enero y Marzo (vid. figura 5).

Figura 5.

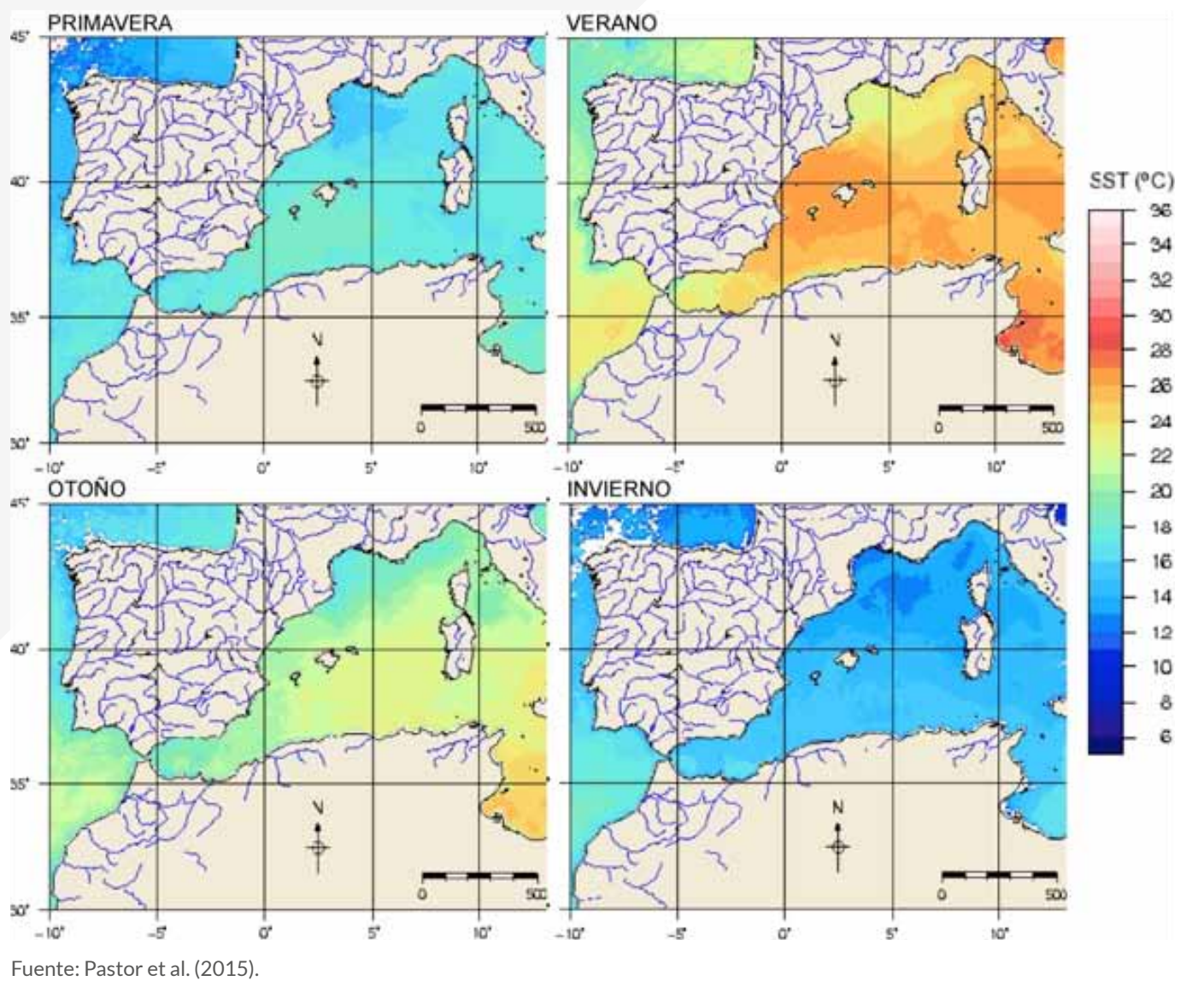

Otro elemento del clima a valorar para el aprovechamiento turístico de un territorio son las precipitaciones, puesto que su presen incluso imposibilita, la propia actividad turística al aire libre, dependiendo de la cuantía que precipite y de la propia hora del día en que se desarrollen.

Por término medio, las precipitaciones que se registran en el territorio ste valor medio anual oculta diferencias notables en el conjunto de espacio geográfico. Las precipitaciones son más abundantes en la comarcas del norte de Alicante y sur de Valencia, por un lado, y en el interior Ceastellón, en la parte septentrional de la Comunidad Valenciana. Por el contrario, los valores anuales son mucho menores $(300 \mathrm{~mm}$ ) en las comarcas meridionales de la provincia de Alicante (L'Alacantí, Bajo Vinalopó y Bajo Segura).

En su conjunto, los valores de precipitación que se registran en el terrtorio valenciano, unido a la insolación y temperaturas medias anuales, suponen valores altos de evaporación y evapotranspiración. De manera que por si solas las precipitaciones no son suficientes para abastecer las demandas de agua existentes en el territorio valenciano, siendo necesario acudir a otro tipo de fuentes convencionales y no convencionales (vid. figura 6).
Otro aspecto de las precipitaciones valencianas que debe llevarse en cuenta a efectos de planificación de actividades económicas y demandas de agua es el carácter concentrado en el tiempo y elevada irregularidad interanual (desarrollo de secuencias secas) e intranual (escaso número de días con lluvia al año). Esto último es especialmente cierto para la temporada con mayor actividad turística (estío). De modo se comprueba que en verano las precipitaciones son muy escasas en la casi totalidad de territorio valenciano -salvo en el interior norte de Castellón- $y$ llegan a rozar su inexistencia en las comarcas litorales de Valencia y Castellón y, en mayor grado, en las meridionales de Alicante. 


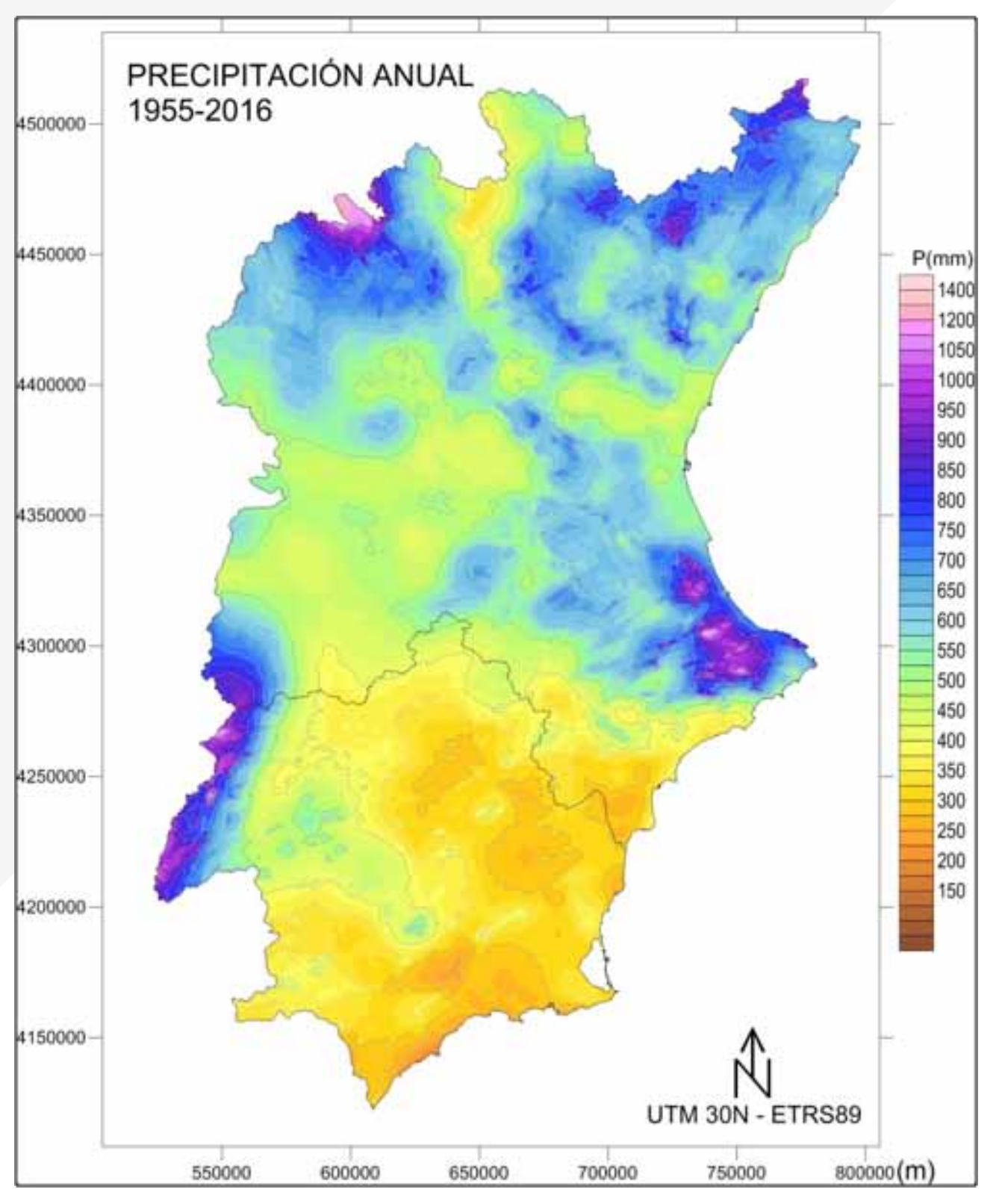
o es lineal. Así, tanto extremos fríos como cálidos no son buenos para la actividad, mientras que un término medio en torno a los $22^{\circ}$ ó $24^{\circ} \mathrm{C}$ confornan el ambiente térmico más ideal. Desde luego, su impacto va también muy parejo al de la humedad relativa y el viento, de manera que valores más altos o bajos de éstos cambian hasta cierto punto el valor térmico ideal, al alza o a la baja. La figura adjunta muestra la distribución de la temperatura media anual, la temperatura media para los meses de verano (Junio, Julio y Agosto) en contraste con la temperatura media de los meses del invierno (Diciembre, Enero y Febrero) (vid. figura 7). 

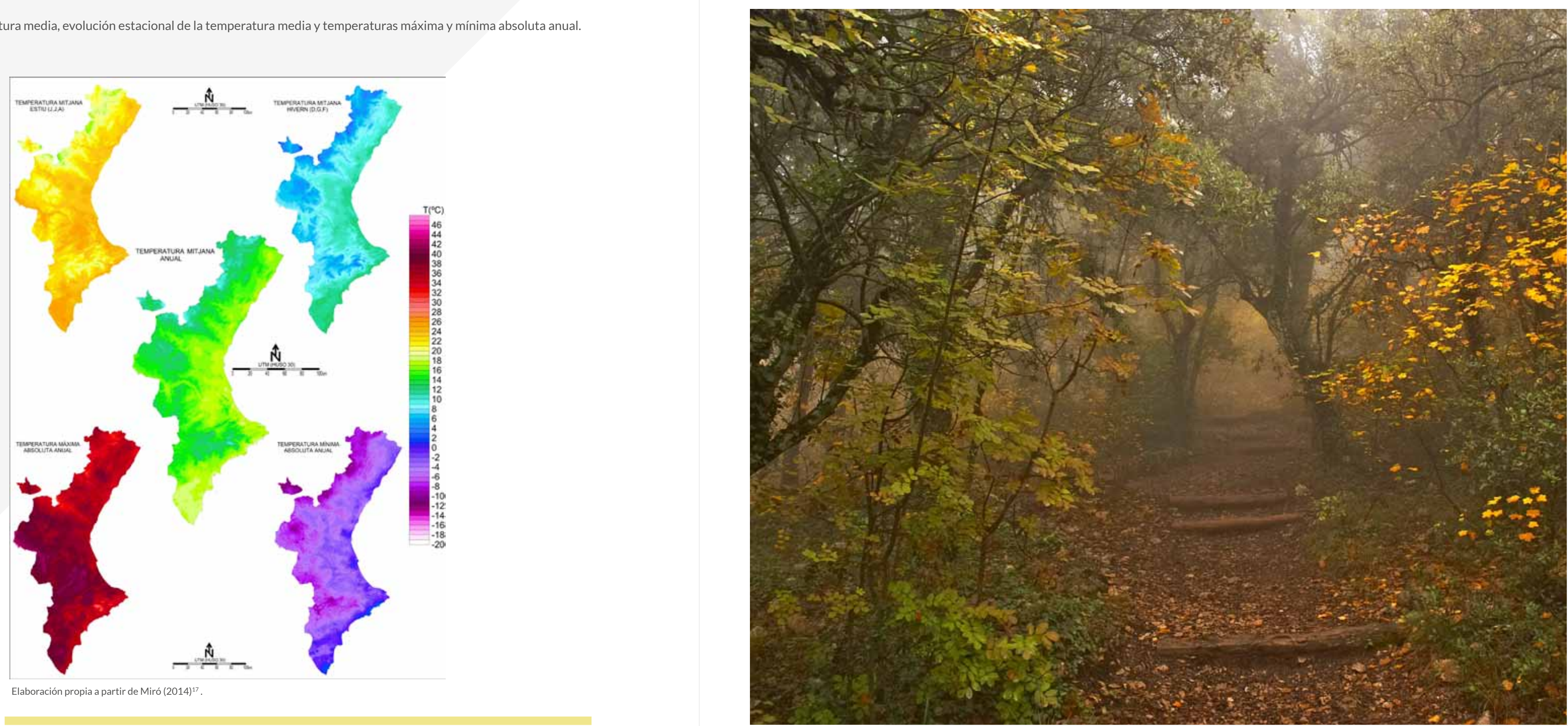
Una temperatura media anual de alrededor de $16^{\circ} \mathrm{C}$ en toda la franja litoral valenciana da idea de su benignidad térmica en el contexto $d$ e las latitudes medias en que nos encontramos. Esta valor anual es más elevado hacia el sur del territorio valenciano; $y$, por contra, es cada vez menor hacia el interior de las tres provincias valencianas, en relación con la distribución de unidades de relieve e incremento de la altitud media del territorio.

En verano, época fundamental para la actividad turística, las mejores temperaturas $y$ confort se trasladan a los valles prelitorales valencian que, a la par de estar ya a cierta altitud, aún reciben bien el influjo de las brisas suavizantes de origen marítimo. No obstante, toda la franja litoral, con temperaturas medias en torno a los $24^{\circ}-25^{\circ} \mathrm{C}$ mantiene un confort térmico bueno durante el día, aunque con temperaturas bastante cálidas por la noche. El mayor disconfort veraniego lo encontramos en hoyas relativamente alejadas del litoral, pero a baja altitud (de Bajo Segura, Bajo Vinalopó e interior de la Marjal Pego-Oliva, comarcas interiores de Valencia y Castellón), donde una relativa dificultad de entrada de brisas unido a la baja altitud proporcionan una temperatura media estival de hasta $25^{\circ} \mathrm{C}$. Por el contrario, en invierno, toda la franja litoral y las comarcas meridionales de Alicante se convierten en un

refugio aún aceptable para el turismo de sol, con temperaturas medias de $12^{\circ}{ }^{\circ} 13^{\circ} \mathrm{C}$. Cuanto más al interior, el disconfort por el frío aumenta, aunque temperaturas entre $6^{\circ} \mathrm{y} 8^{\circ} \mathrm{C}$ de media invernal en los valles

interiores no imposibilitan las actividades turísticas en sus núcleos nos. Por encima de $1000 \mathrm{~m}$. las medias invernales ya bajan de $4^{\circ} \mathrm{O}$

Aunque los valores térmicos diarios más extremos esperables en un año normal son muy puntuales en el tiempo, pueden tener un impacto en el turismo residencial de larga estancia Debe indicarse para temperatura máxima absoluta anual que los valores de mayor disconfort se dan en los valles más interiores y alejados de la influencia de las brisas, con extremas por encima de $40^{\circ} \mathrm{C}$. Por el contrario, en la franja más litoral las extremas no suelen rebasar los $36^{\circ} \mathrm{C}$, situación que también se produce en los relieves prelitorales más cercanos a costa central. Para la temperatura mínima absoluta anual de un año normal, sólo la franja más litoral permanece con una mínima extrema ligeramente positiva, mientras que para todo el interior y prelitoral es inferior a $0^{\circ} \mathrm{C}$. El mayor disconfort vuele a producirse en este caso en los valles más continentales, donde son frecuentes las heladas de rradiación en las hondonadas más proclives.

En aras a establecer una herramienta que mida la aptitud turistica de un clima, la comunidad científica ha desarrollado múltiples índices que combinan las variables climáticas que hemos mencionado, y otras como la humedad y viento, de tal manera que se sintetice en un único parámetro dicha aptitud. El quizás más conocido y empleado al respec- to es el Indice de Confort Climático de Mieczkowski (Mieczkowski, 1985), ó TCl, que oscila entre 0 y 100 (valor idealmente óptimo). De esta manera, se establece el grado de confort y aptitud turística del clima de acuerdo a la tabla adjunta (vid. tabla 4).

Tabla 4. Categorías del TCI (Mieczkowski, 1985).

\begin{tabular}{|c|c|}
\hline VALOR TCI & CATEGORÍA \\
\hline $90-100$ & Ideal \\
\hline $80-89,9$ & Excelente \\
\hline $70-79,9$ & Muy bueno \\
\hline $60-69,9$ & Bueno \\
\hline $50-59,9$ & Aceptable \\
\hline $40-49,9$ & Marginal \\
\hline $30-39,9$ & Desfavorable \\
\hline $20-29,9$ & Muy desfavorable \\
\hline $10-19,9$ & Extremadamente desfavorable \\
\hline$<10$ & Imposible \\
\hline
\end{tabular}

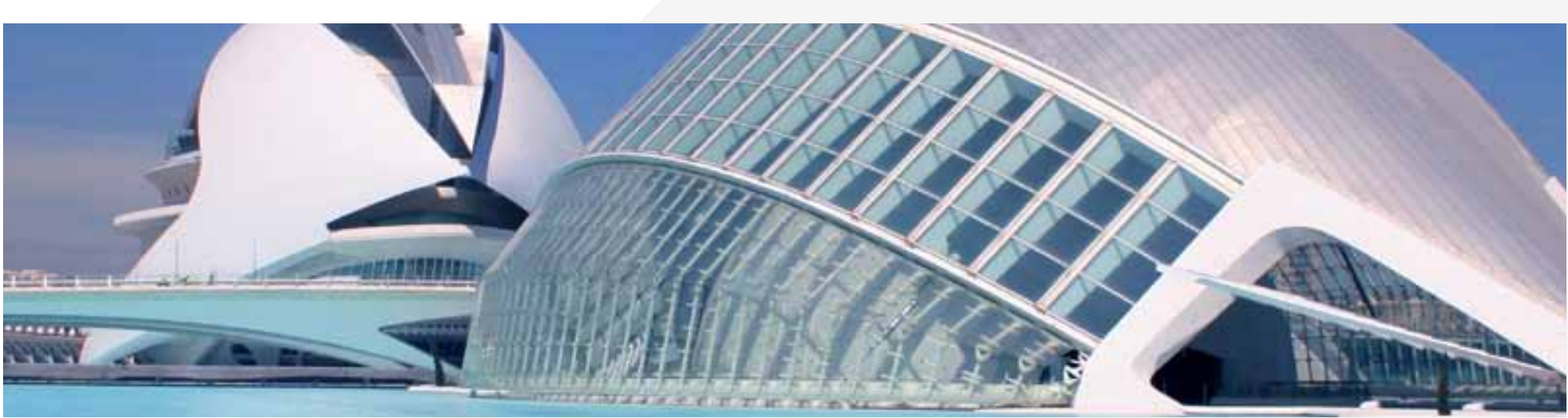


Una estimación del TCI para la Comunidad Valenciana, realizada para cada estación del año, se muestra en la figura adjunta (vid. figura 8). El cálculo ha sido trimestral, según siguiente modo: primavera (marzo, abril y mayo), verano (junio, julio y agosto), otoño (septiembre, octubre noviembre), e invierno (diciembre, enero y febrero).

Índice de Confort Climático de Mieczkowski (TCI) calculado para cada estación del año.

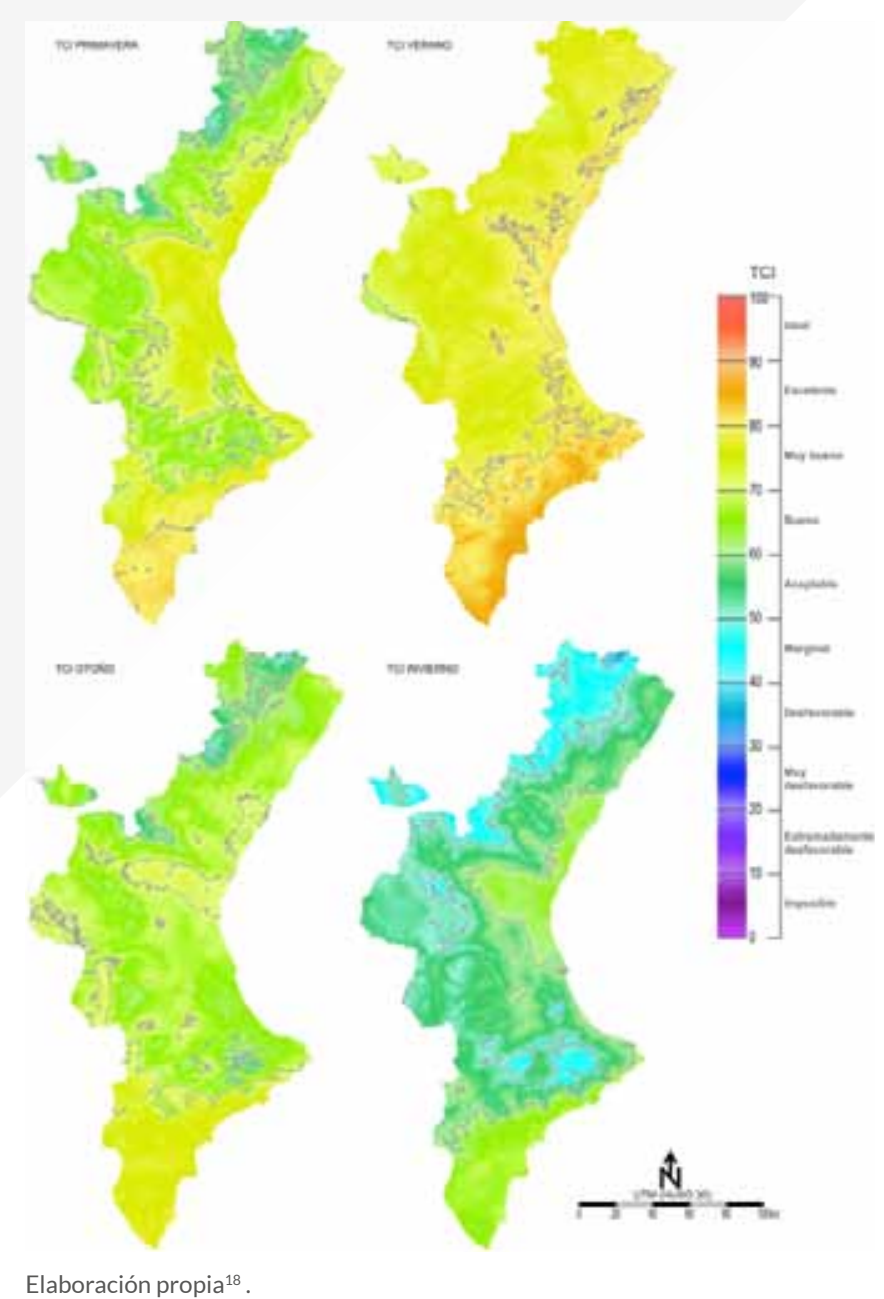

Como muestra la figura, la estación estival es la que proporciona mejores niveles en el TCI. Toda la franja litoral valenciana y algunas áreas montañosas prelitorales de Alicante, dulcificadas por las brisas de origen marino, gozan de un TCl en la categoría de 'excelente' durante el verano. Las áreas interiores que disfrutan de un grado de confort, según este indice, de 'muy bueno', coinciden con aquellas en que las temperaturas máximas caniculares se disparan más y la oscilación térmica diurna es mayor. La eficacia y alcance de las brisas estivales es aquí un factor de diferenciación fundamental.

En el otro extremo, el invierno es la estación con niveles de TCI más bajos, así como se dan las mayores diferencias entre el interior montañoso yel litoral. Solo las áreas litorales de Valencia, sur de Castellón y Alicante mantienen un nivel en la categoría de 'bueno'. Pero va degradándose hacia niveles "marginales" $\mathrm{y}$ "desfavorables" hacia el interior del territorio Valenciano y, en especial, en el extremo interior norte de Castellón.

Para las estaciones equinocciales encontramos niveles del TCl aso mejores en el caso de la primavera, cuando ya alcanza a ser 'excelente' el litoral sur de Alicante y. a mayor parte de las comarcas litorales y prelitorales de la Comunidad Valenciana. Sin embargo en otoño, seguramente debido a una mayor probabilidad de lluvias, el TCI queda en niveles algo inferiores, aunque mantiene niveles de 'muy bueno' en puntos del litoral de Castellón y Valencia, así como en toda la mitad sur de la provincia de Alicante.
No se debe obviar, por último, la existencia de peligrosidad natural en la Comunidad Valenciana y que obliga a la puesta en marcha de medidas de reducción de rit y exposición al riesgo propia de esta actividad económica. Es el caso de la posibilidad de manifestación de movimientos sísmicos, deslizamientos, lluvias torrenciales, temporales de mar con efectos en la franja litoral, sequías y olas de calor. Son peligros naturales que pueden darse en el territorio valenciano y, aunque su frecuencia de desarrollo es, en general, poco elevada, requieren de actuaciones de la administración para minimizar sus efectos. A ellos se unen los incendios forestales que, aunque generalmente tienen un origen no natural, suelen desarrollarse en jornadas con condiciones meteorológicas favorables para su desarrollo y propagación (calor intenso, situaciones con viento de poniente). Entre otras, cumplimiento de la normativa sismorresistente, puesta en marcha de acciones estructurales en cauces, laderas y franja costera, planificación eficiente de recursos de agua y existencia de sistemas de alerta temprana, así como elaboración de protocolos de actuación de cuerpos de seguridad y medios sanitarios para poder hacer frente al desarrollo de eventos extremos y situaciones de crisis, respeto a las zonas de interfaz urbano-forestal. En los últimos treinta años, el riesgo natural se ha incrementado en todo el litoral mediterráneo español incluida la Comunidad Valenciana, en relación con un incremento de la vulnerabilidad y exposición a los peligros naturales potenciales. Y de ello no ha sido culpable la naturaleza y sus manifestaciones a veces extremas, sino la escasa consideración a los rasgos del medio físico existentes en nuestro 
territorio por parte del ser humano que ha llevado a cabo ocupaciones de espacios de riesgo, con evidente desconocimiento del funcionamiento del medio fisico o lo por, con manifesto incumplimiento delas normativas ambientales y territoriales existentes. Los espacios turisticos titorales valencianos son altamente vulnerables puesto que sobre ellos se asienta, de modo temporal o permanente, un volumen de población importante. Y ello obliga a que municipios y administraciones provinciales y regional, velen por la seguridad de los destinos turísticos, también en este aspecto. Esta cuestion, adenas, puede cobrar un protagonismo mayor en las proxximas décadas en el marco del proceso actual de calentamiento térmico, puesto que los modelos de cambio climático en la región mediterránea estiman un aumento de la peligrosidad climática, esto es de la frecuencia de desarrollo de eventos atmosféricos extremos, por efecto de dicho proceso, como se verá más adelante (vid. tabla 5).

Tabla 5. Principales peligros naturales que afectan a la actividad turística en la Comunidad Valenciana

सकास
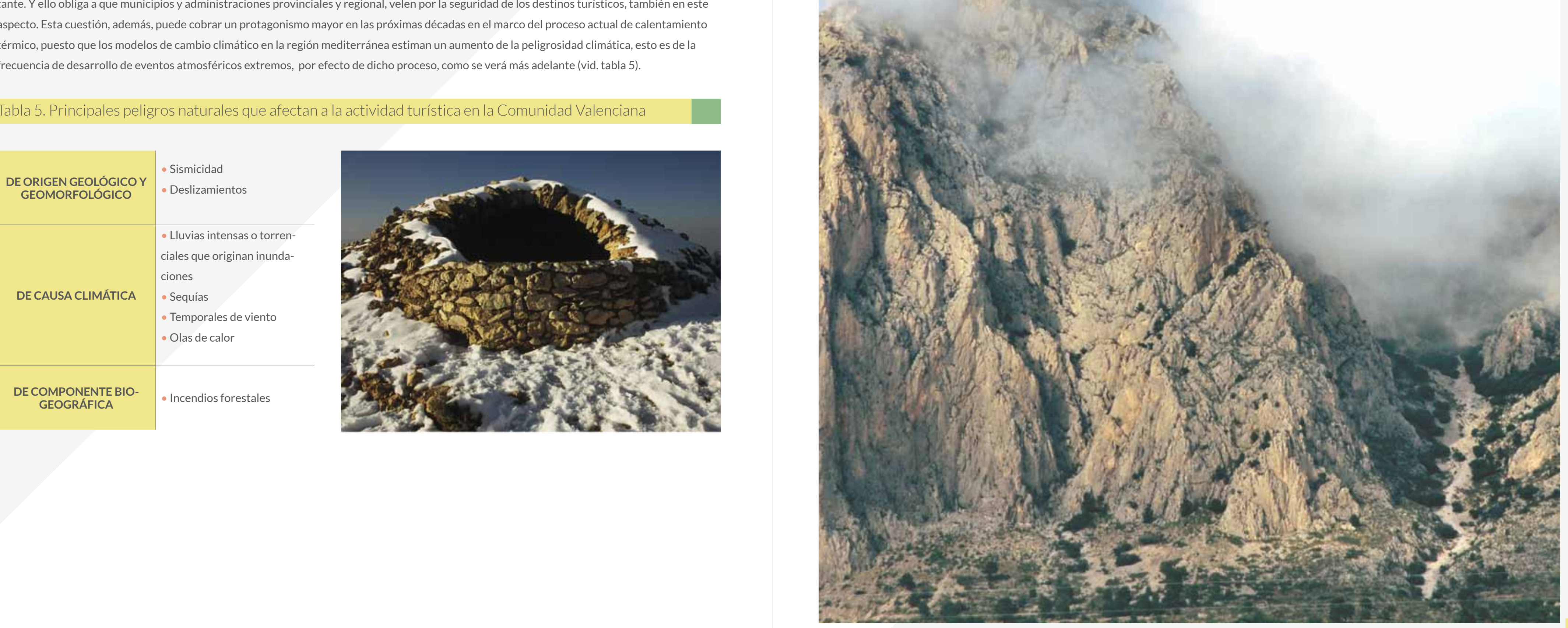


\section{CAMBIO CLIMÁTICO EN LA COMUNIDAD VALENCIANA:

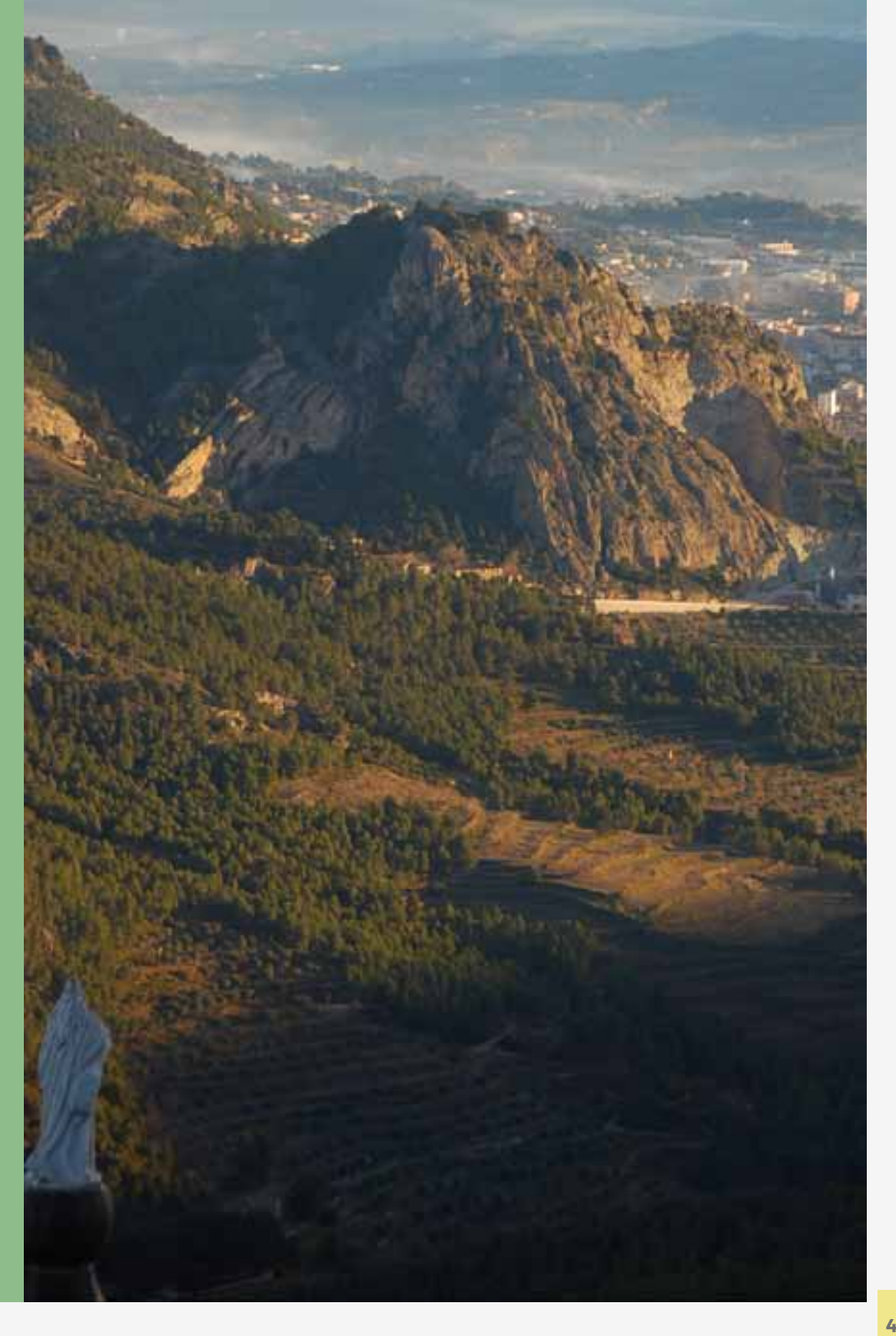



climático por efecto invernadero hay una serie de manifestaciones la atmósfera terrestre, cuya negación resulta cada vez más difíci

- El incremento de temperaturas que se ha registrado en las tres últimas décadas no encuentra explicación, sólo, por causas exclusivamente naturales (radiación solar). Hay otro factor que estáalterando el funcionamiento "normal" del balance energético del planeta, al orisnar una incentivación del poder calorífico de la radiación de onda larga originada en la superficie terrestre y marina que no sale a la atmósfera exterior porque queda confinada en los primeros kilómetros de la atmósfera. Y este hecho está en relación con la presencia de gases primarios procedentes de la actividad económica humana (CO2, oxido nitroso, metano) y depositados en la atmósfera o de la interacción de éstos con otros gases cuya contribución real al balance energético pla- netario sigue siendo una incertidumbre, como el ozono troposférico. Una atmós energético más violentos; esto es, los tipos de tiempo cambian con más rapidez e intensidad. Se hace más frecuente la génesis de situaciones de rango extraordinario. Esto es especialmente notable en las latitudes medias al ser el escenario de desarrollo de los movimientos de expansión de las masas de aire frías (de norte a sur) y cálidas (de sur a norte).

- Desde 1980, las temperaturas han subido más en latitudes medias altas que en las intertropicales, y especialmente, en el hemisferio norte. Ello se refleja tanto en los registros instrumentales de los observatorios como en las termografías realizadas a partir de datos de satélite (p.e. NASA earthobservatory).

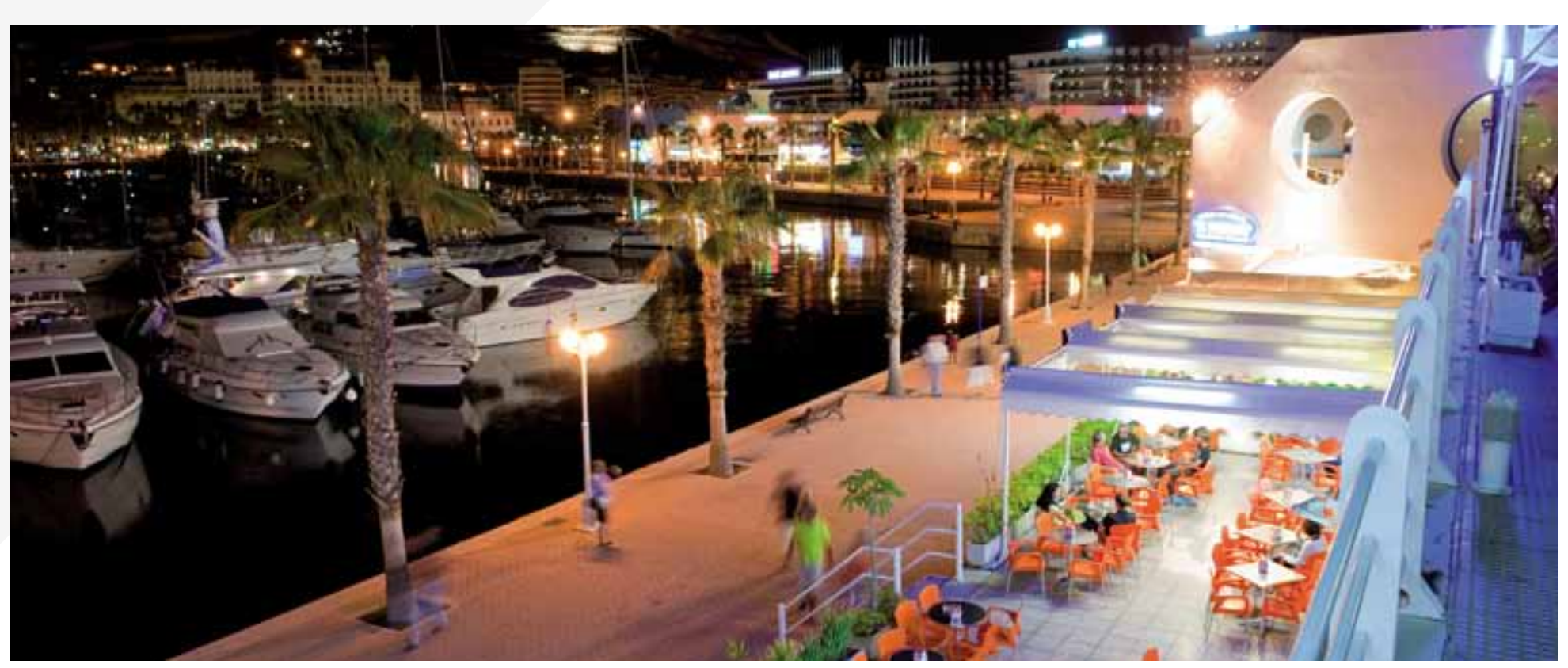

Las condiciones climáticas actuales están experimentando alteraciones y cambios en todo el planeta, y también en nuestras latitudes mediterráneas. Desde los años ochenta del pasado siglo las temperaturas han experimentado un ascenso significativo que se atribuye, dentro de la hipótesis de efecto ivernadero, a la concentración de gases emitidos por el ser humano y procedentes, principalmente, de la quema de combustibles fósiles. Esta subida de temperaturas ha motivado alteraciones en otros elementos del clima (humedad, precipitación, presiones) de verificación más compleja, pero que pueden afectar igualmente a los rasgos climáticos de los territorios. Como se ha señalado, el turismo es una de las actividades económicas mas vulnerables a los cambios climáticos porque la modificación de las condiciones actuales puede suponer cambios en la estacionalidad y el calendario de las temporadas turísticas y cambios en la propia apreciación del confo t climático en territorios turísticos, como el alicantino. Hay tres procesos principales que pueden desarrollarse en nuestras latitudes mediterráneas por efecto del cambio climático con implicaciones directas en la actividad turística: a) un aumento de los extremos atmosféricos (mayor peligrosida climática); b) una reducción de precipitaciones y de volúmenes de agua disponible; $y c$ c) la pérdida de confort climático en el sur y este peninsular por aumento térmico en los meses centrales de verano.

En la Comunidad Valenciana, a efectos de desarrollo presente y proyección futura de la actividad turística en su territorio, son 4 los mecanismos de cambio climático que deben llevarse en cuenta en la planificación (vid. figura 9):

1. Cambios en el confort climático estacional.

2. Evolución de las precipitaciones, a efectos de planificación hidrológica 3. Incremento de eventos atmosféricos extremos. 4. Subida del nivel del mar en la franja costera.

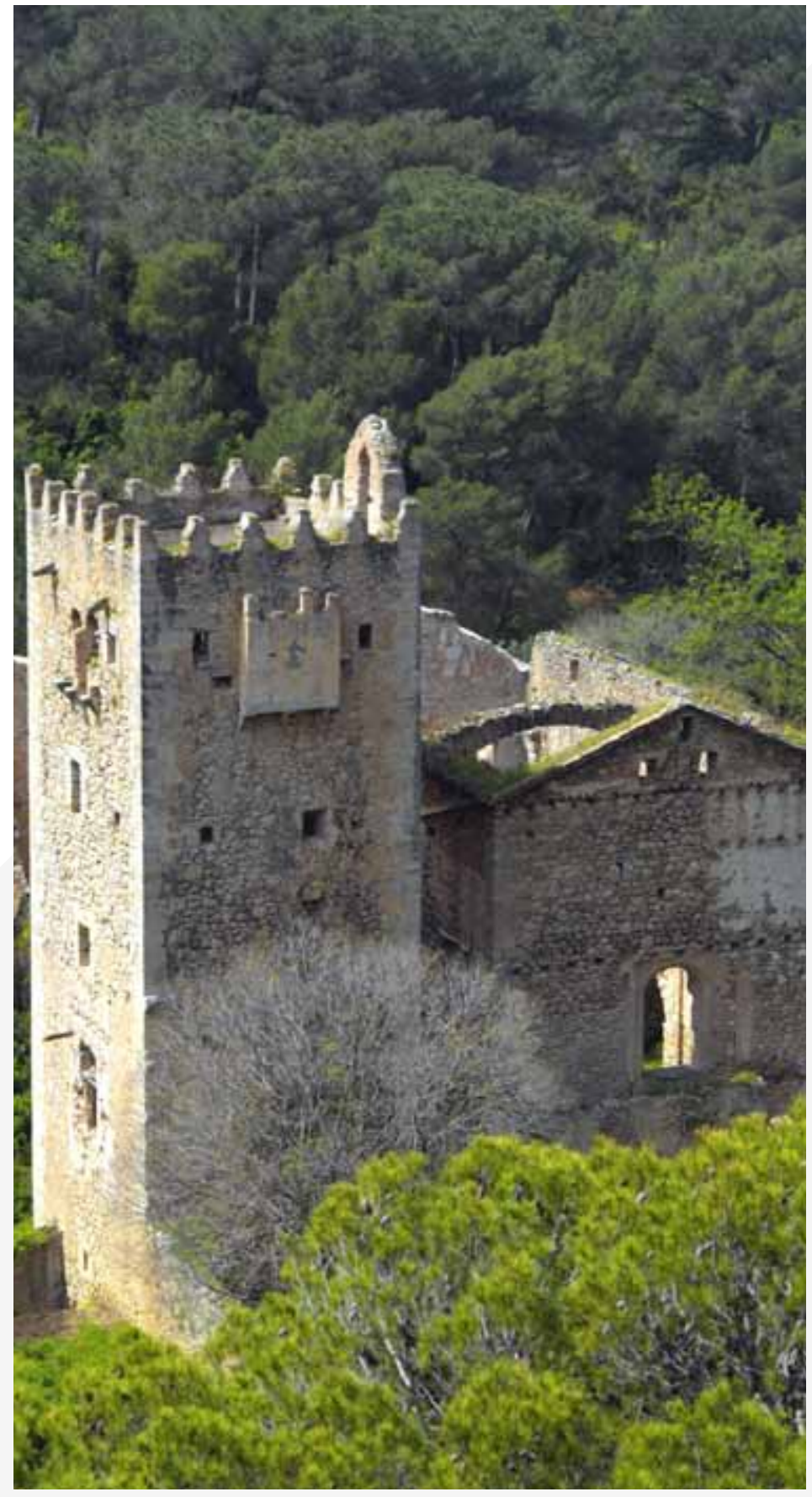




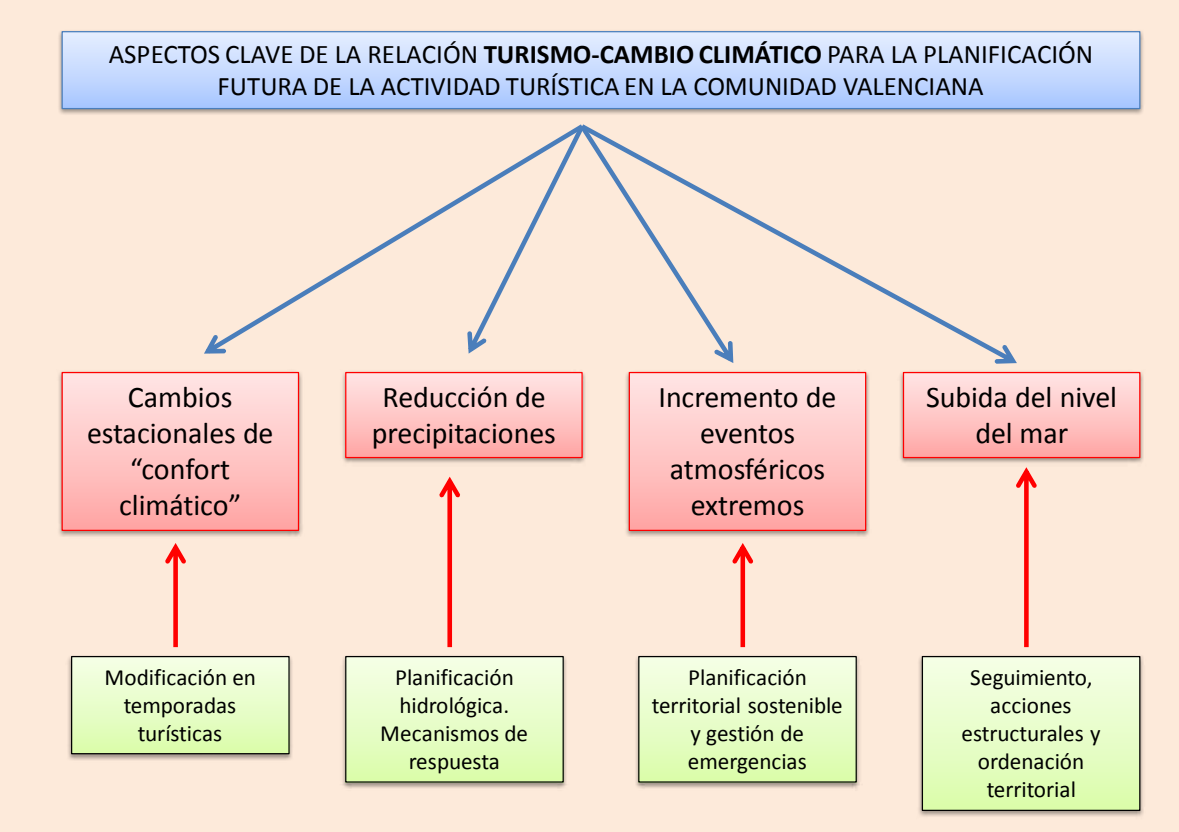

Elaboración propia

El informe "Proyecciones climáticas para el siglo XXI" (Aemet, 2015), como actualización de las proyecciones elaboradas en 2011, ha manejado tres variables (temperatura máxima, temperatura mínima y precipitación) en el análisis de la evolución modelizada del clima para el conjunto de España. Para la Comunidad Valenciana, se ha destacado algunos valores de elementos climáticos significativos para la planificación de la actividad turística. En esencia, la situación prevista nos habla de un incremento de temperaturas, un aumento de la frecuencia de días cálidos y olas de calor y un descenso preocupante de los valores de precipitación (vid. tabla 6 ).

\begin{tabular}{|c|c|}
\hline \multicolumn{2}{|c|}{ C. VALENCIANA } \\
\hline $\begin{array}{l}T^{\mathrm{a}} \underset{\text { MÁXIMA }}{\left({ }^{\circ} \mathrm{C}\right)} \\
\end{array}$ & $+1 \mathrm{~A}+5$ \\
\hline $\begin{array}{l}\text { DURACIÓN OLAS DE CALOR } \\
\text { (DÍAS) }\end{array}$ & 5-35 \\
\hline $\begin{array}{l}\text { DíAS CÁLIDOS } \\
(\%)\end{array}$ & $15-50$ \\
\hline $\begin{array}{l}\mathrm{T}^{\mathrm{a}} \mathrm{MÍNIMA} \\
\left({ }^{\circ} \mathrm{C}\right)\end{array}$ & $+1 \mathrm{~A}+4.5$ \\
\hline $\begin{array}{l}\text { DÍAS DE HELADAS } \\
\text { (DÍAS) }\end{array}$ & -5 A -8 \\
\hline $\begin{array}{l}\text { NOCHES CÁLIDAS } \\
(\%)\end{array}$ & $15-50$ \\
\hline $\begin{array}{l}\text { CAMBIO VOLUMEN PRECIPI- } \\
\text { TACION } \\
(\%)\end{array}$ & 0 A -10 \\
\hline $\begin{array}{l}\text { CAMBIO PRECIPITACIONES } \\
\text { INTENSAS } \\
(\%)\end{array}$ & $0 A-7$ \\
\hline $\begin{array}{l}\text { DURACIÓN PERÍODOS SECOS } \\
\text { (DÍAS) }\end{array}$ & $0 A+2$ \\
\hline 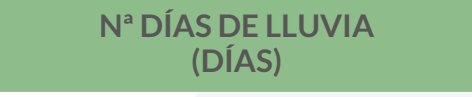 & $-2 A+5$ \\
\hline
\end{tabular}

El impacto de estos procesos de cambio climático afectará previsiblemente a los niveles de confort climático y la propia aptitud del clima para turismo. Sin embargo, estos cambios podrian ser positivos o negativos, dependiendo de la época del año. 
4.1. Cambios en las temperaturas y en el confort climático estacional

EIV Informe del IPCC (2013-14) señala que el cambio climático que pueda desarrollarse en las próximas décadas, si se sigue confirmando la hipótesis de efecto invernadero como parece, no supondrá sólo el aumento de las medias en el valor de la variable temperatura, sino que significará también en la variabilidad, de manera que el clima tiende a un calentamiento pero también a una mayor frecuencia en el registro de temperaturas extremas, con aumento de las medias, máximas y mínimas. Y esto, es también, un indicio de cambio climático, puesto que el ritmo térmico considerado normal en un espacio geográfico sufre alteraciones, experimenta una pérdida de confort térmico; en suma, el clima cambia.

Tras un análisis de la evolución de las temperaturas desde 1940 hasta hoy (vid. figura 10), se evidencia que ya actualmente se ha producido un cambio importante, particularmente en las temperaturas máximas Para realizar este análisis se ha llevado a cabo una distribución del espacio valenciano en sectores geográficamente homogéneos (vid. figura 11)

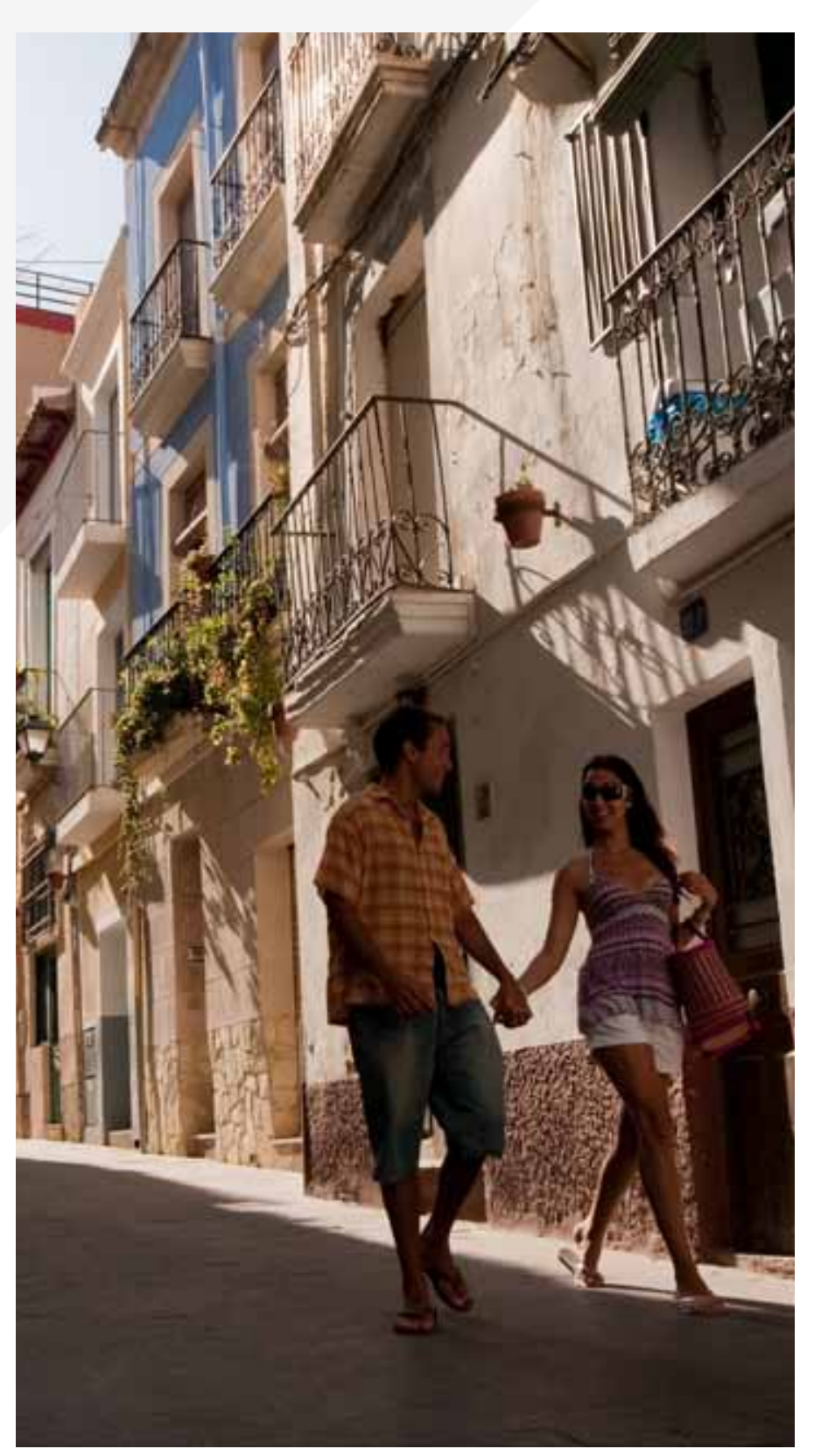

Valenciana.

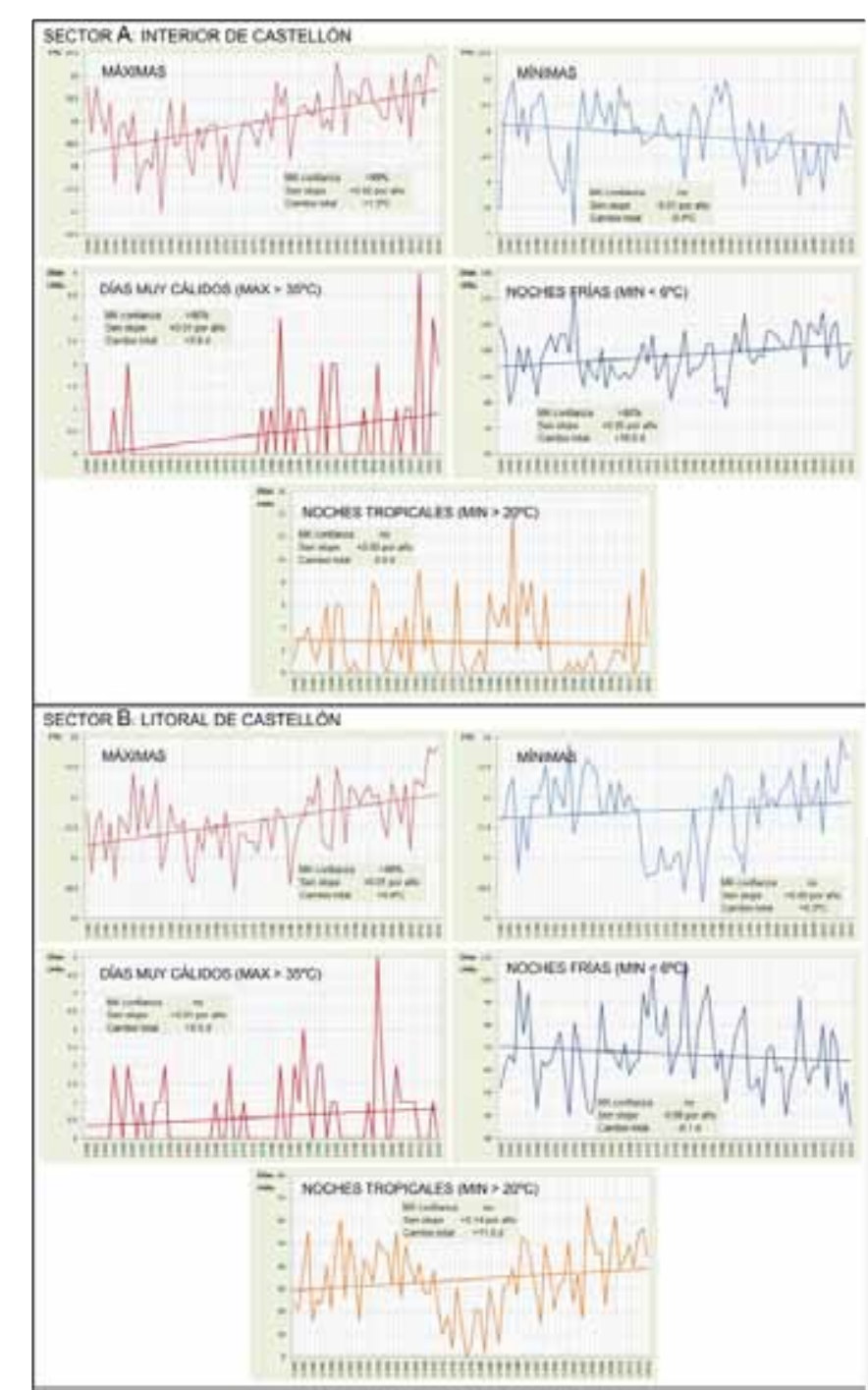




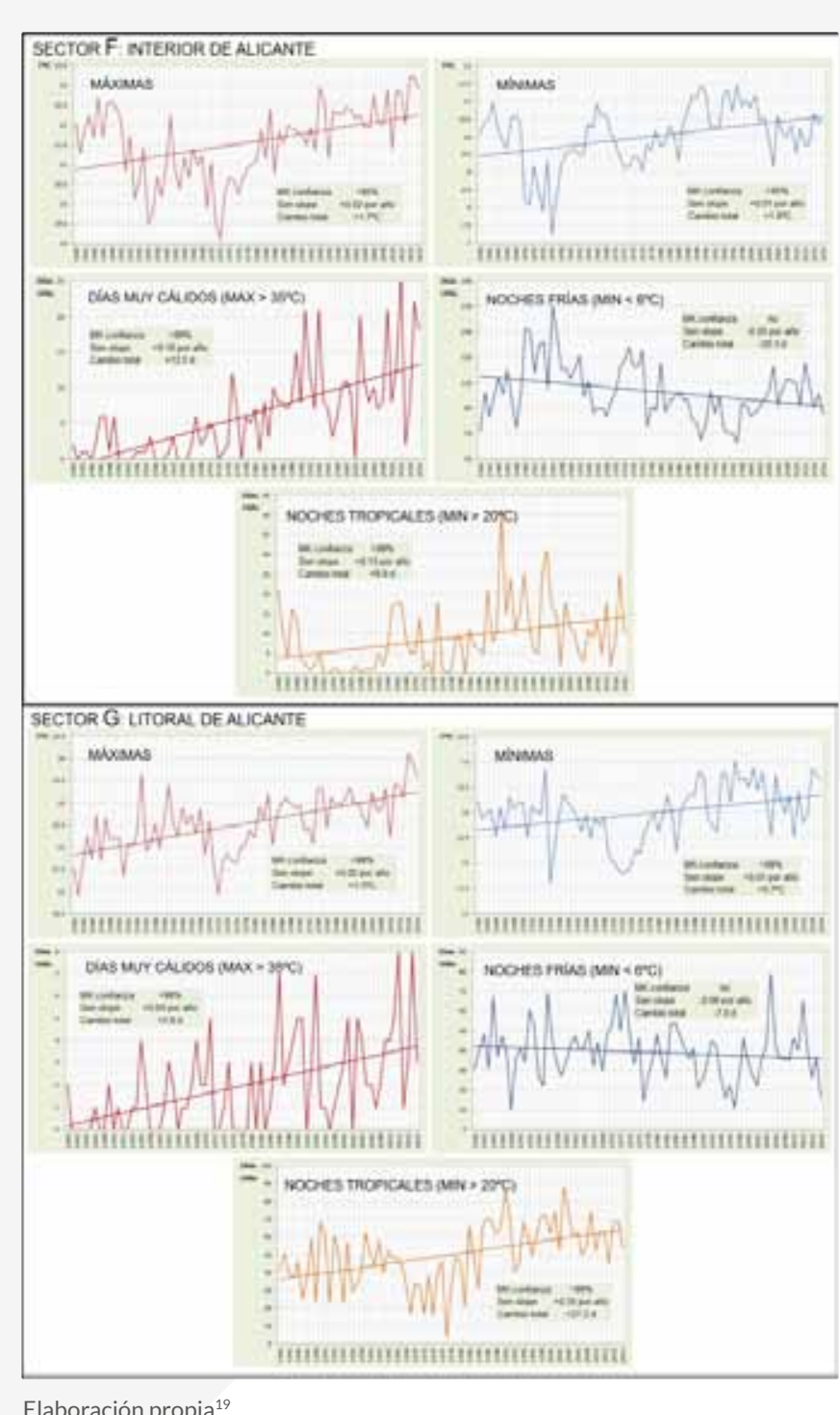

Figura 11

Localización de los observatorios empleados en el presente estudio y agrupación en los 7 sectores de análisis.

$4500000-$

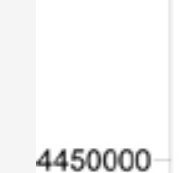

4450000

4400000

4350000

$4350000-$

4300000

4250000

$4200000-$

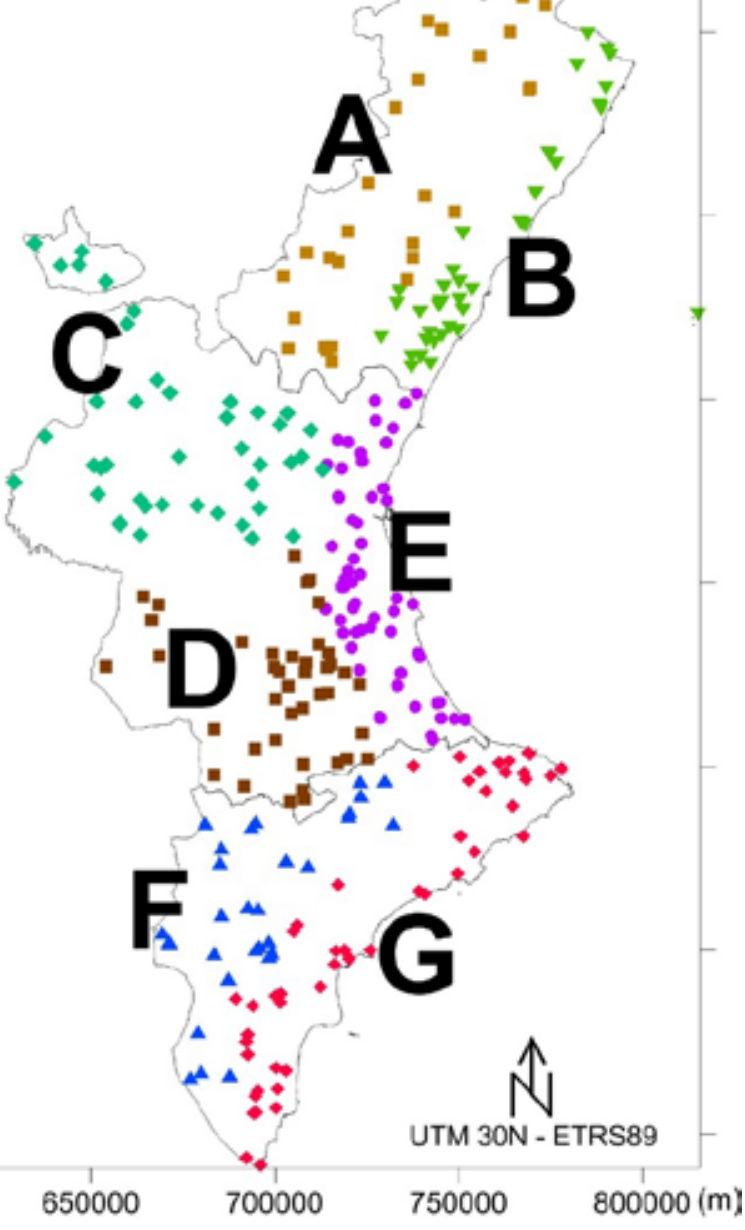

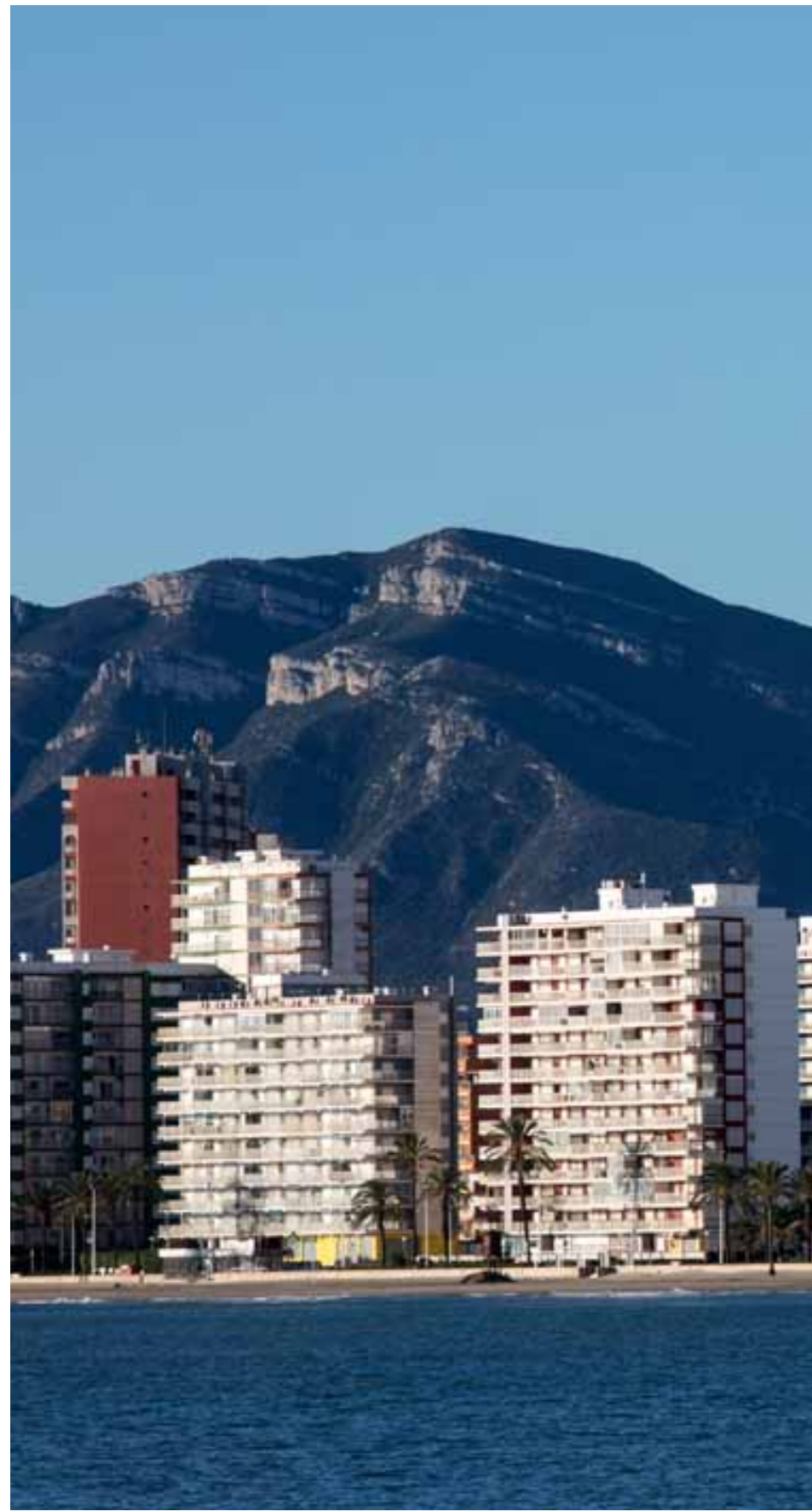

Senta en la Figura 8 divide todos los observatorios temperatura de la Comunidad Valenciana (redes AEMET, SIAR y CEAM) en 7 sectores, que separan el ámbito interior y litoral de cada provincia.

El elevado número de observatorios empleado, un método de relleno de lagunas validado (error en datos diarios $\left\langle 1^{\circ} \mathrm{C}\right.$ ) y el empleo de un moderno método de homogeneización (ACMANT - Domonkos, 2015) dan garantía de la bondad de las tendencias obtenidas.

En todos los casos las máximas se están incrementando por encima de las minimas, con ascensos de las máximas que por regla general ya alcanzan e 2016 los $1.5^{\circ} \mathrm{C}$ (desde 1940). Los incrementos son en general mayores en os sectores interiores que en los litorales. Es especialmente significativo el aumento en la frecuencia de días muy calurosos $\left(\max >35^{\circ} \mathrm{C}\right.$ ), que en muchos sectores (casos de Valencia y Alicante) se han quintuplicado.

Las mínimas, sin embargo, muestran tendencias mixtas, y muchas no son estadísticamente significativas, aunque sílo son en Alicante e interior Sur de Valencia (alincrean con grandes variaciones según sectores. No obstante, el número de noches tropicales $\left(\mathrm{min}>20^{\circ} \mathrm{C}\right.$ ) tiende a aumentar de forma generalizada (vid. figura 12). Aunque el incremento no es estadísticamente significativo en Castelóny litoral de Valencia sílo es en el resto Sin embargo el descenso en to frecuencia de noches frías invernales $\left(<6^{\circ} \mathrm{C}\right)$ es de menor calado $y$, salvo en el interior Sur de Valencia, no se registra un descenso estadísticamente significativo. En algún sector interior (Castellón) incluso aparece una leve pendiente positiva (sin significación estadística). 
"Noches tropicales" (>20ㅇ) en la ciudad de Alicante
$(1970$ y 2015)

\section{0 \\ 60 \\ 40}

Esto, en general, nos señala incrementos térmicos mayores en verano que en invierno, aumentando la amplitud térmica anual, y también las oscilaciones térmicas diarias. En ese sentido es importante considerar que la mayoría de observatorios (particularmente los interiores), se enclavan en valles y áreas sometidas a mayor frecuencia de inversión térmica nocturna, faltando observatorios en zonas altas. Al respecto, el downscaling estadístico realizado por Miró et al (2015) hasta 2011 mostró que las zonas altas se calientan más rápidamente que las bajas, debido a que un aumento en la frecuencia de altas presiones, pantanos barométricos, y masas de aire cálido $850 \mathrm{hPa}$, están causando un aumento de las inversiones térmicas. Lo cual explica un menor ascenso de las mínimas con respecto a las máximas en esas cotas bajas donde se sitúan muchos observatorios. Pero el calentamiento también se estaría produciendo en las mínimas sobre las montañas. Dicho downscaling, realizado sobre todo el territorio con una resolución de $90 \mathrm{~m}$, reveló un calentamiento máximo en el mes Junio, y en cotas altas, entre 1948 y 2011 , como se aprecia en la Figura 13

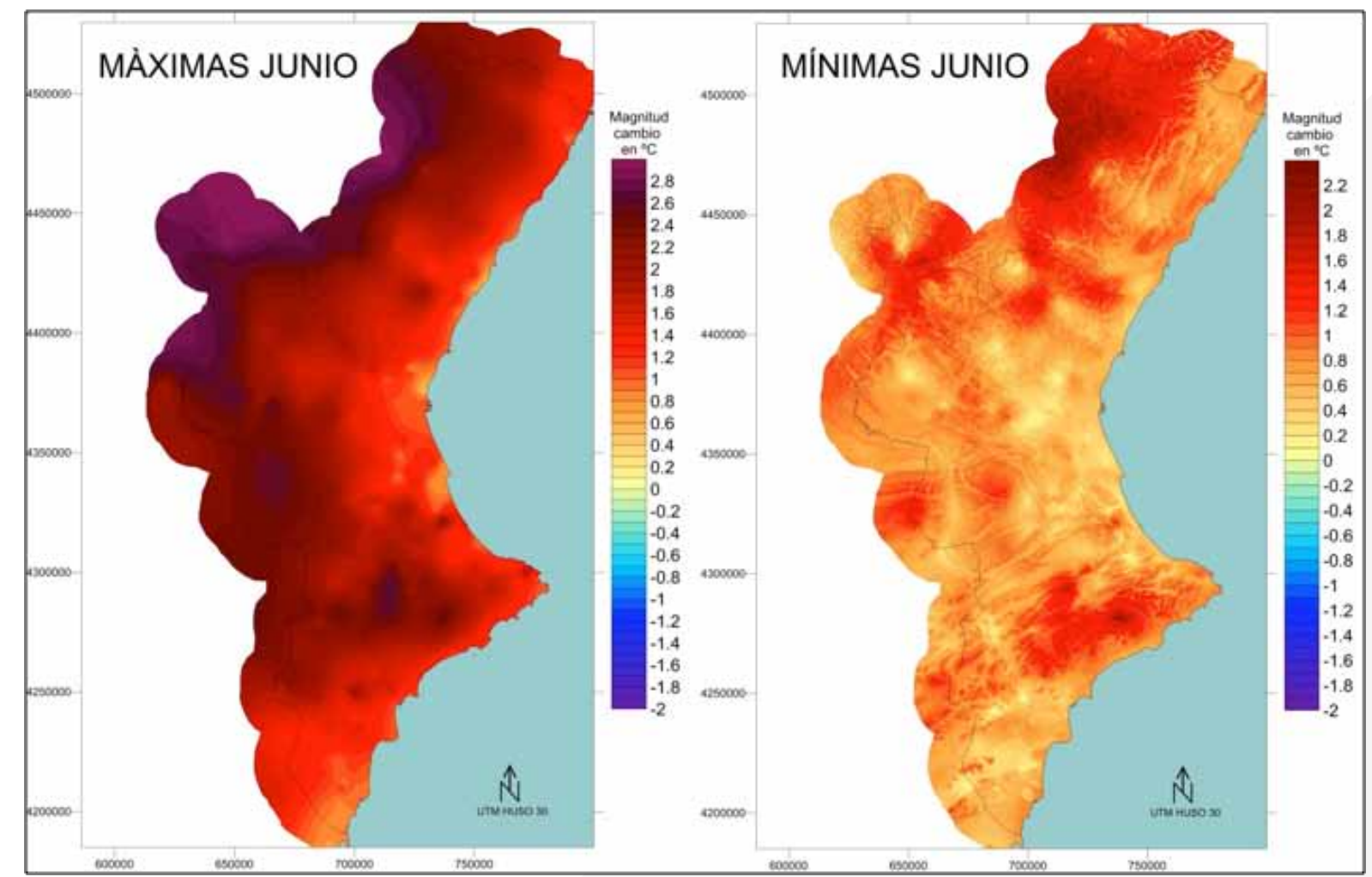

Fuente: Miró [et al.]

Este tratamiento con downscaling también explica el porqué de la disparidad de resultados para con las temperaturas mínimas, frente al evidente ascenso de las máximas, como efecto de un aumento de las condiciones estabilidad atmosférica (Miró et al., 2015). Tanto el downscaling como el análisis masivo de datos observados más reciente se ponen de acuerdo en ello, lo cual indica que los incrementos mayores en las mínimas (respecto de las máximas) registrados en las mayores urbes de la región (p. ej. señalados en Quereda et al., 2001) tienen su origen en la isla de calor urbana.

Aumentos térmicos mayores hacia la segunda mitad de la primavera y el verano, máximos en Junio, señalan una tendencia, ya en proceso, a la pérdida de confort térmico en los meses de mayor afluencia turística. También, una mayor frecuencia de situaciones estables conduce al incremento de las oscilaciones térmicas diarias, particularmente en valles y hoyas, lo que se aprecia en la Figura 14, implicando también una reducción del número de horas diarias con temperaturas idóneas (ni frío ni calor) para la actividad turística. 


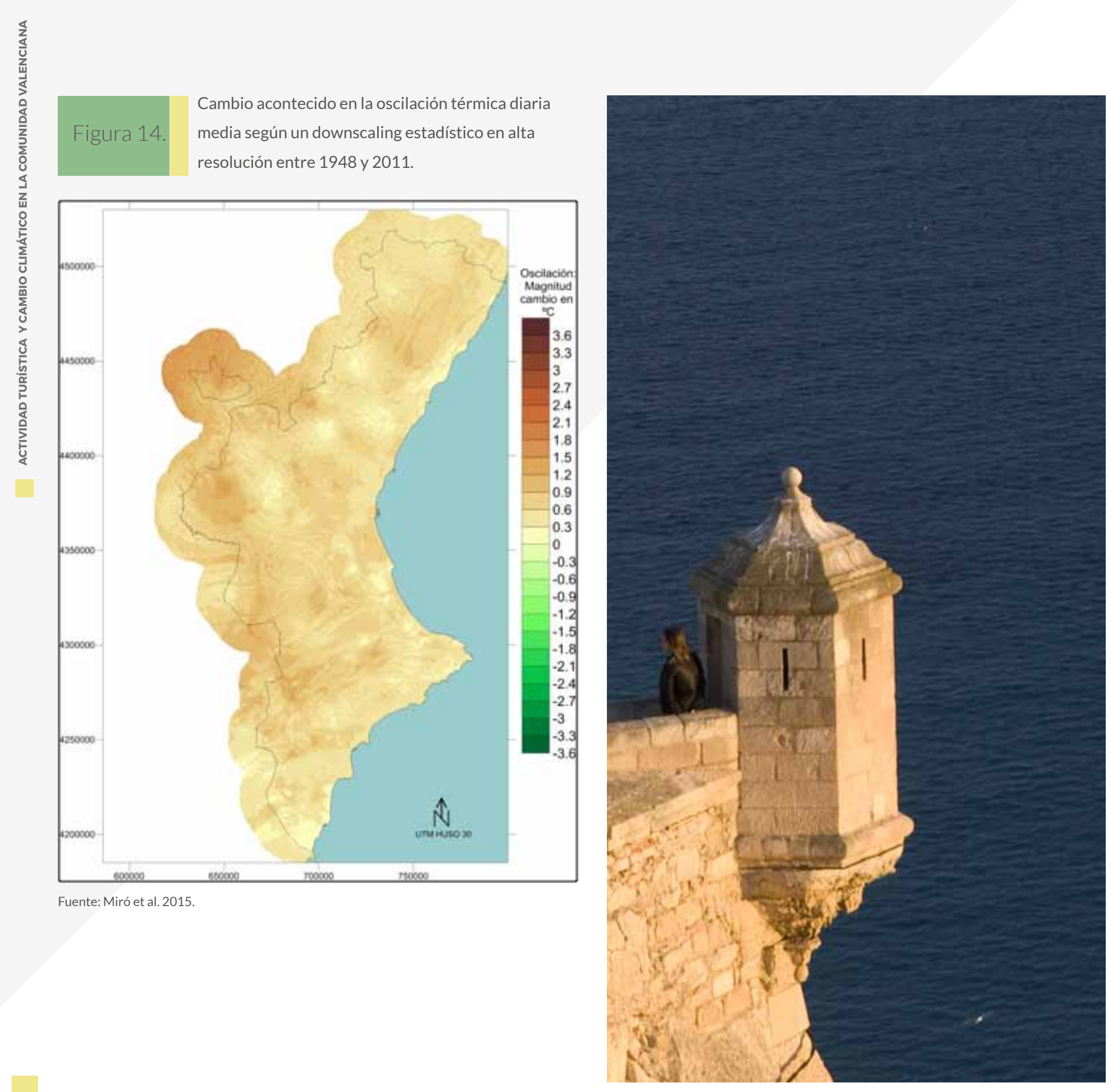

Otro factor importante es el calentamiento que experimenta el mar Me作 ños noventa del pasado siglo, la cuenca occidental del Mediterráneo se calienta antes (junio) y más (la temperatura superficial marina llega a alcanzar picos de $27-28^{\circ} \mathrm{C}$ ) de lo que lo hacía en los años ochenta (López mbiental, que si se acompaña de temperaturas altas y/o noches tropicales incrementa el disconfort térmico. Asimismo, el período de tempe raturas elevadas $\left(>25^{\circ} \mathrm{C}\right)$ de las aguas marinas se prolonga entre junio y septiembre, lo que puede tener una lectura positiva en los periodos de transición estacional.

Para el conjunto de la cuenca del Mediterráneo, se ha estimado un incremento absoluto de $0.22^{\circ} \mathrm{C}$ por década, desde 1973 a 2008 (Skliris et al.2012) y de $0.36^{\circ} \mathrm{C}$ por década entre 1982 y 2016 (Pastor et al. 2017). A partir del uso de datos de satélite (GHRSST Level 4 AVHRR_OI Global Blended Sea Surface Temperature Analysis (GDS version 2) from NCEI), Pastor et al. (2017) han calculado el incremento térmico en las aguas del Mediterráneo para el período 1982-2016 (Figura 15).

Como se indica en Pastor et al. (2017), lo más significativo es que la responsabilidad del calentamiento recae especialmente en los meses fnales de la primavera e inicio del verano (abril a julio) y, en menor medida, en los invernales, lo que coincide en gran medida con las tendencias registradas en la temperatura terrestre de la región, coincidiendo con un máximo calentamiento en Junio.
De este modo se confirma la tendencia no sólo a un aumento mayor de la temperatura de las aguas del mar en los meses centrales de verano, sino la prolongación señalada del período anual con aguas cálidas frente a las costas del litoral mediterráneo español. 
Figura 15. Cambio acontecido en la temperatura superficial de las aguas del Mediterráneo entre 1982 y 2016. Arriba, total. Centro y abajo, mensual.

\section{SST total increase 1982-2016}

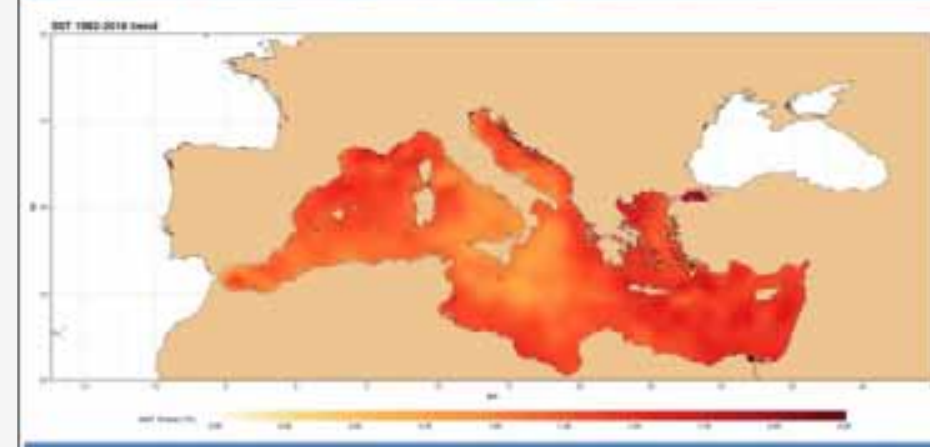

SST monthly trend

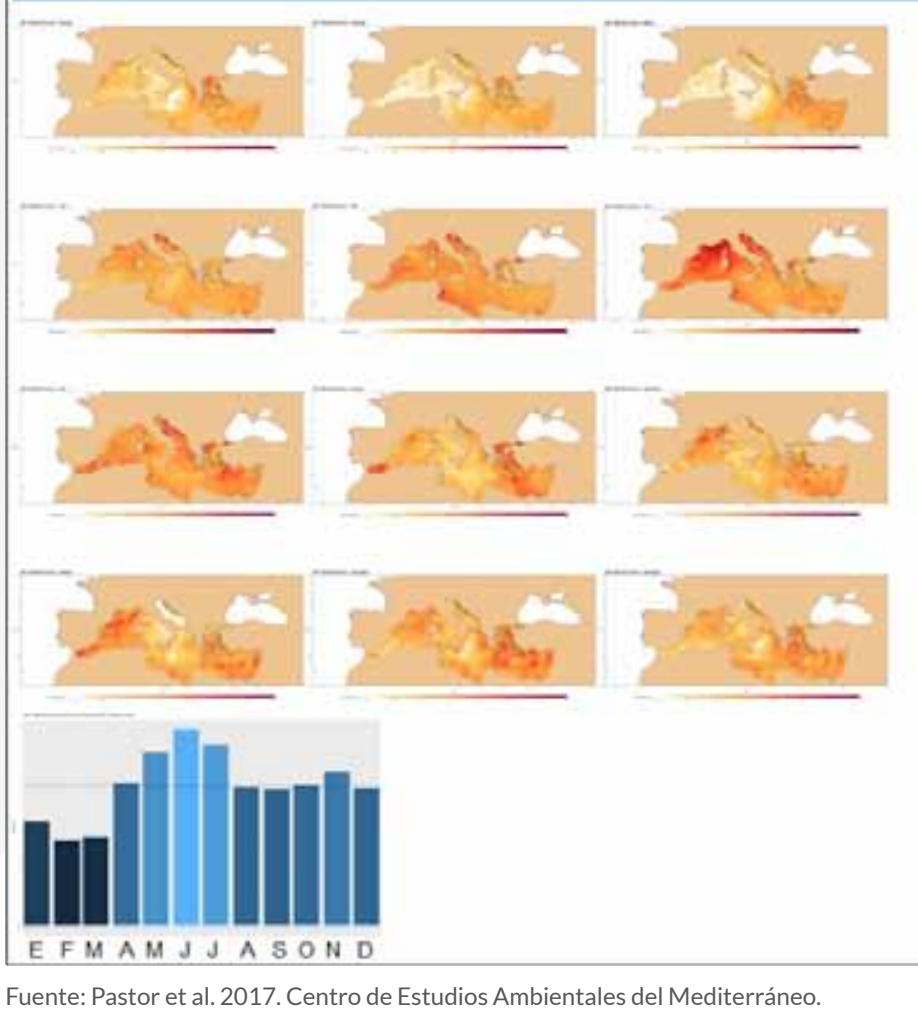

A efectos de confort climático para la actividad turistica, la Figura 16 muestra el cambio previsto en el TCI según una proyección para el periodo 2071-2100. Este cambio refiere a un hipotético estado futuro del clima en el caso las tendencias actuales siguiesen efectivamente su curso hasta dicho periodo futuro. Puede observarse una pérdida clara de confort para el caso del verano, esencialmente a causa de un aumento de episodios de calor asociados a bajo confort. La pérdida es mayor en los valles y hoyas (hasta 8 puntos en algún lugar), pero también es cercana a los 5 puntos de pérdida de confort en la mayor parte del litoral. El descenso sólo es débil, y hasta se invierte en algún caso, para las montañas y partes más elevada de la Comunidad Valenciana, al menos para las más expuestas a las brisas, que mantendrían aqui su suavidad debido a la pérdida de temperatura por la altitud.

Sin embargo, el caso contrario ocurre para el invierno. En este caso tenemos una mejora de confort en toda la Comunidad (entre 2 y 5 puntos). con una prolongac a tiv para la posible prolongación de la temporada estival en los meses de septiembre y octubre, si se cumplen estas previsiones de los modelos de calentamiento térmico planetario en nuestro territorio.
Cambio previsto en el Índice de Confort Climático de Mieczkowski (TCI) para la Comunidad Valenciana de acuerdo a las proyecciones climáticas para el periodo 2071-2100.

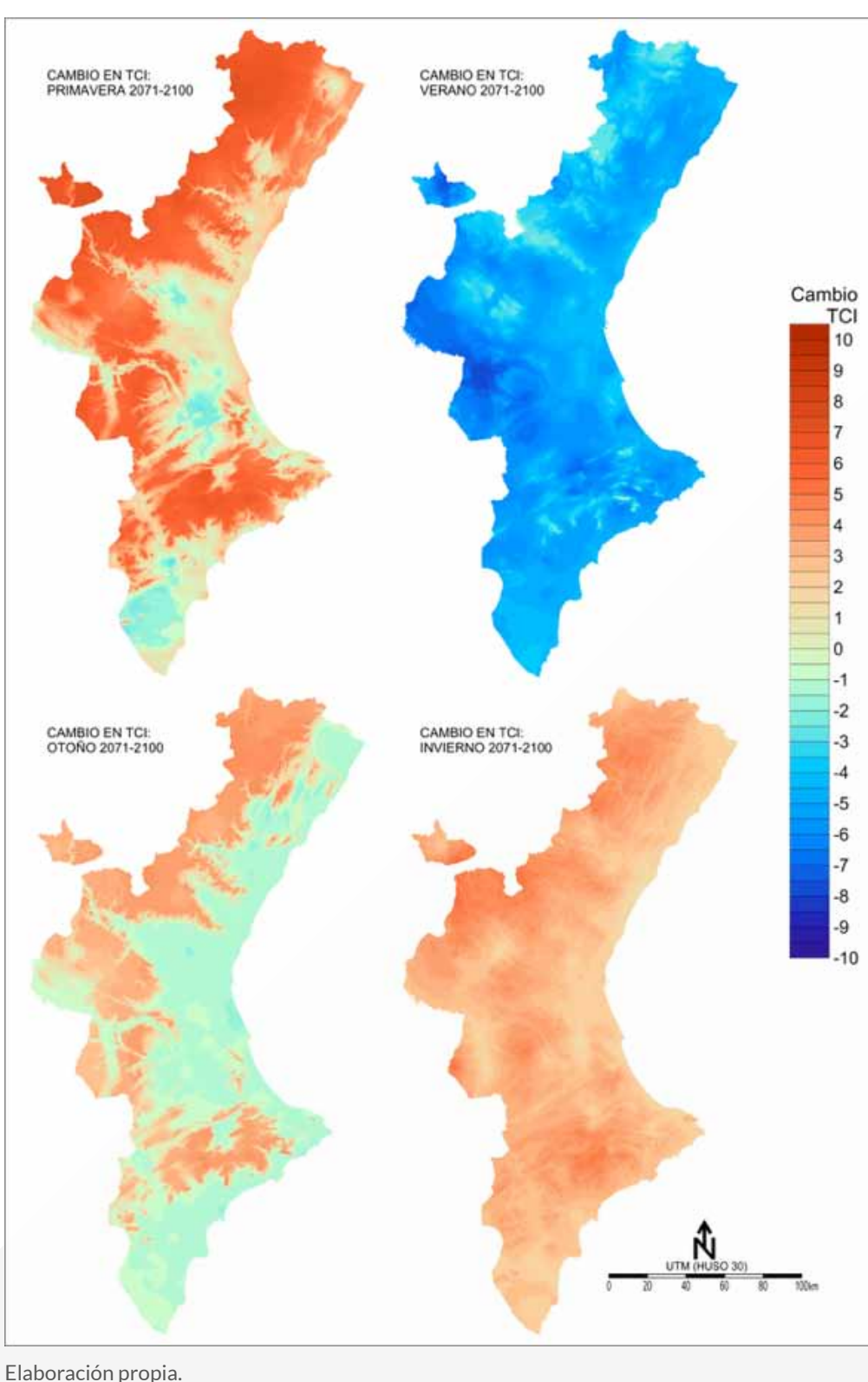


Si se comparan las figuras 8 y 16 del presente estudio se puede comprobar la evolución prevista en el Índice de Confort Climático de M czkowski (TCl) hacia final del presente siglo en el marco de la hipótesis actual de calentamiento térmico planetario. Como se ha señalado es notoria la pérdida de valores de confort en las áreas litorales valenci nas en verano. Sin embargo, resulta asimismo notable la ganancia que experimenta este indicador en las estaciones de primavera y, especi mente, otoño, lo que indica una prolongación de rasgos térmicos estivales hacia los extremos de dicha estación, con la posibilidad que ello supone de aprovechamiento del clima para el desarrollo del turismo de sol y playa en el territorio valenciano (vid. figura 17).

"Información calculada a partir de los patrones de cambio térmico detectados en Miro et al. (2015), apilicando un forzamiento segun la proyección revista por AEMET en su modelo de regionalizacion ARS 5 WCC (httpon
Figura 17.

Valores previstos en el Indice de Confort Clima tico de Mieczkowski (TCI) para la Comunidad Valenciana de acuerdo a las proyecciones climá ticas para el periodo 2071-2100.

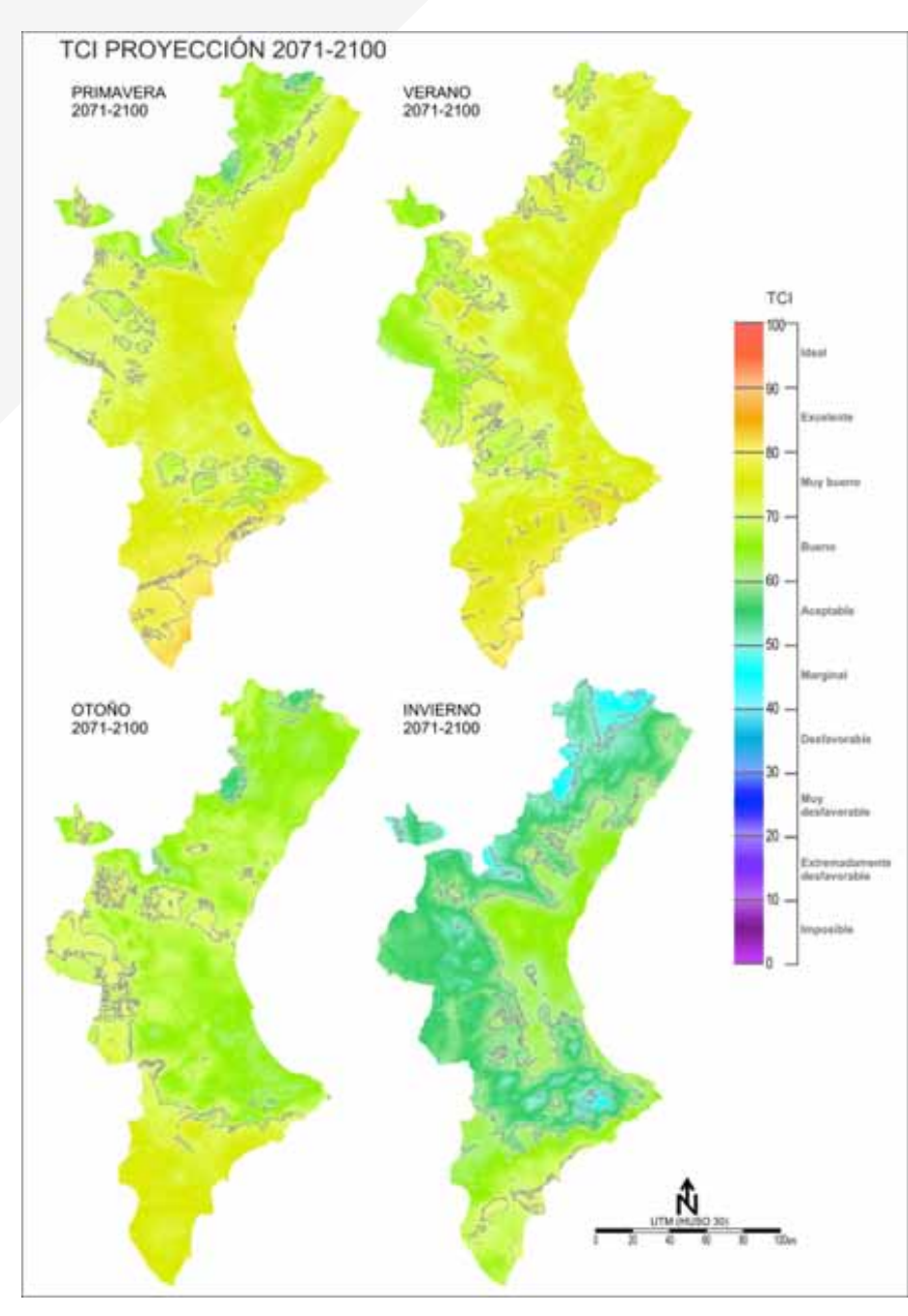

4.2. Evolución futura de las precipitaciones, a efectos de planificación hidrológica

Otro elemento climático cuya evolución presente y futura interesa mucho en el territorio valenciano, a efectos de planificación de las actividades económicas $y$, entre ellas, de manera destacada el turismo por su gran importancia en el VAB regional, es la precipitación. La disminución de cantidades anuales que indican los modelos de cambio climático deberá considerarse en cuenta, a partir de ahora, en la planificación hidrológica y territorial que se realice en el litoral mediterráneo español.

La figura 18 (superior) muestra las tendencias que presentan las precipitaciones anuales en el territorio valenciano, en el período 1955-2016, obtenidas a partir de más de 800 observatorios en las Cuencas Hidrográficas del Júcar y Segura, y siguiendo los métodos de relleno de lagunas y homogeneización indicados en Miró et al. (2017) y Domonkos (2015). Se aprecia un predominio de tendencias negativas ya en curso, particularme te en la cuenca alta y media del Júcar y la media-baja del Turia, así como en el Vinalopó y litoral central de Alicante. Sólo el Norte de Alicante y Sur de Valencia, cuenca media del Segura y Gúdar se libran de tendencias negativas estadísticamente significativas.

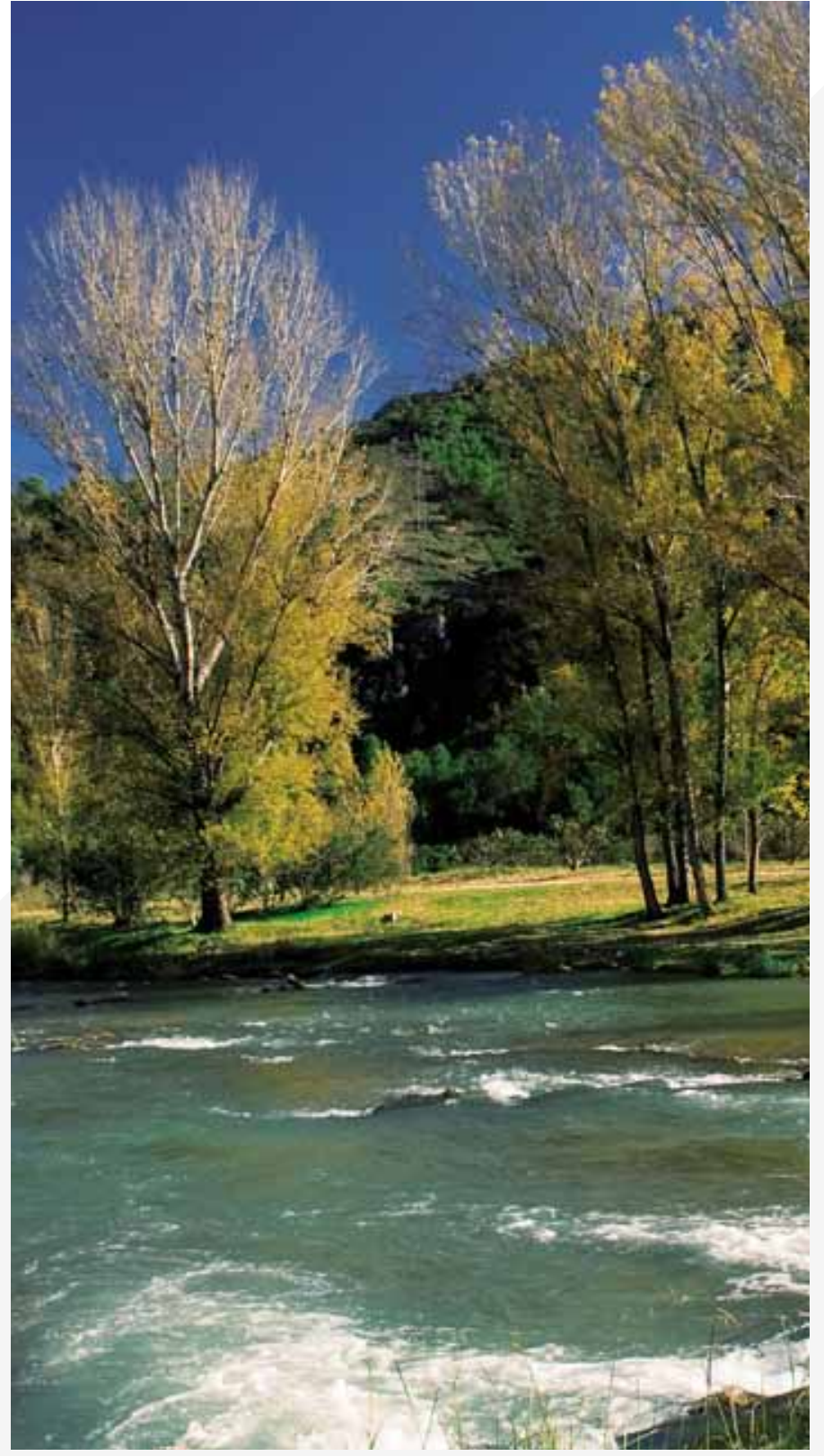




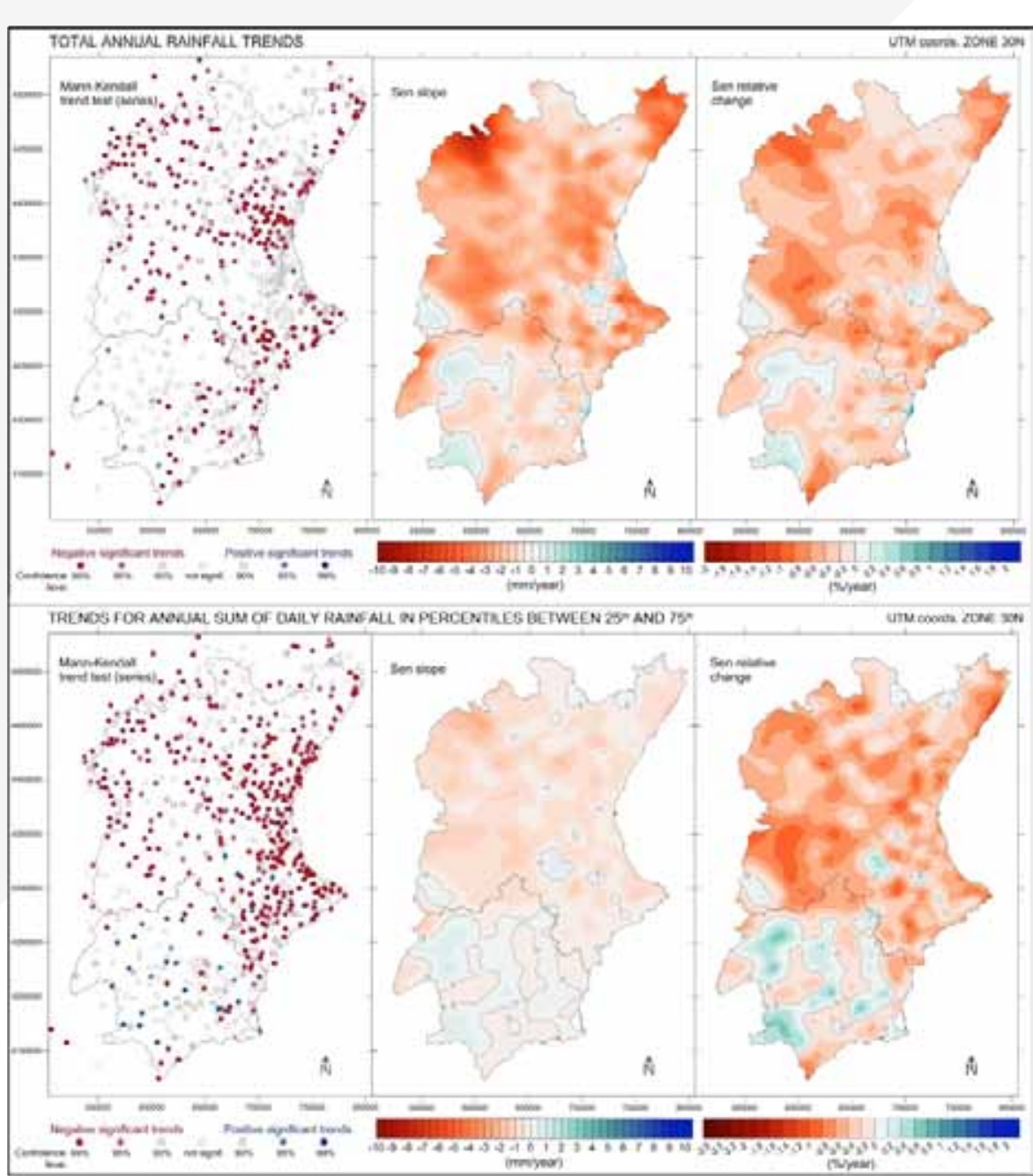

Elaboración propia $2^{21}$
Adicionalmente, la causa principal de estas tendencias negativas recae en las precipitaciones no extremas, o moderadas (percentiles medios), como se aprecia en la parte inferior de la Figura 18. Dichas precipitaciones son precisamente las de mejor aprovechamiento hídrico. Ello afecta particularmente a toda la cuenca del Júcar, que presenta un comportamiento hídrico algo más regular que la cuenca del Segura, y que ahora va perdiendo, mientras que la del Segura se mantiene sin cambios.

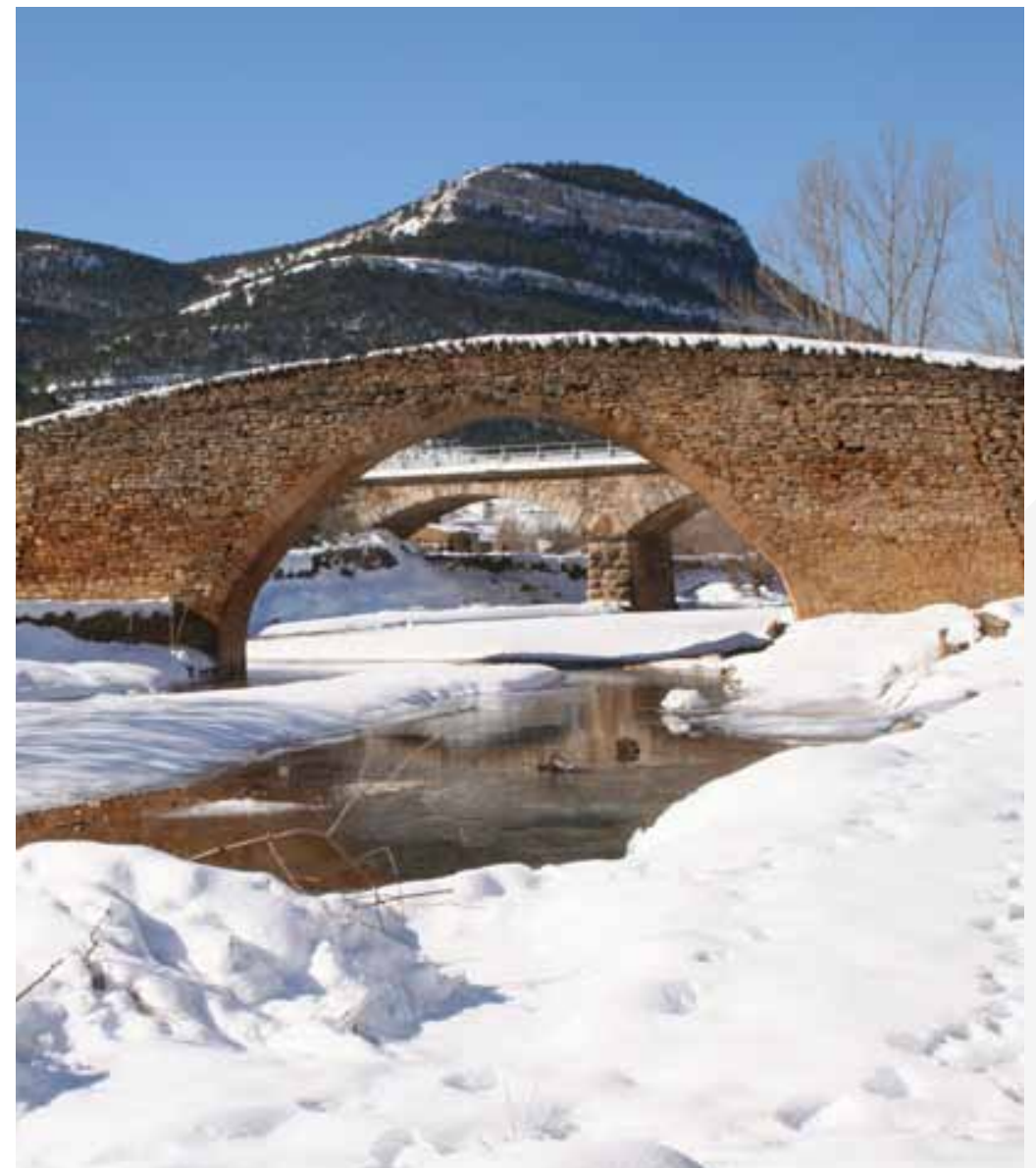

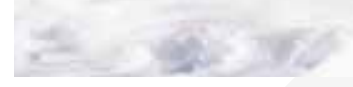

Precipitación total anual en los primeros 30 años y los últimos 30 años del periodo 1955-2016, y cambio acontecido entre ambos periodos.

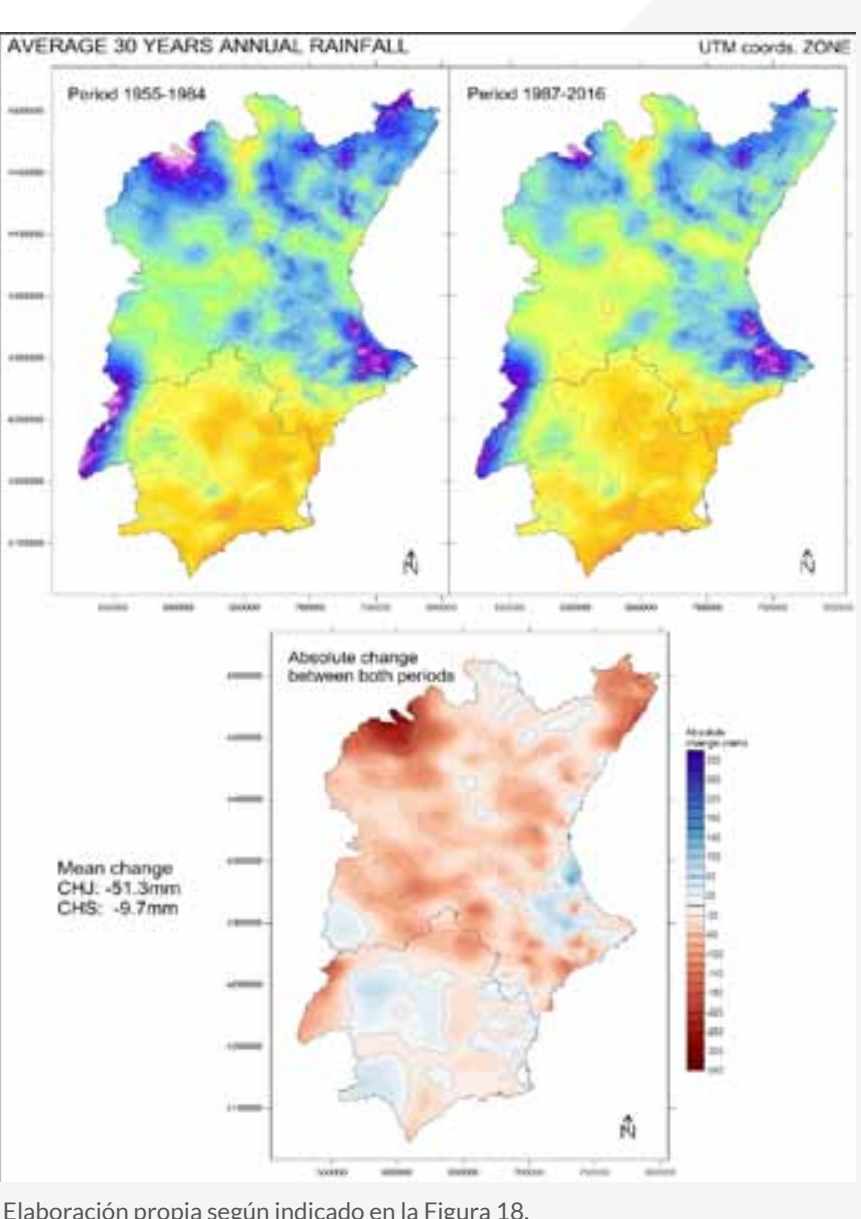


Todo ello supone que entre el periodo de los primeros 30 años analizados (1955-1984) y el periodo de los 30 años más recientes (1987-2016) ya han acontecido cambios importantes en la distribución territorial de la precipitación, como se aprecia en la Figura 19. Es preocupante la pérdida superior a $200 \mathrm{~mm}$. anuales ya acontecida en cabecera del Júcar, en la zona propiamente adyacente a la cabecera de Tajo, de donde se nutre el transvase Tajo-Segura, además de aportar el caudal base y regular del Río Júcar. Dentro de la cuenca del Júcar predominan las pérdidas de precipitación a excepción clara del tercio Sureste de Valencia y Nordeste de Alicante, donde aparecen ciertas zonas con incrementos. Aunque la cuenca del Segura queda mucho más compensada entre áreas con descensos e incrementos de precipitación, la cabecera del Río, donde se producen los aportes principales, también registra pérdidas superiores a $100 \mathrm{~mm}$
La distribución estacional de estos cambios en la precipitación se muestra en la Figura 20. En este caso destaca que la mayor de precipitación en las cabeceras del Júcar y Segura coinciden con el invierno, estación que aporta las precipitaciones y nevadas más aprovechables por el sistema hídrico. Destaca también la perdida generalizada de precipitación en los meses de verano, que se vuelven aún más secos, mientras que la primavera también pierde precipitación en la mayor parte del territorio a excepción del sector entre Castellón y Teruel. Sin embargo, el Otoño e Invierno registran incrementos de precipitación en gran parte de la cuenca del Segura, el litoral de Valenciay el sector del Sur de Valencia y Norte de Alicante, asociada a temporales de Levante, mientras que enel resto predominan los descensos. acontecido entre ambos periodos.

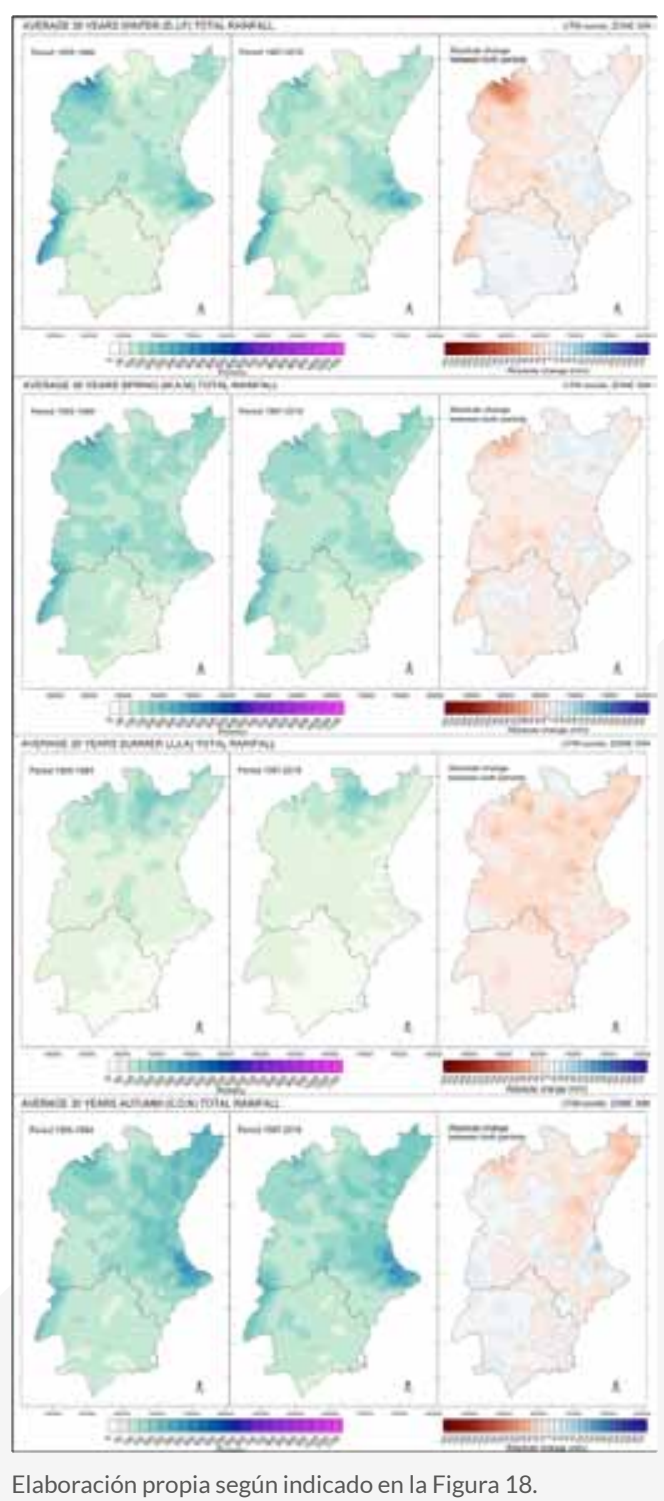


Estos datos son importantes a efectos de planificación hidrológicay sus efectos en las actividades económicas puesto que las lluvias invernales y de primavera son fundamentales para el desarrollo de actividades en verano, frente a las otoñales que por su carácter intenso, son menos aprovechables incluso para su almacenamiento.

Un aumento de periodos secos, por su duración y su frecuencia, también se está confirmando ya sobre el análisis del periodo 1955-2016 (Figura 21). En la parte superior de la Figura 21 se expresa la tendencia de la duración media, en número de días consecutivos, de los periodos sin llover. Se observa un predominio de tendencias al aumento de la duración de estos periodos, conduciendo a condiciones más secas a prolongarse los periodos de evapotranspiración sin compensación por lluvia

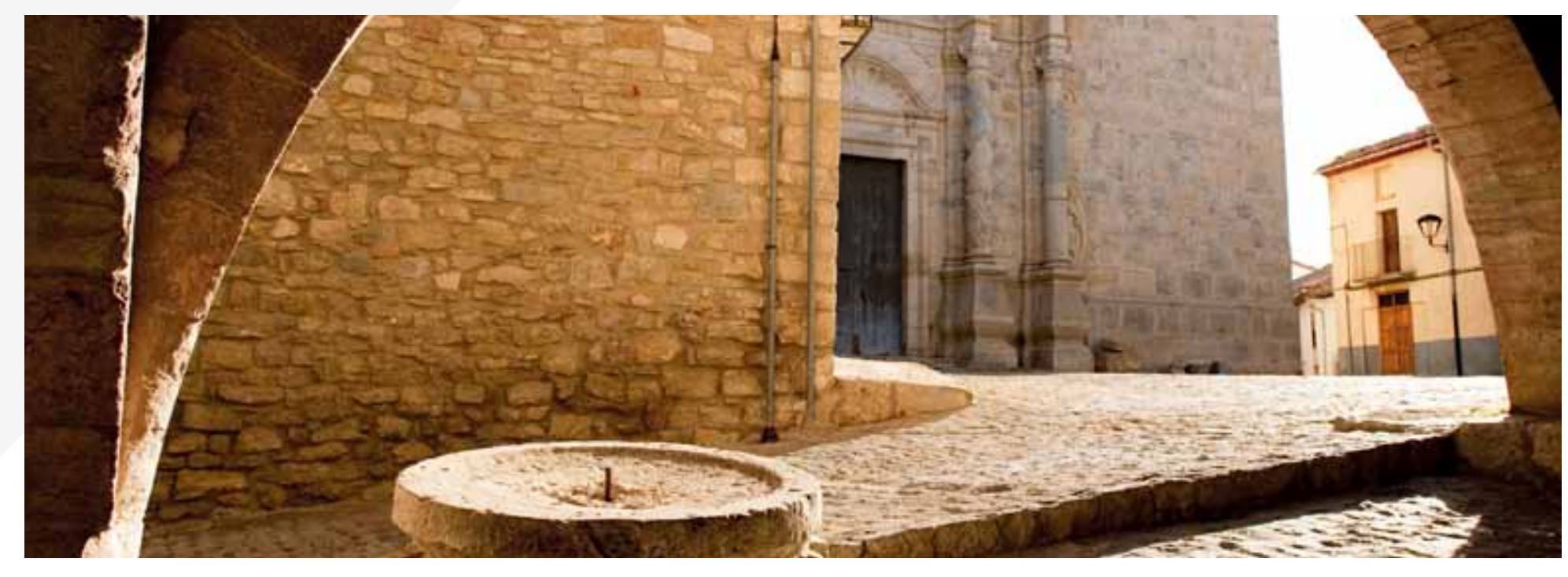
elas rachas máximas anuales de días consecutivos sin llover, lo que da idea de si vamos hacia una mayor frecuencia y/o expansión temporal de las sequías. Aunque aquí se entremezclan muchas tendencias puntuales sin significación estadística, predominan las tendencias hacia un aumento en la duración de las rachas máximas sin llover. Si consideramos el número total de días secos al año (vid figura 21 inferior) predomina un claro aumento en el sector del Júcar. Sin embargo, la cuenca del Segura no registra en conjunto tal aumento de días secos, salvo en sus extremos Norte y Sur.

En cualquier caso, es importante recalcar que los principales sectores de cabecera y fuente de recursos hídricos (trasvases) de la Comunidad Valenciana (núcleo hidrográfico de la serranía lbérica en su sector meriodional) están sometidos a importantes tendencias a la pérdida de precipitaciones efectivas y aumento de periodos secos. Lo que es crucial para unacorrecta panificación hídrica futura tanto en la cuenca del Júcar como en la del S 
Un aumento del riesgo de sequia tambièn tendrá efectos daninos -pérdida de imagen de calidad-en los espacios turísticos. Así, el aumento de demandas para usos urbano-turísticos en las regiones del mediterráneo español y Canarias debido al auge de la promoción inmobiliaria señalada (vid. supra), ha rebajado el umbral de riesgo de manera que en la primera década del presente siglo ya no son necesarias reducciones muy acusadas de precipitación a lo largo del año hidrológico para disparar alertas de sequía que pueden ir agravándose si las condiciones pluviométricas de escasez permanecen en el tiempo.

Al respecto, es necesario hacer mención a la reducción de precipitaciones que estiman los modelos de cambio climático para el territorio españolen las de Planificacionididobgca (2008) cono hactor a revisión de los planes de Demarcación Hidrográfica (horizonte 2027) que se lleva a cabo por parte del Ministerio de Agricultura, Alimenta-

ción y Medio Ambiente. Para un escenario con fecha en el año 2027, la disminución de la aportación hídrica natural en España, por reducción de precipitaciones, varía entre el 2-3\% en las demarcaciones sep-

tentrionales peninsulares y el 11\% en las más meridionales (Segura y Guadiana).

La proyección de estos resultados hacia finales de siglo (2100) se ha realizado manejando un modelo de emisiones intermedio entre los escenarios A2 (business as usual) y B2 (medio-bajo), manejados en el IV Informe del IPCC. Como muestra la figura (vid. figura 22) en algunas regiones españolas la reducción de escorrentía prevista para finales de siglo alcanza valores superiores al $25 \%$, lo que, de cumplirse, comprometería la satisfacción de demandas en amplios territorios si se atiende a la aportación natural exclusivamente. Figura 22.

Reducción de escorrentía en España en el horizonte 2071-2100, según escenarios climáticos A2 y B2.

Tabla 7. Disminución de vol

\begin{tabular}{|c|c|c|c|c|}
\hline Demarcación Hidrográfica & Recursos híd & otales en régimen I & I (hm3/año) & $\begin{array}{l}\text { DEMANDAS DE } \\
\text { AGUA }\end{array}$ \\
\hline MIÑO-SIL & $\begin{array}{l}\text { Mínimo } \\
3.086---2.993\end{array}$ & $\begin{array}{c}\text { Medio } \\
12.828---12.443\end{array}$ & $\begin{array}{l}\text { Máximo } \\
23.924\end{array}$ & $\begin{array}{c}\text { AGUA } \\
617\end{array}$ \\
\hline GALICIA COSTA & $1.481---1.451$ & $12.124---11.882$ & 22.518 & 819 \\
\hline CANTABRICO ORIENTAL & $1.227---1.202$ & $4.691---4.597$ & 7.332 & 486 \\
\hline ANTABRICO OCCIDENTAL & $2.599---2.547$ & $12.637---12.384$ & 17.762 & 589 \\
\hline DUERO & $4.952---4.655$ & $12.592---11.836$ & 27.472 & 3.860 \\
\hline TAJO & $2.499---2.324$ & $9.540---8.872$ & 20.996 & 4.065 \\
\hline GUADIANA & $516---459$ & $5.084---4.525$ & 15.676 & 2.312 \\
\hline GUADALQUIVIR & $1.135---1.044$ & $8.070---7.424$ & 23.111 & \\
\hline GUADALETE Y BARBATE & $164---151$ & $1.409---1.296$ & 4.472 & 3.160 \\
\hline SUR & $495---455$ & $3.011---2.770$ & 9.152 & 1.350 \\
\hline SEGURA & $334---297$ & $1.005---894$ & $2.536---2.257$ & 1.834 \\
\hline JUCAR & $1.423---1.294$ & $3.476---3.163$ & 7.254 & 2.962 \\
\hline EBRO & $8.742---8.304$ & $15.975---15.176$ & 25.984 & 10.378 \\
\hline
\end{tabular}

Fuente: Instrucción de Planificación Hidrológica, 2008. Demarcaciones Hidrográficas. Ministerio de Agricultura, Alimentación y Medio Ambiente.
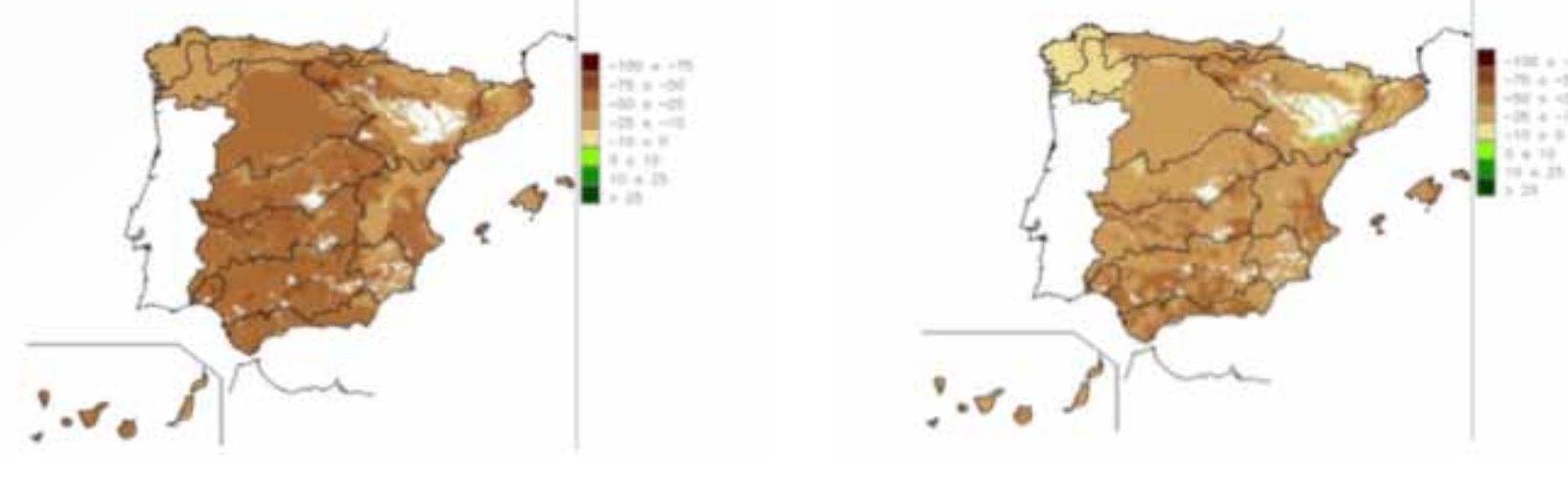

En efecto, la reducción de precipitaciones prevista por los modelos de cambio climático para España compromete la satisfacción de demandas de agua en las Demarcaciones Hidrográficas de

- Segura (incluso en años de precipitaciones extraordinarias)

- Júcar (en años de sequía y de normalidad)

- Cuencas Internas de Cataluña (en años de sequía) ${ }^{22}$

- Sur (en años de sequía)

- Guadalquivir (años de sequía)

- Guadalete-Barbate (DHCAA) (años de sequí)

- Guadiana (años de sequía)

- Tajo (años de sequía)

- Ebro (años de sequía)
Para el caso de la Comunidad Valenciana, AEMET pone a disposición pública proyecciones con horizonte 2100 basados en diversos tipos de modelización y distintos escenarios previstos por el IPCC. A modo de resumen, la Figura 23 muestra dos proyecciones generadas por AEMET, una modelización estadística (regionalización por análogos), y otra dinámica. Vemos que mientras la primera vislumbra reducciones en la precipitación anual en torno al 15-20\%, la segunda apunta a reducciones en la precipitación entre el 20 y el $40 \%$. También la segunda apunta a un mayor incremento de las rachas secas sin llover.

Fuente: CEDEX (2011)
"En las Cuencas Internas de Cataluña, los volúmenes de agua en años sol

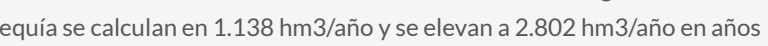
de normalidad, para la satisfacción de unas demandas de agua de 1.357 


\section{MODELIZACIÓN ESTADISTICA}
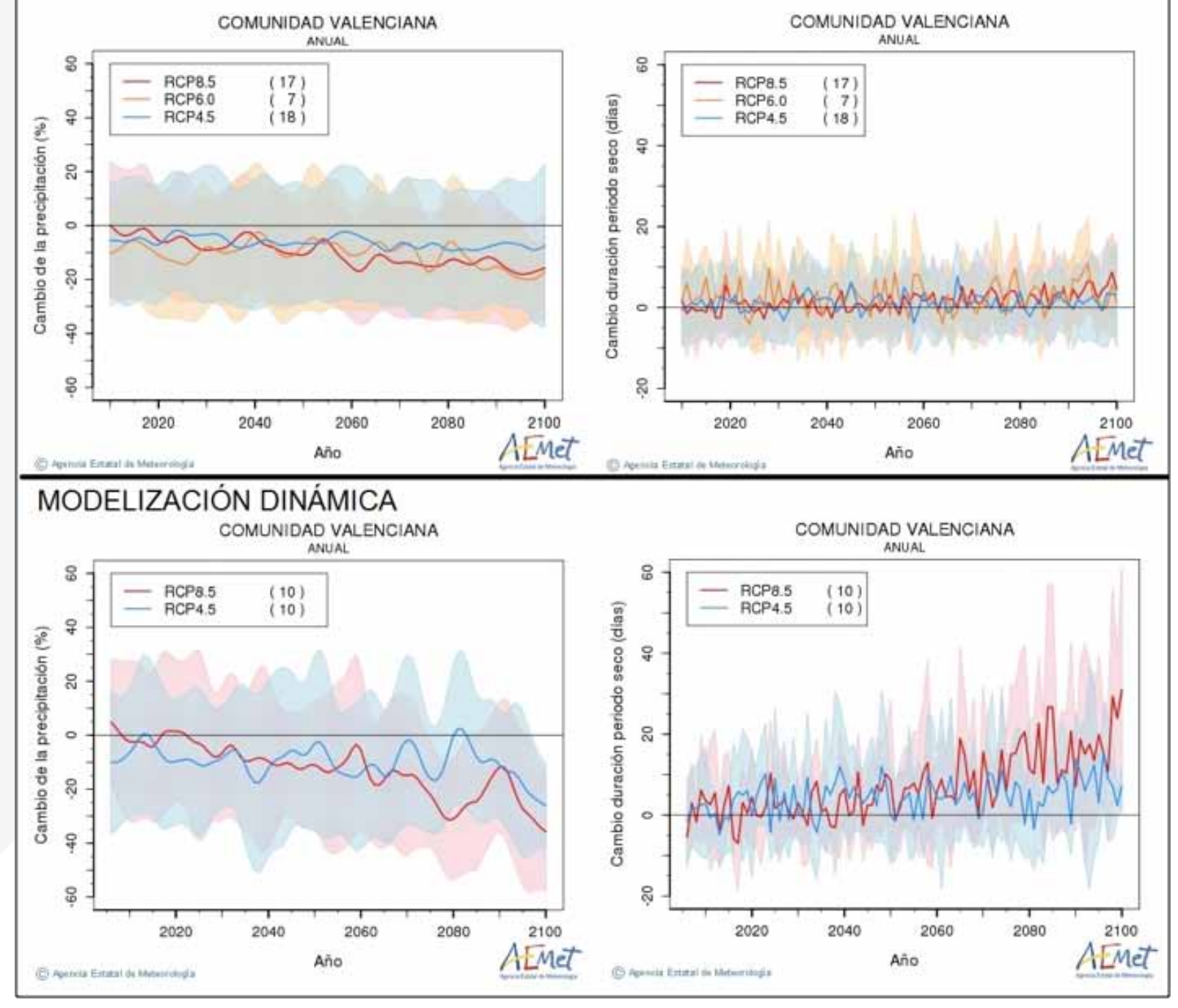

Dentro del territorio valenciano, y en concreto, de las Confederacio-

nes Hidrográficas del Júcar y Segura, las proyecciones generales ante-

riores pueden esconder grandes diferencias espaciales. Al tomar la re-

lación estadística de cambio que hemos detectado estar ya en marcha

entre 1955 y 2016 , hemos realizadouna proyeción lineal al año 2100

dimensionada según el consenso medio de cambio general mostrado

por las proyecciones de AEMET, eliminando las grandes fluctuaciones

locales (Figuras 18 y 20) que supondrían mucha incertidumbre en la

proyección. El resultado es la proyección suavizada que se presenta en

la Figura 24. De continuar los patrones actuales de cambio, da idea de

la situación que podemos esperar en las dos cuencas para el año 2100
Los resultados muestran una disminución generalizada de las precipia del Júcar (zonas más húmedas de la Serranía de Cuenca), donde la reducción superaría el 50\%, lo que pondría en jaque el abastecimiento hídrico de toda la región. También se aprecian reducciones importantes en el litoral Norte de Castellón llano de Albacete, litoral central de Alicante, litoral Sur de Murcia, y el nacimiento del Segura. En estos casos la disminución anual de precipitaciones estaría entre el 30 yel $50 \%$. En el lado contrario, quedarían cerca de balance, o incluso con incrementos positivos, el tercio Sureste de Valencia, extremo Norte de Alicante Gúdar la cuenca media del Segura y el litoral del Bajo Segura.

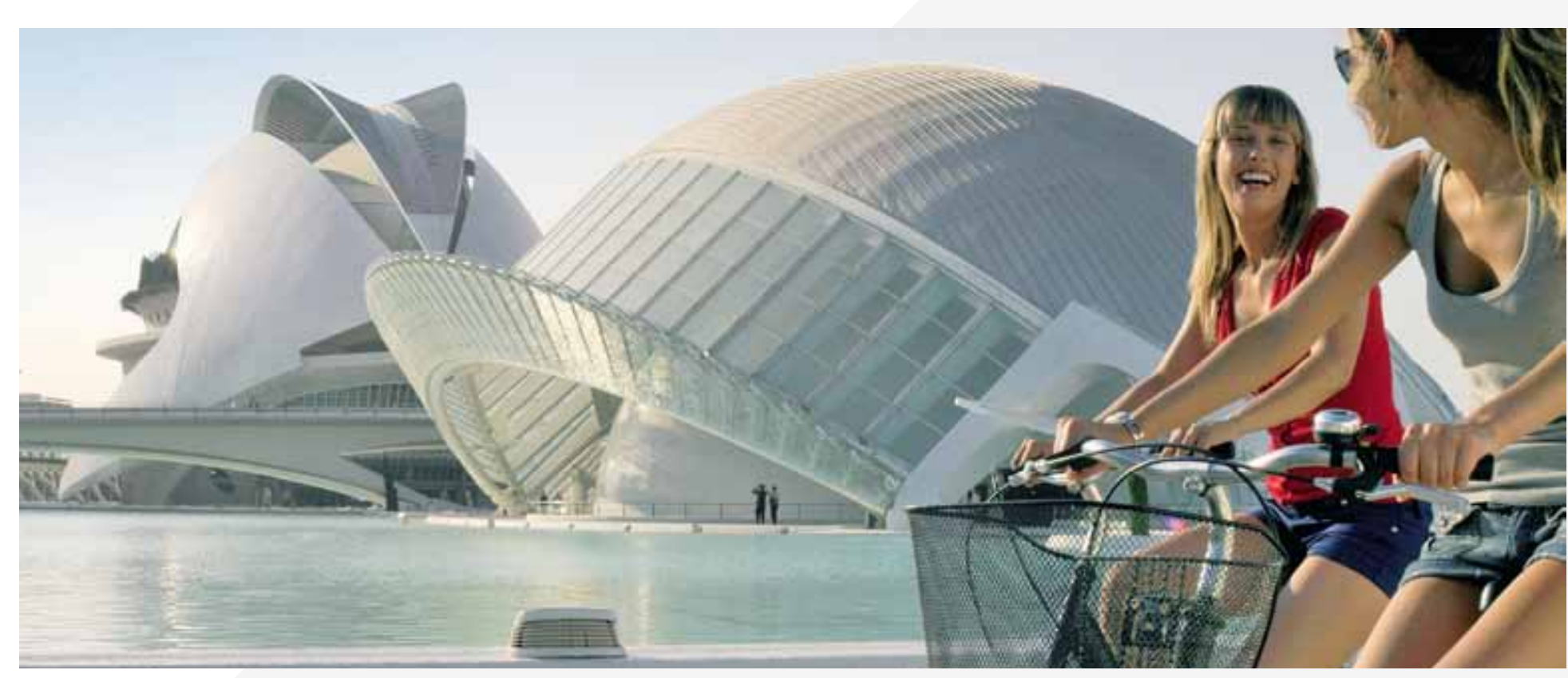




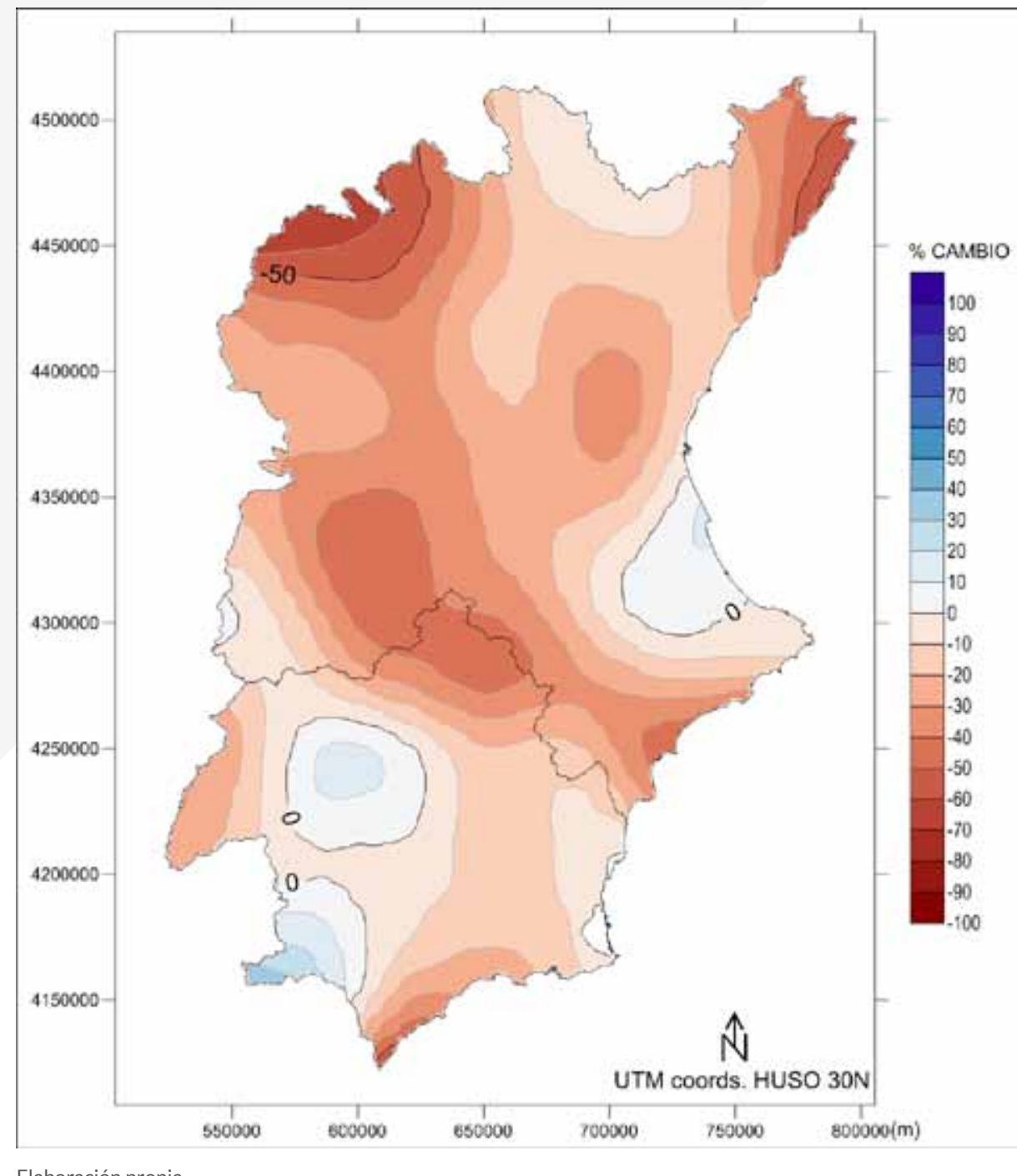

encing

importante, en término de ingresos y empleo, como el turismo. En e

marco de la planificación sostenible de los recursos de agua donde las transterencias de agua entre cuencas hidrograficicas van a tener màs dificultad en desarrollarse la garantía del abastecimiento futurode áreas turísticas del litoral mediterráneo español y de ambos archipiélagos a partir del uso de aguas "no convencionales" (depuración-reutilzación y desalación) será no sólo una opción, sino una necesidad.

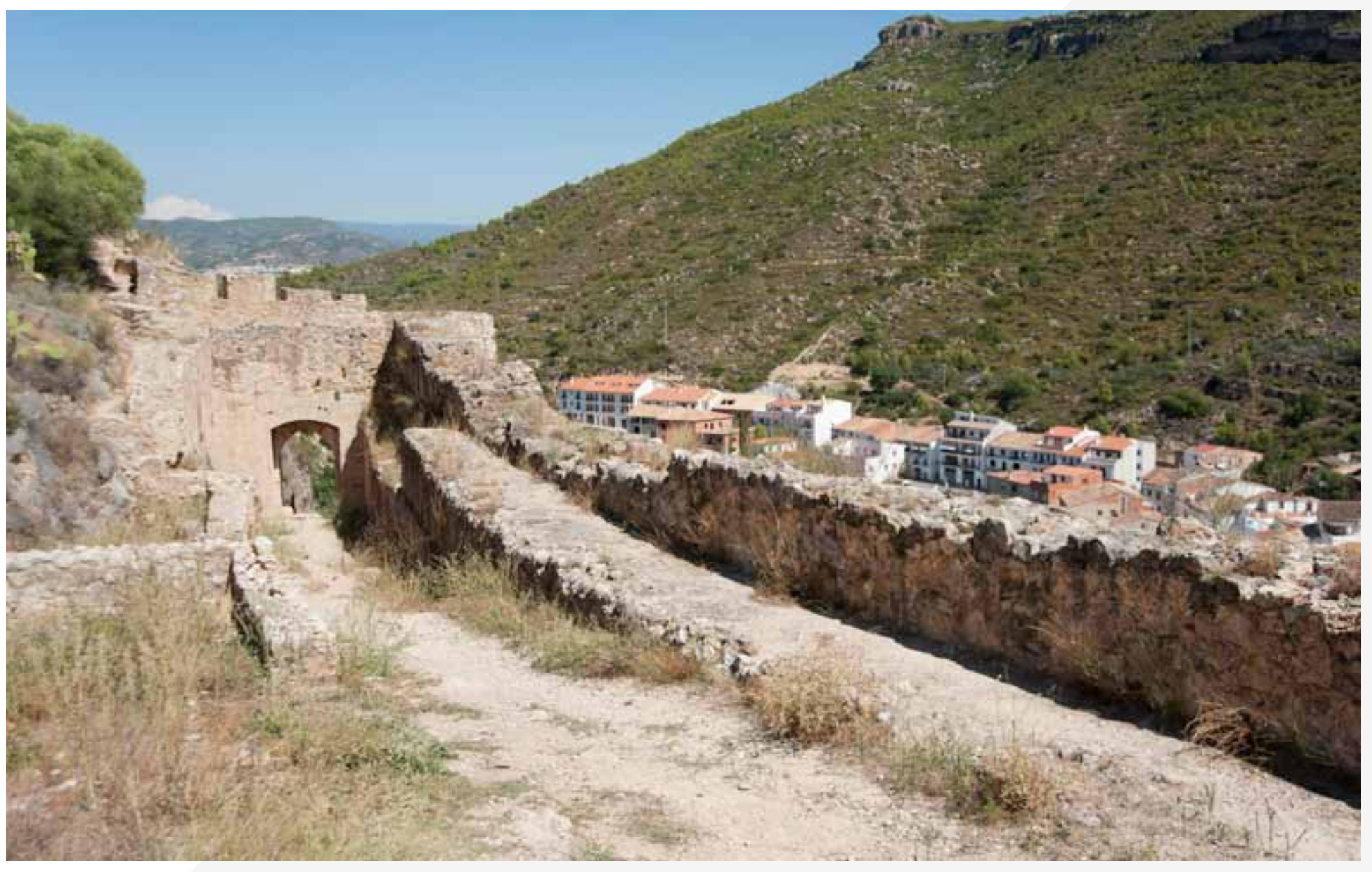


4.3. Incremento de eventos atmosféricos extremos

En general, el aumento del riesgo climático debido al aumento de la peligrosidad atmosférica -frecuencia mayor de desarrollo de episodios de rango extraordinario-, se relaciona directamente con la caracterización de Españ y. muy singularmente, del litoral mediterráneo, como territorio de riesgo: algunos de sus espacios geográficos ocupan los primeros puestos en la clasificación europea de espacios geográficos con riesgo que se ha incluido en el informe sobre peligros naturales y tecnológicos en Europa (vid. ESPON 2006)

Se puede señalar que el riesgo ante los peligros naturales -especialmente los de causa atmosférica- es mayor en 2016 que lo era hace treinta años ello en relación no tanto con el incremento de la peligrosidad natural -mayor frecuencia de desarrollo de los episodios extremos, sino en relación con el aumento de la población yla les en áreas urbanas del litoral español. Junto al proceso de "litoralización" del riesgo experimentado en nuestro pis por el desarrollo del fenómeno turístico de sol y playa, a partir de los años ochenta del pasado siglo han sid los aspectos "humanos" del riesgo los que han cobrado protagonismo en la valoración de los peligros climáticos (vid. figura 25).

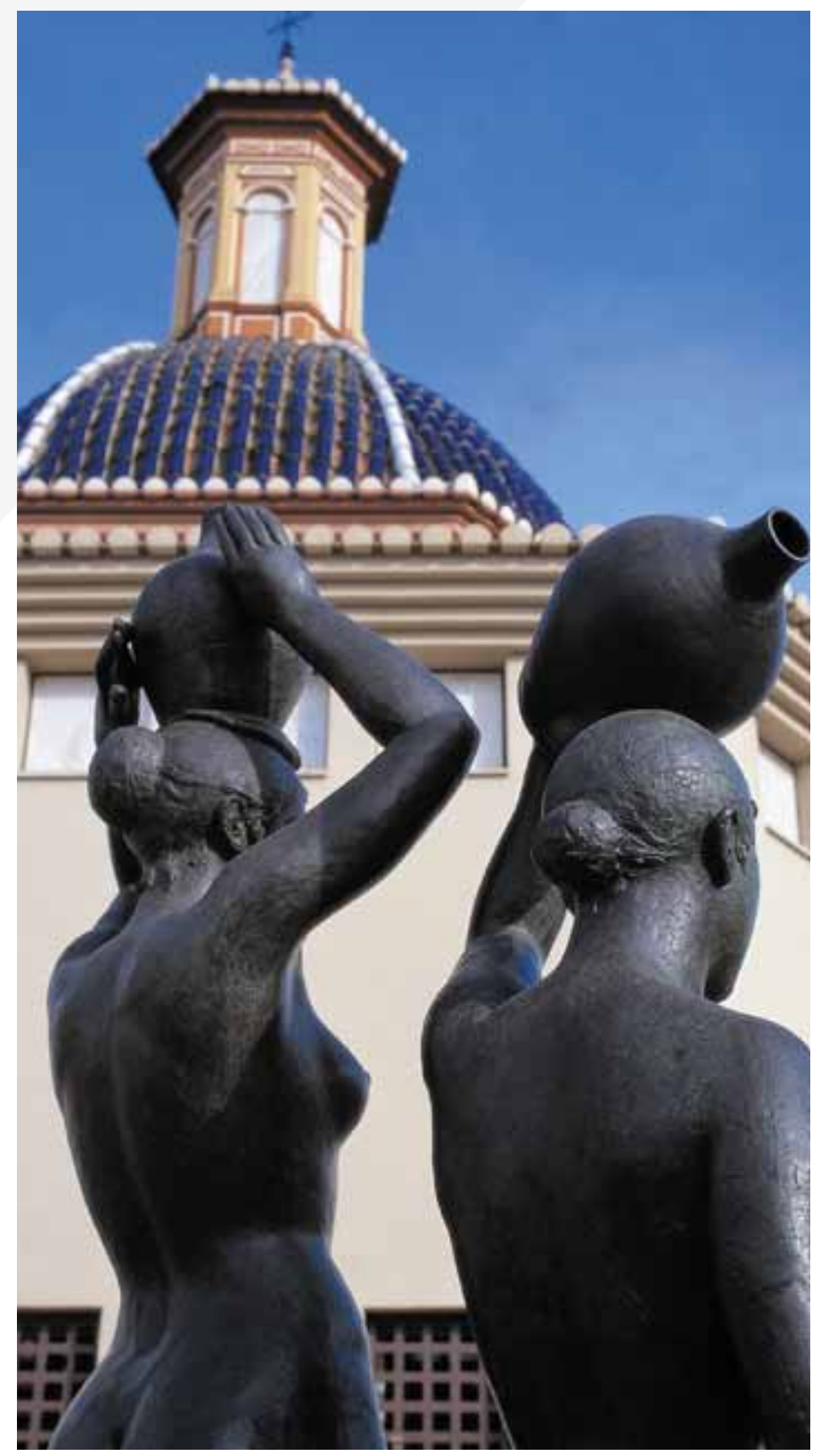

Figura 25. Incremento del riesgo en un escenario de cambio climático.

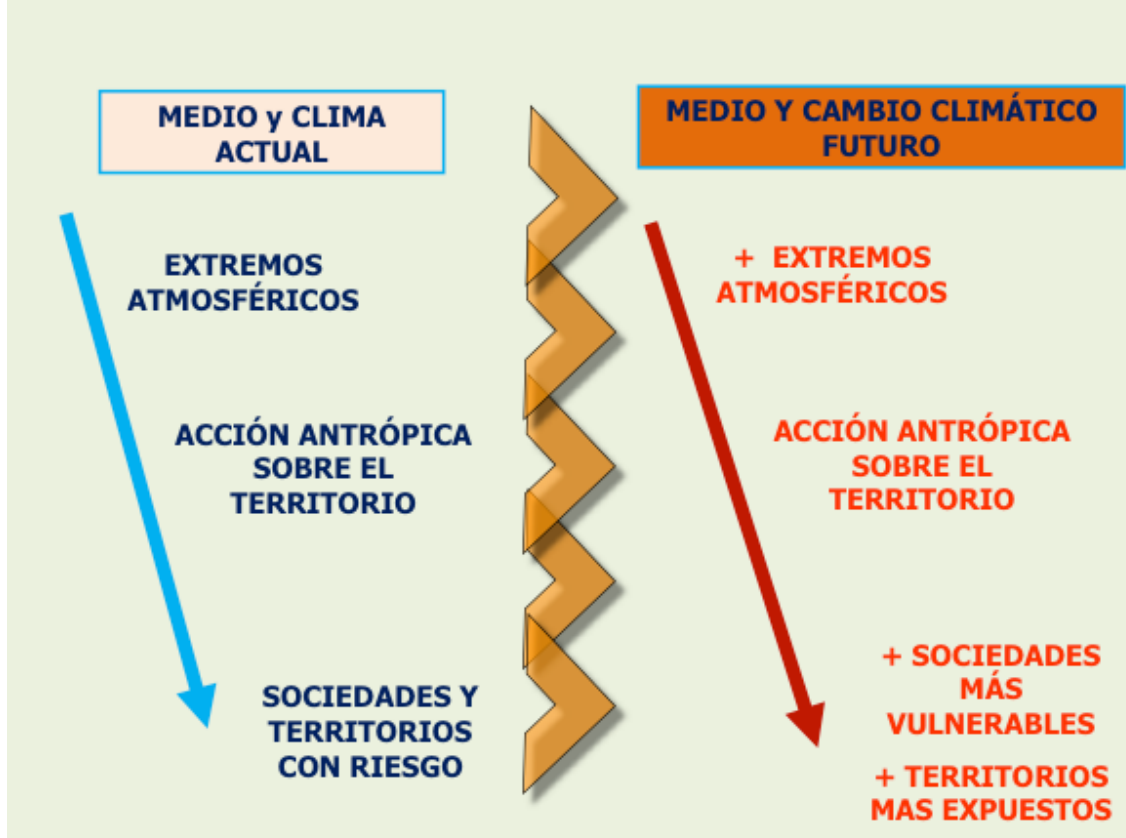

Un aspecto importante en el aumento de la exposición y vulnerabilidad ante los episodios atmosféricos de rango extraordinario es el importante aumento del parque de viviendas que se ha producido en algunas regiones españolas desde la década de 1990 del pasado siglo y, especialmente entre 1995 y 2007. El denominado "boom inmobiliario" de los últimos lustros ha tenido en el litoral mediterráneo español un escenario principal de desarrollo. El enorme desarrollo que ha tenido la construcción residencial en nuestro país es una de las causas del incremento señalado de la vulnerabilidad y la exposición ante los peligros climáticos. Con datos del Observatorio Español de la Sostenibilidad (2011). sólo en las áreas litorales españolas se han transformado 150.000 ha. en el período 2000-2006. En otras palabras, en las últimas dos décadas se ha edificado por encima de lo racionalmente sostenible en España y algunas de esas edificaciones se han llevado a cabo en zonas con peligrosidad natural. Especialmente en áreas expuestas al peligro de inundación, pero asimismo en sectores con riesgo ante sequías, temporales marítimos y deslizamientos. Y en gran medida se trata de áreas de expansión urbanoturistica, ocupadas por residentes extranjeros que no conocen la dinámica natural del territorio y se convierten así en grupos muy

vulnerables ante un evento atmosférico extremo. 

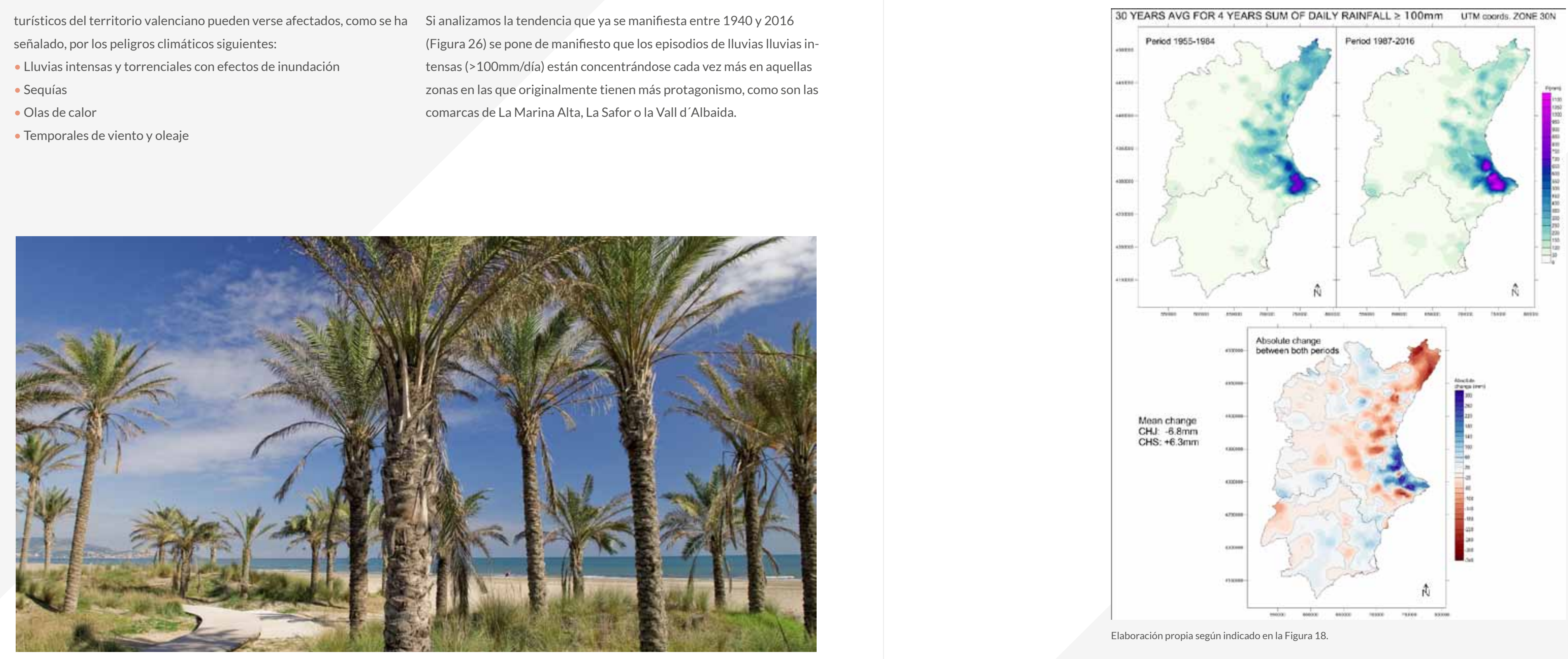
Ello obliga a mantener y mejorar las políticas de gestión del riesgo de inundaciones mediante la ordenación del territorio (PATRICOVA), asi como las medidas de gestión de las emergencias en municipios turisti-

cos. El área litoral es el espacio de mayor riesgo, en virtud de la elevad vulnerabilidad y exposición existente ante el peligro de lluvias intensas y crecidas fluviales. Además, en relación con el señalado aumento de las temperaturas del mar Mediterráneo en los meses cálidos del ano. ciones de emergencia establecidos para este tipo de eventos, puesto convectivas intensas en territorio valenciano con volúmenes de lluvia

muy abundantes (vid. figura 27). De manera que la temporada alta en fecha más temprana (desde junio) que las actualmente previstas (septiembre) y prolongados hasta finales de noviembre. turística requerirá la puesta en marcha de protocolos de actuación

Por lo que respecta al tratamiento de valores térmicos extremos que

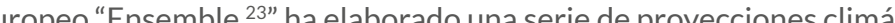
ticas hacia final del presente siglo manejando una serie de parámetros de gran interés para la actividad turística como el número de días con peninsular, del sur y sureste se presume un incremento significativo

Cambios previstos en el número de días con temperaturas máxima $>40^{\circ} \mathrm{C}$ temperatura mínima superior a $20^{\circ} \mathrm{C}$. Proyecció 2071-2100 (respecto al período de referencia 1961-90).
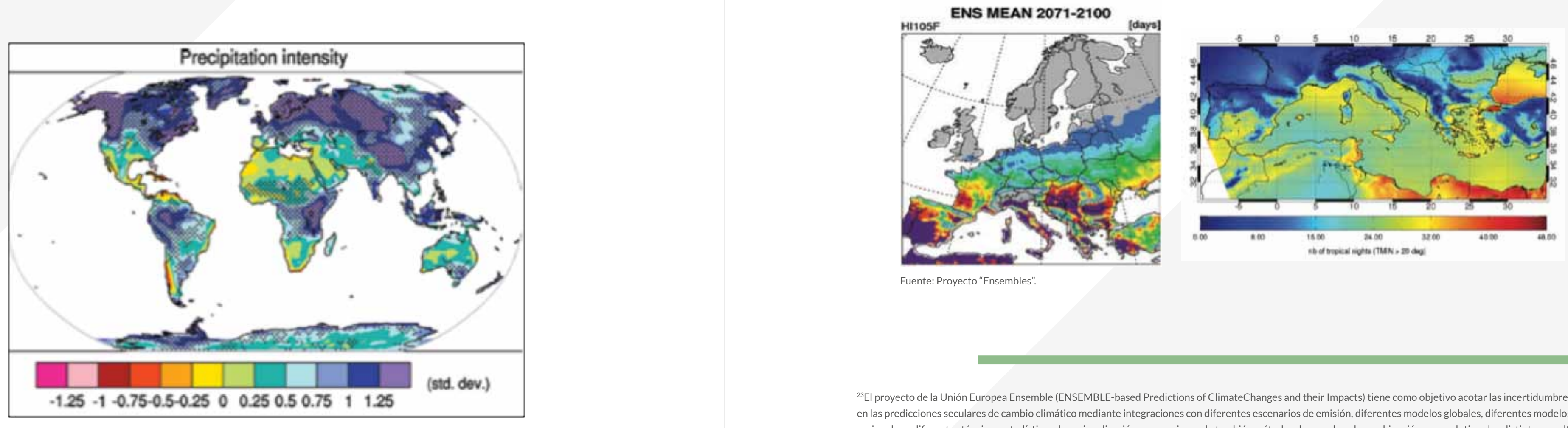
Fuente: PCC.

\section{1}


En este sentido, los modelos regionalizados de cambio climático para invernadero. En la Comunidad Valenciana, y en relación al período elámbito español (Aemety Oficina Española para el Cambio Climático) de referencia 1961-2000, se manfesta un aun

ción en a proyección de paŕmetros climáticos hacia fina

noches cálidas de días calurosos y en la propia duración de las olas de

sente siglo para diversos escenarios de emisiones de gases de efecto

calor (vid. figura 29)

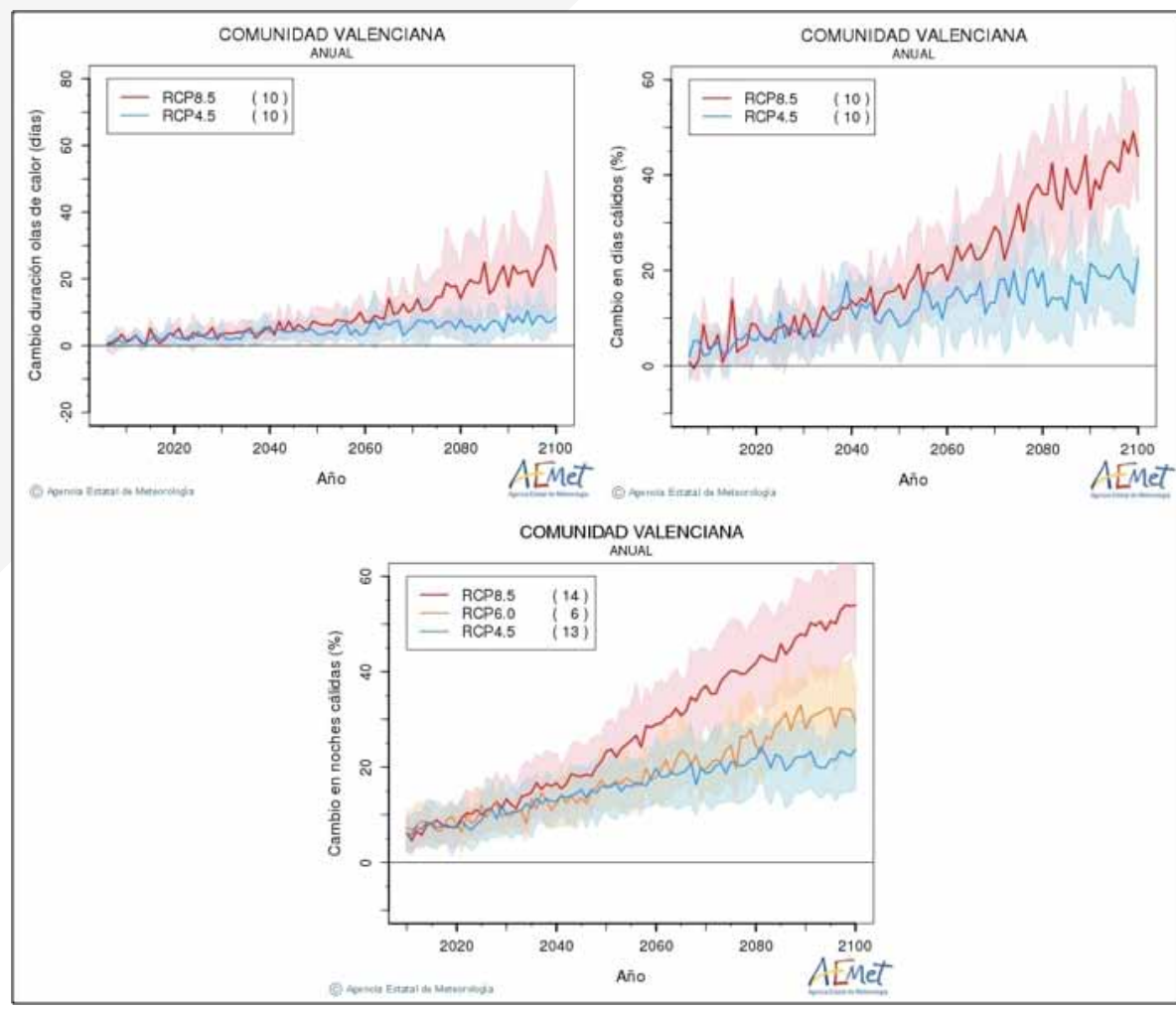

Fuente: Aemet. Modelos climáticos regionalizados. Horizonte 2100.
Este aumento de extremos de temperatura se produce básicamente en la frecuencia de eventos cálidos. En ese sentido es elveranola

se aprecia en la Figura 30 (y que ya se ha puesto de manifiesto para las estación del año que será más problemática, para la cual las proyecciones prevén los mayores incrementos tanto en temperaturas máximas como en mínimas, pero especialmente en el caso de las máximas, como mo, serán mucho más suaves.

Cambios previstos en las temperaturas máximas y mínimas para el verano y el invierno. Proyección 2000-2100 (respecto al perído de referencia 1961-2000)
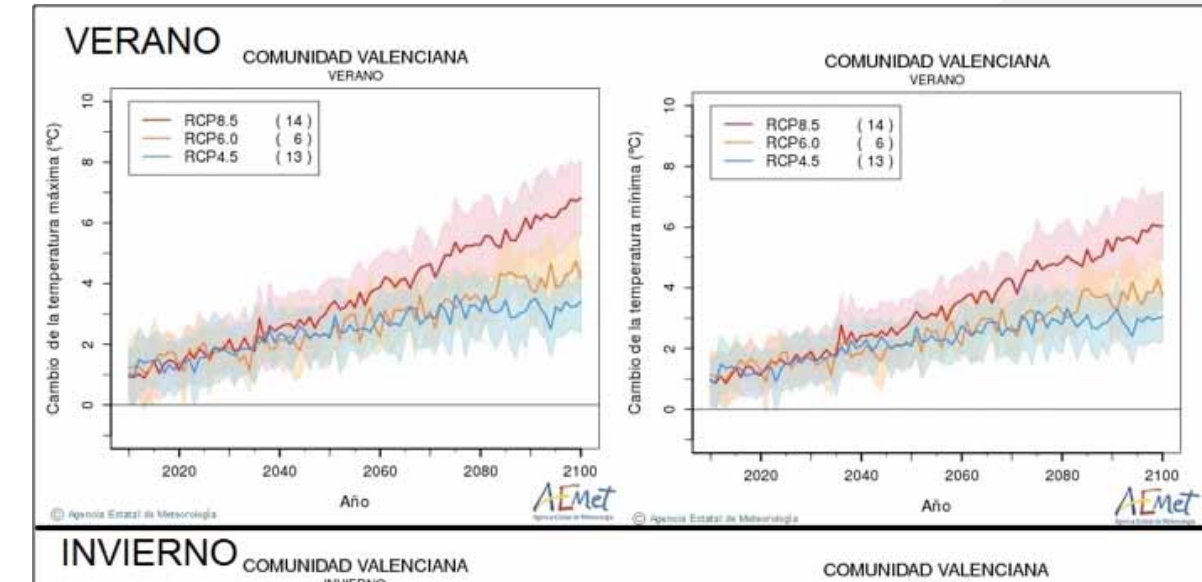

COMUNIDAD VALENCIANA

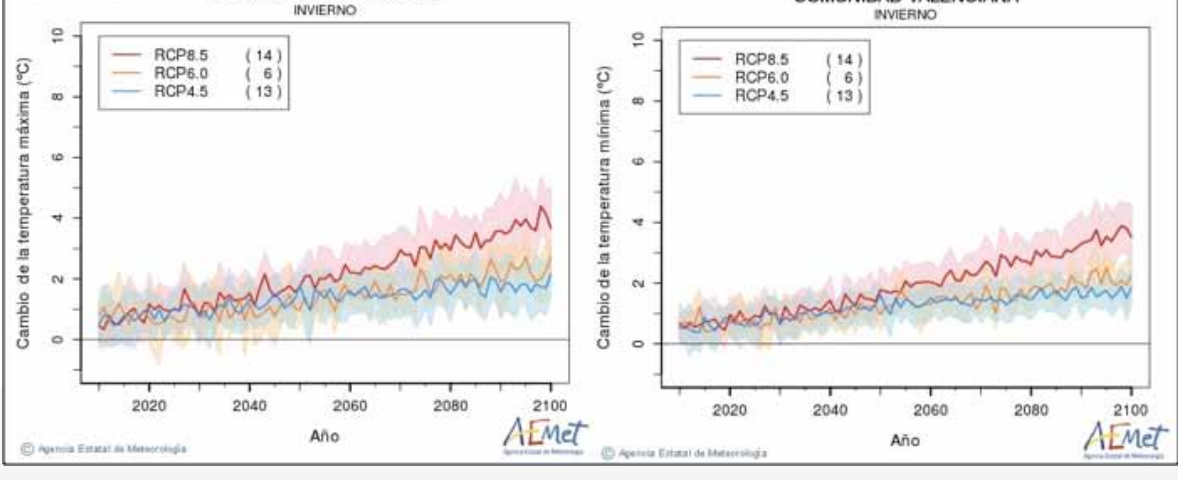

Fuente: Aemet. Modelos climáticos regionalizados. Horizonte 2100. 
El tratamiento de valores climáticos extremos resulta, pues, fundamental en las proyecciones de cambio climático y en el diseño de medidas de adaptación y mitigación de sus efectos en las actividades económicas. No obstante, el análisis meramente cuantitativo (datos climáticos) del confort climático adolece de una carencia fundamenta la propia sensación térmica del ser humano y su umbral de tolerancia, que resulta muy diversa. Por otra parte, el desarrollo de un verano extremadamente cálido (p.e. 2003 ó 2015) a priori no encuentra un relación directa con un descenso de turistas en un destino turístico de sol y playa; por el contrario, verano húmedo y lluvioso puede tener efectos más negativos sobre las reservas de última hora en ese tipo de destinos de sol y playa nada acostumbrados a la lluvia durante la temporada alta. Otra cuestión es que veranos tórridos se conviertan en habituales y se pueda crear la imagen de destinos con climas poco confortables, para los que las políticas de adaptación al cambio climático deben tener diseñadas medidas para evitar pérdidas de competitividad futuras.

Para el caso de la actividad turística que, como se ha señalado, presenta una vulnerabilidad elevada y una exposición a la peligrosidad climà tica asimismo elevada en los productos turísticos más demandados (so y playa, nieve, urbano), el desarrollo de eventos extremos de carácter atmosférico tiene como efectos el incremento del riesgo natural y aumento de efectos sobre la salud humana. En este sentido, las pro- yecciones climáticas para las próximas décadas señalan un aumento de las temperaturas (medias y máximas) asicomo elincremento de la variabilidad atmosférica y de su carácter extremo en latitudes mediterráneas. A ello se une un incremento de la vulnerabilidad por el aumento de grupos de riesgo de enfermedades cardiovasculares y pulmonares, motivado por la tendencia al envejecimiento natural de la población en España así como a la llegada de residentes europeos, especialmente en la fachada este peninsular. Olcina y Martín (2012) han analizado la relación existente entre la presencia de oxigeno en aire, en relación con la circulación de las masas de aire, y el desarrollo de enfermedades pulmonares y cerebrovasculares. La presencia de la masa de aire tropical continental favorece la reducción del porcentaje de oxigeno en el aire y dispara los ingresos hospitalarios por este tipo de dolencias. Si los modelos de cambio climático están anunciando una frecuencia mayor de "olas de calor" estivales en el área mediterránea, de ello se deduce la importancia del establecimiento de sistemas de alerta temprana a la población, residente y estacional (turistas) que estimen la variación del volumen de oxígeno en aire disponible por exceso o por defecto. Ello pueden contribuir a minimizar los impactos de estos cambios ambientales a las personas incluidas en grupos de riesgo (personas susceptibles de padecer enfermedad cardiovascular) e igualmente, a personas con patología relacionadas con elaparato respiratorio.

\subsection{Subida del nivel del mar en la franja costera}

En estrecha relación con el comportamiento térmico del agua del mar está el efecto del calentamiento en la subida del nivel de mar y su afección a las áreas litorales. Desde 2002, el grupo de Ingeniería Oceanográica y de Costas de la Universidad de Cantabria se desarrolla el proyecto C3E (Impacto del cambio climático en la costa española $2^{26}$ ), financiado por el Ministerio de Medio Ambiente, que ha ido enriqueciéndose, en método y resultados, a lo largo de sus diversas fases de ejecución. En 2014 se han hecho públicos los resultados de la tercera fase de este proyecto y se apuntan los siguientes datos a tener en cuenta para la adaptación futura de los espacios costeros en España:

- Al igual que pasa en el resto del mundo, en España los impactos observados atribuibles al cambio climático son aquellos que corresponden a cambios en la temperatura del océano o a la acidificación. Con la información existente, los impactos observados relativos a inundación o erosión en zonas costeras no son atribuibles a cambio climático pues están altamente afectados por la acción del ser humano.

- El oleaje es una de las principales dinámicas susceptibles de cambio que afectan a nuestra costa. En los últimos años se han observados aumentos en la intensidad del oleaje en el Cantábrico y disminución en el Mediterráneo y Canarias.

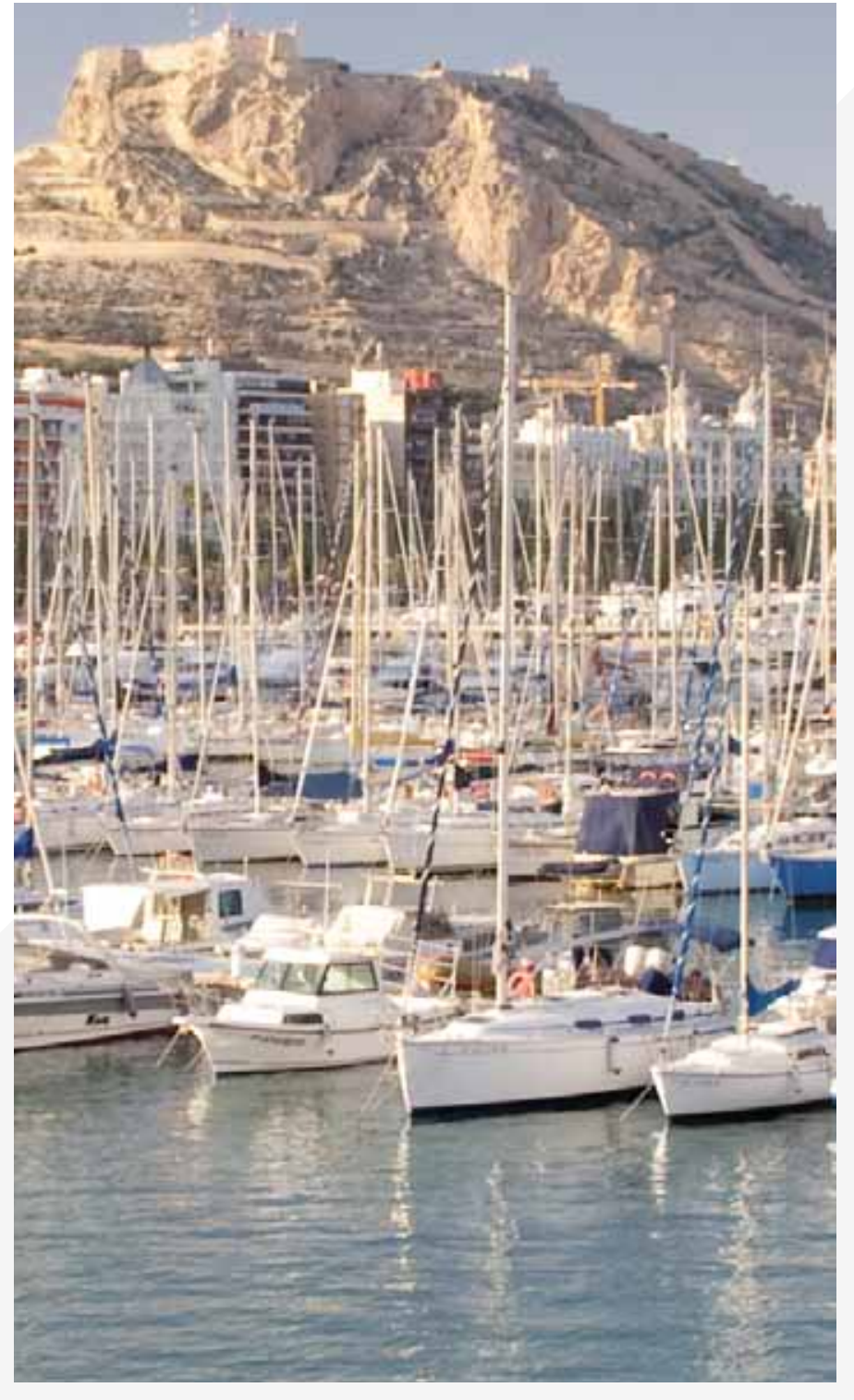


- El aumento del nivel del nivel medio del mar en la zona AtlánticoCantábrica sigue la tendencia media global observada entre 1,5 y 1,9 $\mathrm{mm} / \mathrm{año}$ entre 1900 y 2010 y de entre $2,8 \mathrm{~mm} /$ año y $3,6 \mathrm{~mm} /$ año entre 1993 y 2010. Sin embargo, existe una mayor incertidumbre en cuanto

- Considerando un escenario tendencial de aumento de nivel del mar a 2040 (aproximadamente $6 \mathrm{~cm}$ ). las playas de la cornisa cantábricoatlántica y norte de las Canarias experimentarán retrocesos medios cercanos a los 3 metros, 2 metros en el Golfo de Cádiz y valores medios entre 1 y 2 metros en el resto de las fachadas.

Un factor que, sin duda, va a influir en el grado de riesgo de la costa española frente al cambio climático es la ocupación humana del litoral,

abla 8. Tasas de la subida del nivel del mar en la costa española, desde 1990, según diversos estudios.

\begin{tabular}{|c|c|c|}
\hline ESTUDIO O INFORME & $\begin{array}{c}\text { LITORAL CANTÁBRICOY } \\
\text { ATLÁNTICO }\end{array}$ & LITORAL MEDITERRÁNEO \\
\hline Marcos et al. (2005) & Entre $+2.12 \mathrm{y}+2.91 \mathrm{~mm} /$ año & --- \\
\hline Marcos et alt. (2009) & Entre 1.84 y $2.64 \mathrm{~mm} /$ año & Entre $-0.6 \mathrm{y}+0.48 \mathrm{~mm} /$ año \\
\hline Instituto Español de Oceanografía & --- & Entre $+2 \mathrm{~mm} /$ año $y+10 \mathrm{~mm} /$ año. \\
\hline Informe C3E (2014) & Entre $2.8 \mathrm{y} 3.6 \mathrm{~mm} /$ año & Sin determinar \\
\hline
\end{tabular}

Fuente: Ministerio Medio Ambiente (2014) Cambio climático en la costa española geográfico. al nivel medio del mar en el Mediterráneo por efectos regionales.

Por su parte, la proyección de retroceso de las playas en la costa española para 2040, si se cumplen las previsiones climáticas estabecidas en los modelos del IPCC, se estiman retrocesos de playa de hasta 3 metros en la zona atántico-cantábrica; de $2 \mathrm{~m}$. en el Golfo de Cádiz, y de 1,5 a $2 \mathrm{~m}$. en el litoral mediterráneo. Por su parte, la cota de inundación seguirá una tendencia al alza y se prevén un aumento del 8 produciéndose un crecimiento urbanístico descontrolado en muchas áreas de la costa española, especialmente en el litoral mediterráneo, que ha culminado con una "artificialización" rotunda de este espacio

A efectos de valorar la subida del nivel del mar en la costa española, se ha desarrollado, junto al proyecto $\mathrm{C} 3 \mathrm{E}$, otros estudios que han aportado tasas diversas de incremento del nivel del mar, para los últimos veinticinco años, tal y como se recoge en la tabla adjunta (vid. tabla 8).
\% en la fachada norte de la costa española y el Mar de Alborán para el año 2040 (lo que supone en torno a $20 \mathrm{~cm}$ más de cota de inundación) El sur-sureste de las Islas Canarias muest en torno al 2-3\% para el año 2040 (vid. figura 31.

Figura 31 Subida media del nivel del mar (cm) en la costa española. Horizonte 2040.

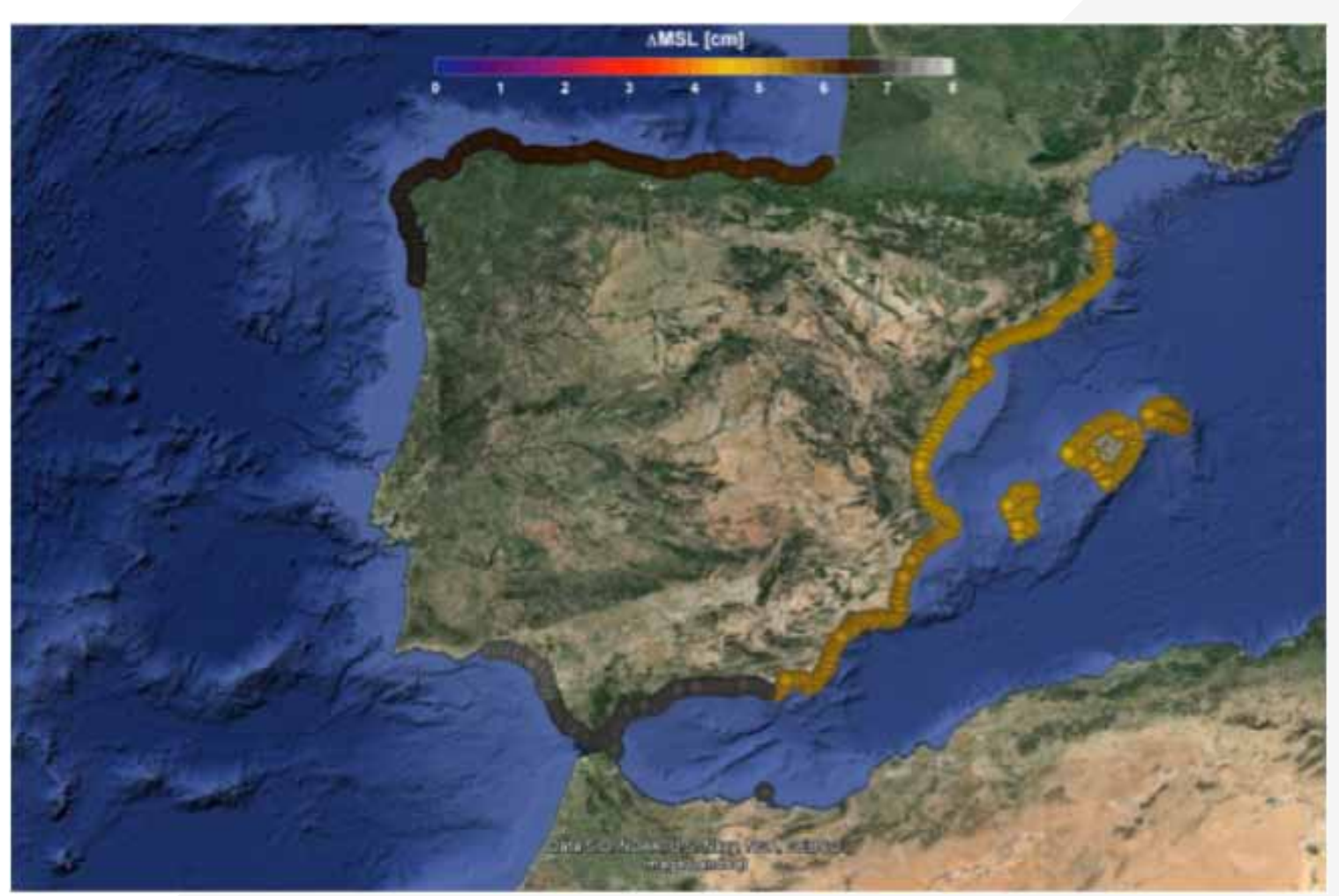

Fuente: Informe C3E. Universidad de Cantabria 

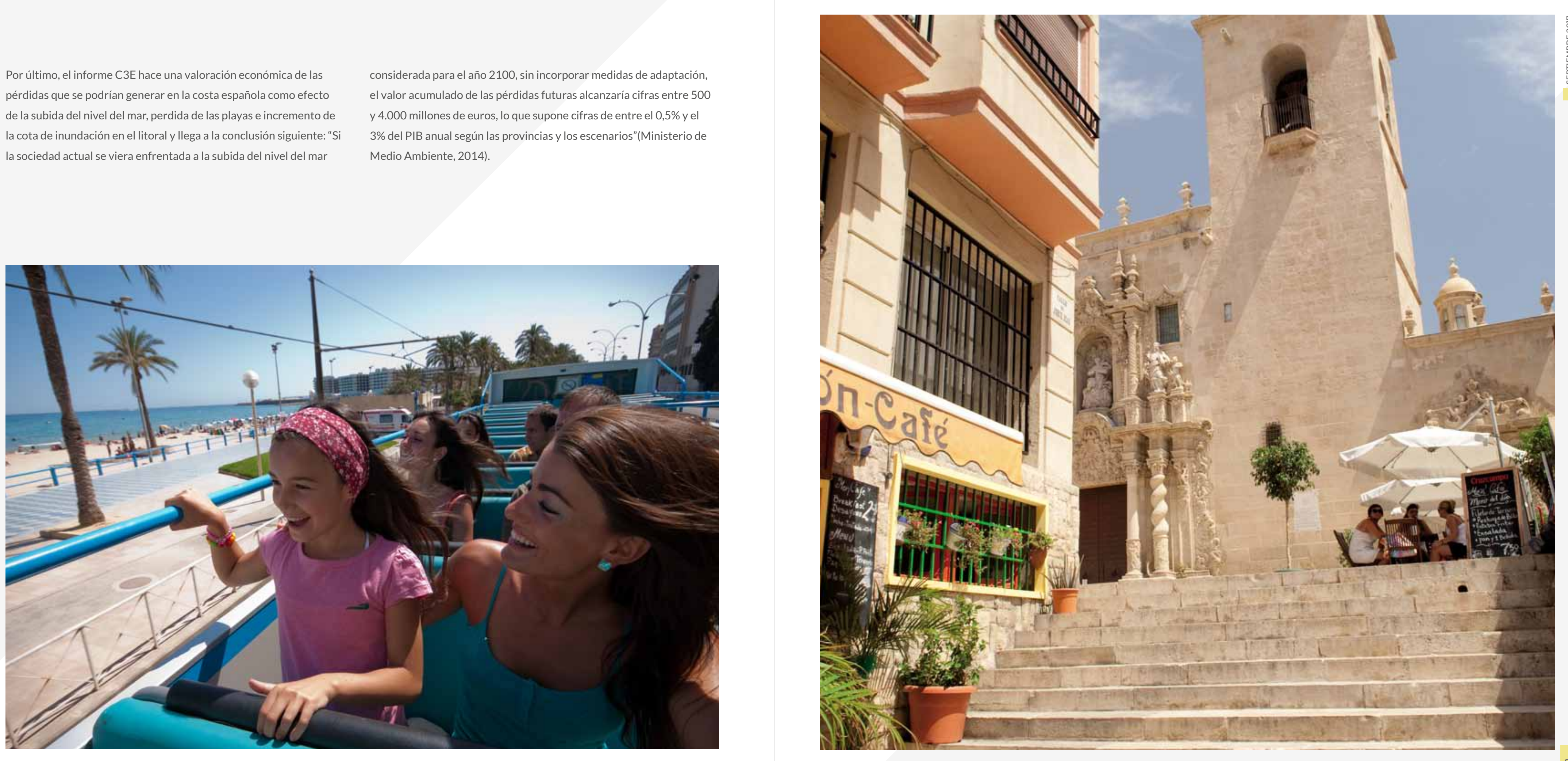
5 TURISMO:

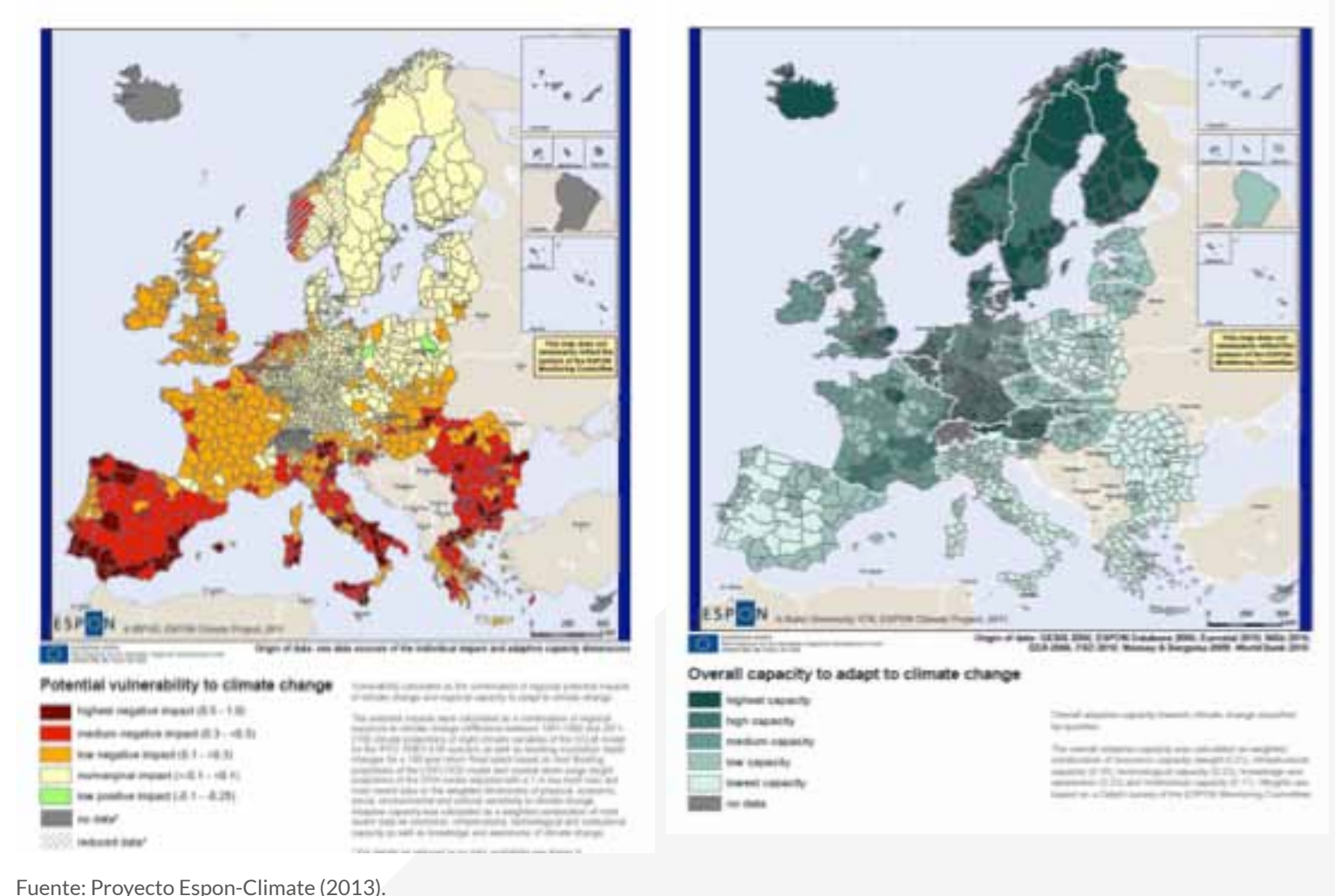


En el àmbito español, se ha seleccionado el ititoral mediterráneo como

agua y sus implicaciones en la actividad turística. Se han establecido

español en relación con el nivel de peligrosidad y con el grado de

ocupación territorial y de preparación-adaptación ante la reducción de volúmenes de asua disponible prevista para finales del presentesigo. En esta clasificación (vid. figura 33), algunas áreas turísticas del litoral alicantino muestran una elevada vulnerabilidad ante la reducción prevista de volúmenes de agua a causa del calentamiento planetario.

Vulnerabilidad potencial a la reducción de recursos de agua prevista en los modelos de cambio climático en las zonas turísticas del litoral mediterráneo español.

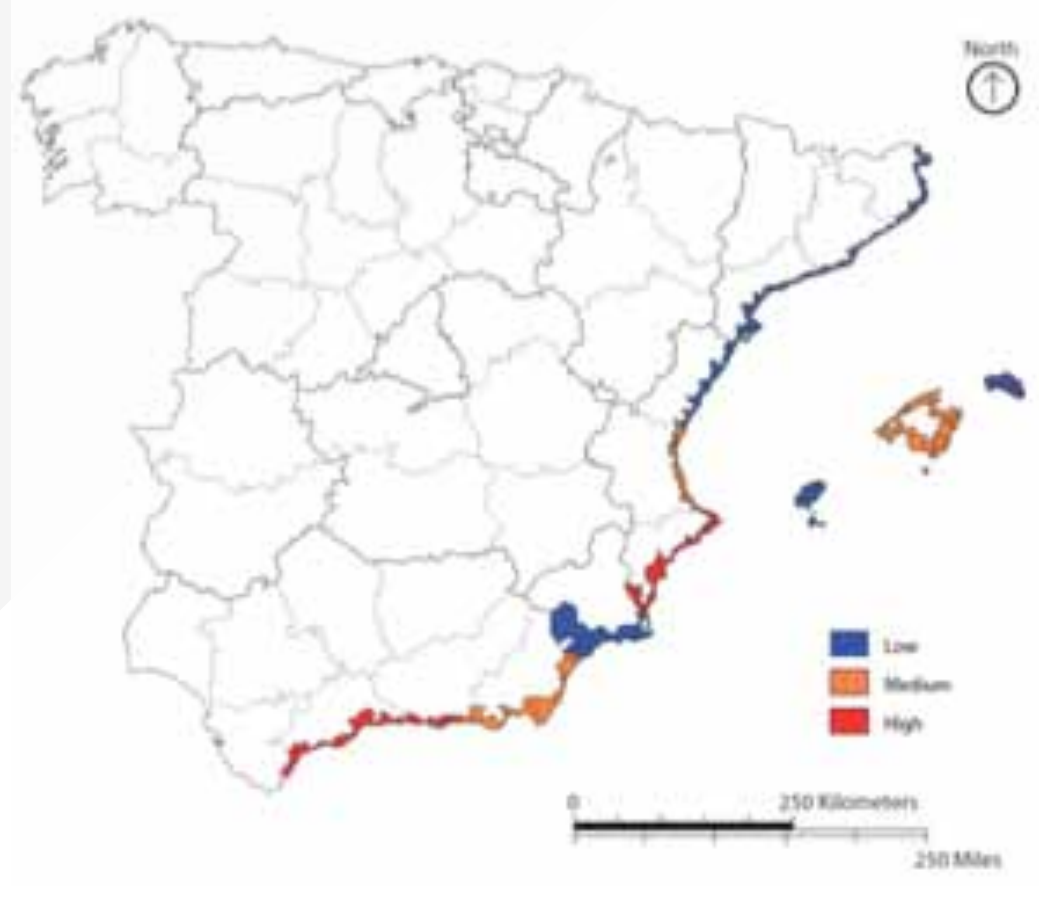

Fuente: Sauriet al. (2014).
Si relacionamos el desarrollo de la actividad turística en la Comunidad

Valenciana, como reflejo de lo ocurrido en el litoral mediterráneo

de las ciudades de Alicante y Valencia en el último tercio del siglo XIX coincide curiosamente, con una fase cálida de la temperat español con la evolución del clima en los śltimos 150 años, resulta todo el planeta que, sin duda, permitió el desarrollo de inviernos algo curioso observar que los orígenes de la promoción del clima invernal más suaves.

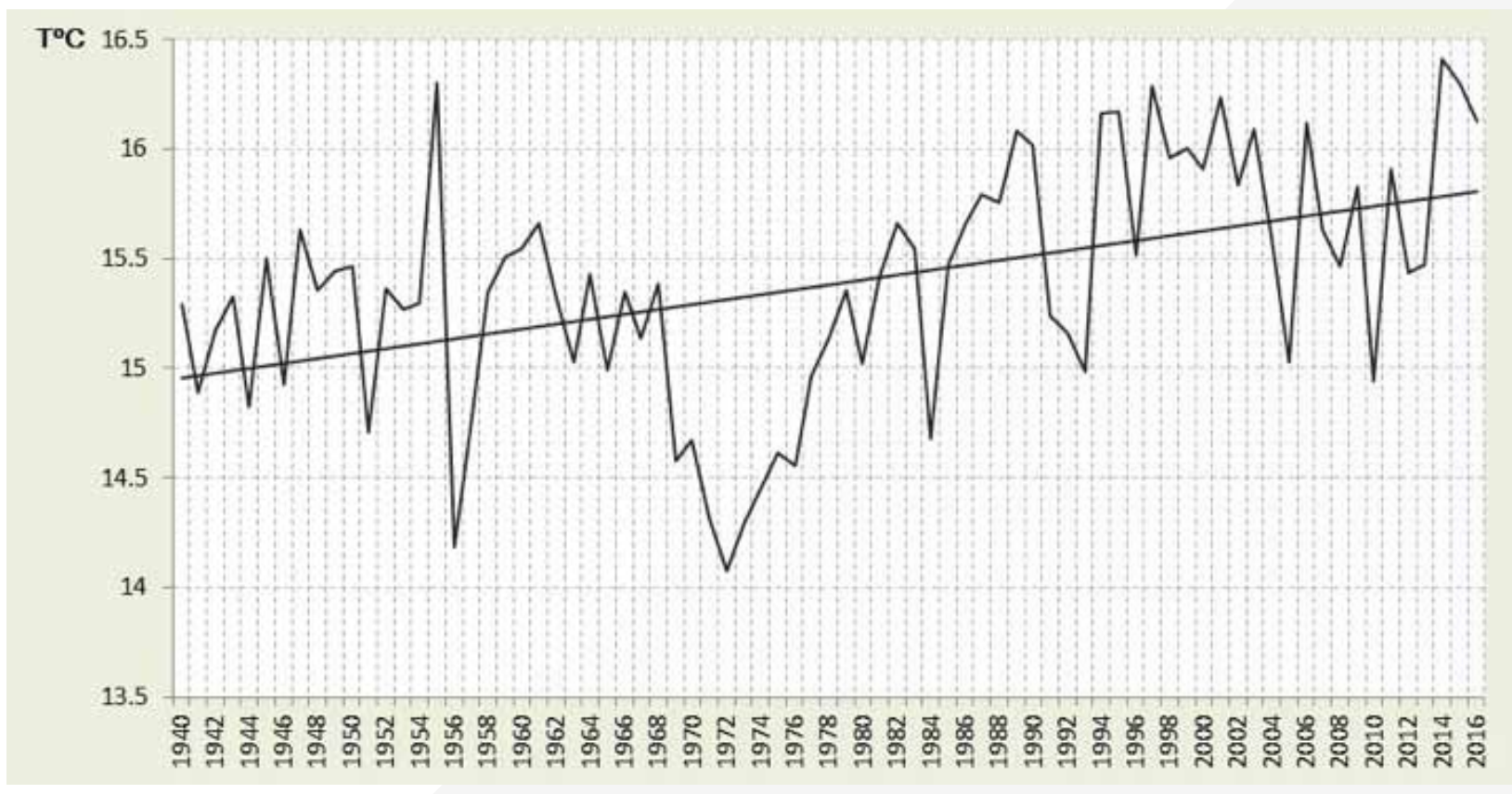


La promoción de los veranos cálidos como reclamo principal del turismo masivo de sol y playa que se inicia desde finales de los años cincuenta del siglo pasado, coincide con una fase fría en la evolución de las temperaturas terrestres y también en nuestras latitudes mediterráneas, que termina hacia 1980. Por su parte, las cuatro últimas décadas han registrado un aumento de temperatura anómalo, por

encima de lo normal, dentro de una fase cálida del clima terrestre que es la que establece la tendencia actual de calentamiento por efecto invernadero. Como se observa en la figura adjunta (vid. figura 34), hasta ahora dicha tendencia ha sido mayor en el interior de la Comunidad Valenciana (estaciones por encima de $300 \mathrm{~m}$. de altitud), y algo màs

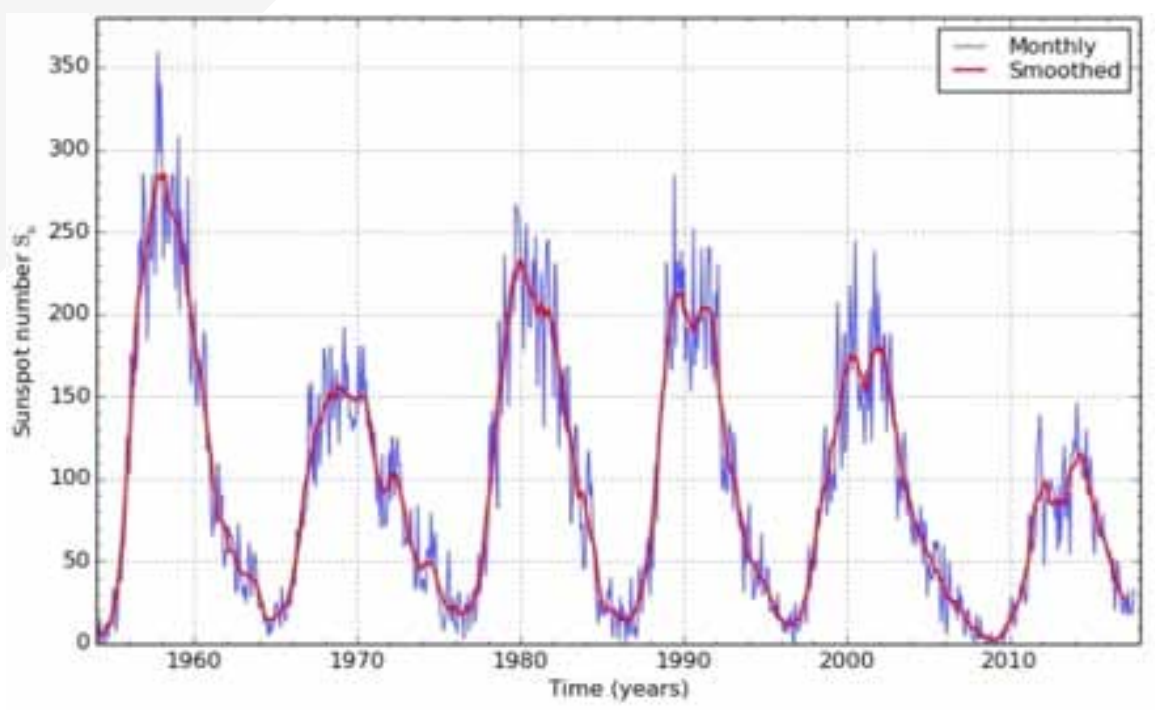

fuente: Roval Observatory of Belgium. Silso Graphics moderada en el iltoral (observatorios por debajo de $300 \mathrm{~m}$.). En este escenario intervienen dos ciclos solares especialmente intensos, en los ãos ochenta y noventa, que, sin duda, están en el origen del incremento de casos registrados de afecciones cutáneas graves debidas a a sobreexposicion al sol y falta de precaución ante la intensidad de radiación solar, por efecto, en muchos casos, de la sobrevaloración a la piel morena dentro de la moda del culto al cuerpo que vive la sociedad actual. No obstante, los ciclos solares más recientes han sido más débiles, muy especialmente el último, lo que sin embargo no ha revertido la tendencia al calentamiento (vid. figuras 35 y 36 .

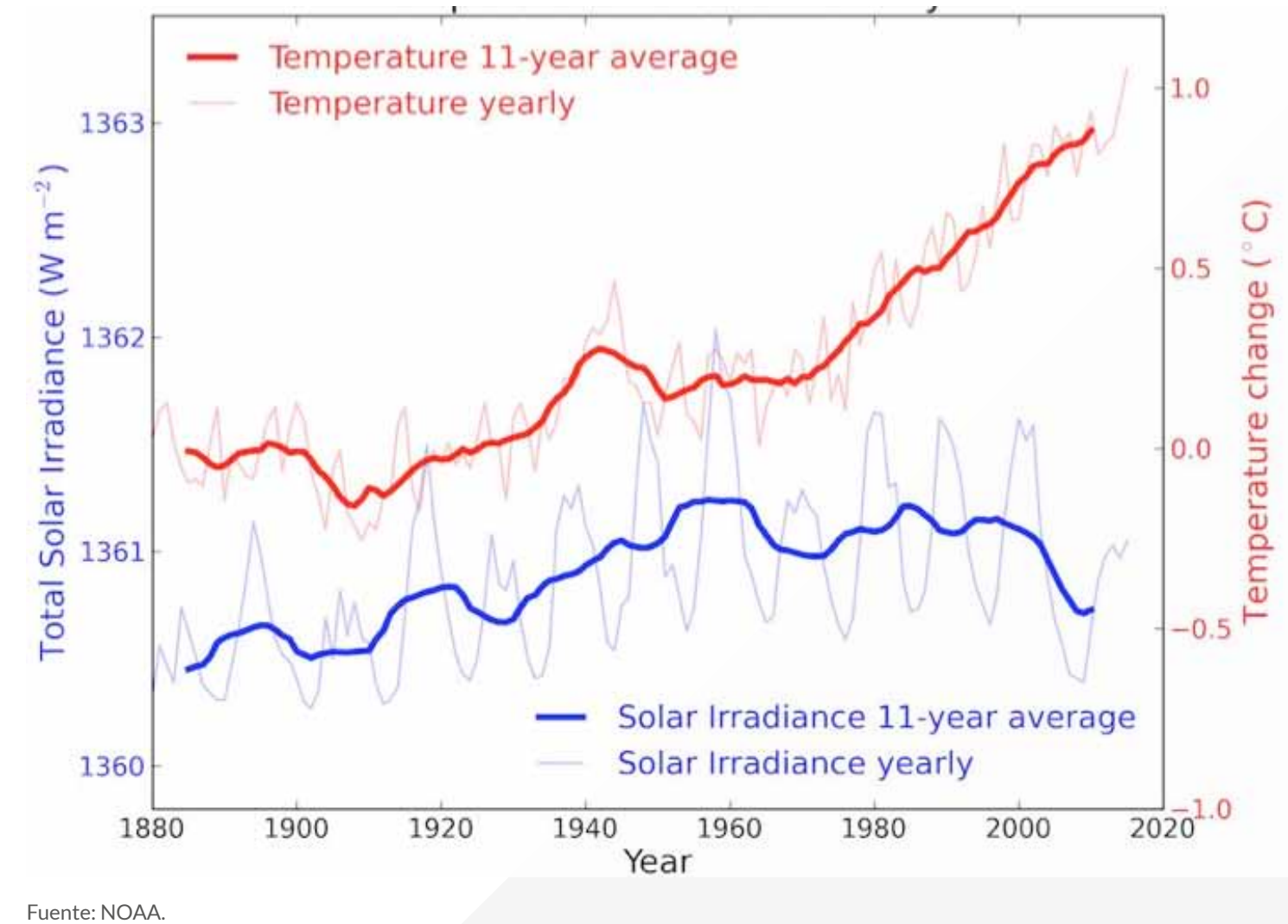


En la actualidad resulta dificili negar el actual ciclo de calentamiento planetario que, como se ha señalado (vid. supra) ya no encuentra explicación por causas sólo naturales (variaciones en la radiación solar). Siguen quedando, sin embargo, incertidumbres en el comportamiento de algunos elementos climáticos, especialmente en la precipitación cuya modelización es compleja; en la actualidad, numerosas regiones del mundo - entre ellas, España-no manifiestan tendencias claras este elemento climático.

Esto nos recuerda que los modelos de cambio climático no son predicciones, al estilo de la predicción meteorológica diaria realizada en los servicios meteorológicos de los Estados. Tan sólo marcan tendencias, pero ahí estriba su valor. Si las tendencias que muestran resultan

poco cambiantes con el paso del tiempo, como ocurre con los modelos climáticos incluidos en los diferentes informes de cambio climático realizados por el IPCC desde 1990, entonces la probabilidad de que se cumplan es elevada. Por ello, la próxima década es decisiva para confirmar las actuales hipótesis de trabajo del IPCC y mejorar, aún más, la modelización climática para alcanzar escalas de detalle (local scale). Ahora bien, la necesidad de mantener la investigación climática con el fin de ir confirmando todos los extremos de la hipótesis principa de trabajo (efecto invernadero de origen antrópico) no debe significar inacción de las administraciones públicas o de los agentes privados en las medidas de mitigación y adaptación que deben aplicarse en los territorios.

En la actualidad, no son aún abundantes los ejemplos de adaptación a cambio climático en la escala local en España y aun menos, en municipios turísticos de escala media o pequeña. La adaptación se ha entendido, en muchos casos, como un conjunto de medidas de sostenibilidad ambiental con efectos, de modo muy secundario, en una posible mejora del problema del cambio climático. $O$ bien, se han realizado actuaciones estructurales en los municipios para minimizar los efectos de episodios atmosféricos extremos -básicamente inundaciones sequías, entendiendo que éstos son efecto del cambio climático.

La escala local es fundamental para poner en marcha medidas de adaptación al cambio climático; es la escala de la "práctica", de la "acción", frente a las escalas superiores (estatal y regional) que son escalas de las "políticas". En España, la plasmación concreta de la puesta en marcha de medidas de adaptación al cambio climático durante los últimos años en los municipios se está materializando en las acciones siguientes:

1. Energía: implantación de sistemas de iluminación eficientes. Se persigue, una reducción del gasto energetico municipal y, en última instancia, una reducción de emisiones de gases de efecto invernadero. Se han aprobado ordenanzas municipales de eficiencia energética.

2. Agua: medidas de ahorro. Se han aprobado ordenanzas municipales, motivadas en ocasiones por el desarrollo de secuencias de sequía. Asimismo, se han desarrollado planes locales de reutilización de aguas residuales para riego de espacios verdes municipales, con implantación de sistemas propios para la conducción de aguas depuradas.
3. Riesgos climáticos: obras de defensa. Se han desarrollado obras de encauzamiento de cursos fluviales, instalación de depósitos de agua pluvial para reducir el efecto de avenidas de agua en el núcleo urbano parques inundables para la retención de volúmenes de agua torrenci En cumplimiento de las normativas (estatal y autonómica) de protección civil o de aguas, se han elaborado, asimismo, planes municipales de gestión de inundaciones y de sequías.

4. Litoral: Obras de defensa. Se han llevado a cabo obras de defensa en el litoral frente a temporales. Se trata, en todo caso, de infraestru-turas y equipamientos desarrollados tras la ocurrencia de un episodio de viento y oleaje fuerte.

5. Ordenación territorial: Se han aprobado planes específicos de ordenación del territorio para la reducción del riesgo de inundaciones, de escala regional, con implicaciones en la planificación urbanística local. Se han diseñado planes de ordenación urbanística adaptados a los supuestos del cambio climático, aunque, los avatares políticos no hayan permitido desarrollarlos. Y se han desestimado planes y proyectos urbanísticos debido a los efectos negativos sobre los recursos de agua existentes en el municipio o en cumplimiento de las normativas estatales o autonómicas del suelo en relación con la prohibición de ocupación de espacios de inundación con riesgo acreditado.
6. Salud: Se han desarrollado planes y protocolos de actuación para eventos a gional como local (grandes municipios). La activación de estos protocolos supone la existencia de planes de aviso meteorológico (escala estatal o regional).

7. Información y participación ciudadana: Se ha creado una red de ciudades por el clima, con participación creciente de los municipios españoles. Además, en diversos municipios se han creado consejos locales de medio ambiente o, específicamente, de cambio climático. Asimismo, se han desarrollado indicadores de seguimiento de cambio climático, donde se lleva a cabo evaluación continua de aspectos energéticos, hídricos, de riesgos naturales o de salud a escala municipal.

De manera que en los municipios españoles se están desarrollando prácticas concretas de adaptación ante el cambio climático, en genera poco conocidas, y cuyos efectos son difíciles de evaluar en el corto intervalo de tiempo, pero de gran interés al tratarse de acciones pione ras en un contexto de largo plazo.

Para justificar y fundamentar las estrategias de adaptación al cambio climático en la escala local existen en España una serie de herramientas cuya consulta y seguimiento, a la hora de actualizar dichas acciones, es necesario abordar. La tabla adjunta resume estos documentos (vid. tabla 9). 
Tabla 9. Herramientas de consulta para el diseño de estrategias y medidas de adaptación al cambio

\begin{tabular}{|c|c|}
\hline MODELOS CLIMÁTICOS & $\begin{array}{l}\text { - Informes del IPCC ( } 5^{\circ} \text { informe ,2013-14; } 6^{\circ} \text { informe, en } \\
\text { fase de elaboración) } \\
\text { - Modelización de escenarios climáticos (AEMET, renova- } \\
\text { ción regular) }\end{array}$ \\
\hline $\begin{array}{l}\text { MODELOS } \\
\text { PLUVIO-HIDROLÓGICOS }\end{array}$ & $\begin{array}{l}\text { - Modelización de evolución de precipitaciones y volúme- } \\
\text { nes de agua disponibles (CEDEX, 2012) } \\
\text { - Informes de Demarcaciones Hidrográicas (en cumpli- } \\
\text { miento de la Directiva 60/2000) } \\
\text { - Sistema Nacional de Cartografía de Zonas Inundables } \\
\text { (SNCZI) } \\
\text { - Cartografía de inundaciones de las CC. AA. } \\
\text { - Planes de Gestión de Inundaciones (Demarcaciones } \\
\text { Hidrográficas) }\end{array}$ \\
\hline $\begin{array}{l}\text { MODELOS DE } \\
\text { GASTO DE AGUA }\end{array}$ & $\begin{array}{l}\text { - Planes de Gestión de Sequía (Demarcaciones Hidrográf- } \\
\text { cas o Agencias Autonómicas del Agua) }\end{array}$ \\
\hline $\begin{array}{l}\text { MODELOS DE } \\
\text { EFECTOS EN ELLITORAL }\end{array}$ & $\begin{array}{l}\text { - Proyecto I3C de efectos del cambio climático en la costa } \\
\text { española }\end{array}$ \\
\hline $\begin{array}{l}\text { MODELOS DE } \\
\text { IMPACTO ECONÓMICO }\end{array}$ & $\begin{array}{l}\text { - Informe JRC PESETA (II informe actualizado en 2014) } \\
\text { - Informes sectoriales de efectos del cambio climático } \\
\text { (turismo) }\end{array}$ \\
\hline
\end{tabular}

A nivel estatal, la Administración ha elaborado un Plan Nacional de Adaptación al cambio climático, cuyo efecto práctico, de momento, es poco evidente. En el sector turístico, llama la atención la ausencia de acciones relacionadas con la adaptación al cambio climático en el Plan Nacional e Integral de Turismo 2012-15, elaborado por el Ministerio de Industria, Energía y Turismo. Tan sólo hay mención a la apuesta por la sostenibilidad, en su triple acepción ambiental, económica y social, como eje de actuación en procesos de renovación de destinos, instalaciones y empresas en los municipios turísticos; en concreto se han incluido líneas de ayuda económica, en acción coordinada con el resto de administraciones (regional y local) para la implantación de sistemas de ahorro de agua y energía ${ }^{28}$.

Por su parte, las Comunidades Autónomas del litoral mediterráneo spañol han desarrollado instrumentos programáticos para la aplcación de las políticas públicas en materia de turismo, considerando que el marco competencial en España establece que la ordenación y planificación del turismo corresponde a las comunidades autónomas (art. 148.1.18 de la Constitución), de tal manera que es en los distintos planes regionales de turismo donde resulta patente la sensibilidad y nivel de preocupación por el cambio climático, aunque ésta sigue siendo muy escasa Las Comunidades Autónomas del litoral mediterráneo

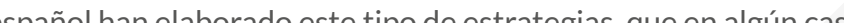
(Cataluña) se acompaña de la elaboración periódica de un completo informe sobre el estado del cambio climático y su modelización futura el territorio de referencia. Para la adaptación de la actividad turística hay previstas una serie de actuaciones en cada región, que se vinculan

a la promoción de destinos sostenibles, la incentivación de medidas de ahorro (energía, agua) en establecimientos hoteleros, las acciones de formación del personal y de información a los clientes de las instalaciones turísticas en las cuestiones de sostenibilidad (vid. Olcina y Vera 2016b).

Así, en Cataluña, donde el turismo es un sector estratégico de su economía y del modelo de organización territorial, la política turística se basa en un instrumento denominado Pla Estratègic de Turisme de Catalunya 2013-2016, (Generalitat de Catalunya, 2013) que define el modelo turístico de Cataluña y los principios directores que orientan la acción de los agentes públicos y privados del sector. El propósito es crear un modelo que permita que Cataluña mantenga la posición de liderazgo entre los primeros destinos turisticos internacionales. En el diagnóstico previo del turismo que realiza el referido plan, en el apartado de amenazas se indica de forma explícita el cambio climático. que afectará a la diversidad de recursos y reforzará la competitividad del Norte. Como oportunidad, se indica que el incremento de temperaturas supondrá una extensión de la temporada para el turismo de sol y playa. En el desarrollo de los programas que integran el plan, el denominado programa de destinos, habla entre otros aspectos de la renovación de ba oferta obsolete "teniendo en cuenta las nuevas situaciones climáticas...". También en el programa de excelencia, dentro de la sostenibilidad ambiental se indica la concienciación del sector sobre la importancia de los efectos del cambio climático y se apunta como proyecto concreto una campaña de sensibilización sobre el tema. No obstante, cuando se observa la tabla de actuaciones priorizadas de 
plan, con asignación de presupuesto (p. 31), no aparece explicitamente dicha campaña ni acción concreta.

En Baleares, otras de las comunidades que ha hecho del turismo un sector estratégico de su estructura económica y territorial, el instrumento que rige la política turística es el Pla integral de turismo de les Illes Balears 2015-2025 (Govern de les Illes Balears, 2015). En este plan, al referirse a la dimensión ambiental del turismo, se señala (p. 8) que Baleares, uno de los principales destinos del turismo en la Unió Europea, debe llegar a ser un referente medioambiental y ecológico en turismo, con líneas como el uso de las energías renovables y la eficiencia energética. Para ello, prevé introducir una serie de medidas conducentes a reducir las emisiones de gases efecto invernadero, a aumentar la autosuficiencia energética y a mejorar la producción de energía eléctrica, que tienen que llevar implícita una actuación en e sector transporte.

Se entiende que estas acciones favorecerán la generación de nuevas oportunidades de negocio y la dinamización del sector económico. No obstante, a la hora de concretar medidas, el plan de acción 2015, como instrumento operativo, además de mencionar los principios de desarrollo sostenible y calidad medioambiental, no incluye medidas específicas al respecto. Se podría interpretar que los aspectos del cambio climático son competencia de la Oficina del Cambio Climático con la que cuenta esta comunidad, pero sorprende la ausencia de referencias explícitas en su política turística, considerando la importancia estratégica de este sector en el archipiélago.

En el caso de la Comunidad Valencian illama poderosamente la atención la inexistencia de referencias al tema cambio climático en su Plan
Estratégico Global del Turismo 2010-2020 (Generalitat Valenciana e Invat.tur, 2010). Además el plan incluye un apartado de prospectiva, con un análisis y percepción del sector turístico, realizado con la participación de los agentes sociales, que se estructura en cuatro apartados clave: entorno; infraestructuras y transporte; oferta; y perfil del turista. En el apartado concreto de entorno, se indica de forma explíita: "Percepción de escasa incidencia al cambio climático" (p.9), lo que lleva a planificación regional del turismo.

Sorprende el caso de la Región de Murcia porque el instrumento rector de su política turística, el Plan Director de Turismo de la Región de Murcia 2006-2012 (Región de Murcia, 2006), en el marco de la planifcación estratégica de esta región, muestra una clara voluntad expansionista del turismo y apuesta por grandes infraestructuras, complejos turísticos de nuevo corte, etc., a pesar de introducir retóricamente el concepto de desarrollo sostenible Es probable que esta orientación derive del hecho de haber sido formulado en un contexto de crecimiento y grandes expectativas para el incremento de la actividad turistica en la región. Pero, en todo el plan no aparece ni una sola mención al tema de la adaptación al cambio climático. Se apunta la existencia de una linea de indicadores para el seguimiento y cumplimiento de los objetivos del plan, dentro de los cuales aparecen indicadores ambientales y su evolución, sin mención alguna a la cuestión del cambio climático. En Andalucía, el Plan General de Turismo Sostenible de Andalucía 2014-2020 (Junta de Andalucía, 2013) se define como el instrumento básico y esencial en la ordenación de los recursos turísticos para todo el ámbito geográfico de la Comunidad Autónoma y tiene como referencia los once objetivos temáticos aprobados por el Reglamento (UE) $n^{\circ} 1303 / 2013$, por el que se establecen disposiciones comunes sobre los distintos Fondos Europeos, contribuyendo a la consecució de dichos objetivos mediante el desarrollo de una serie de lineas estratégicas y programas que constituyen los ejes fundamentales del Plan. Entre los once objetivos temáticos contemplados, el $5^{\circ}$ lleva por título "Promover la adaptación al cambio climático y la prevención y gestión de riesgos", por tanto, aparece de forma explícita una referencia a este tema como marco principal del plan. Además, para el desarrollo y la programación de este Plan General se han tenido en cuenta una serie de Estrategias andaluzas convergentes con las orientaciones $d e$ la Estrategia Europa 2020, entre las que figura la Estrategia Energética 2014-2020 que tiene como finalidad genérica ayudar a desligar crecimiento económico y utilización de recursos, apoyar el cambio hacia una economía con bajas emisiones de carbono, incrementar uso de fuentes de energía renovables, modernizar nuestro sector del transporte y promover la eficacia energética. Además, este plan tien también una relación y coherencia con la Estrategia Andaluza ante el Cambio Climático (2002), formada por un conjunto de medidas a ejecutar desde los distintos departamentos del Gobierno andaluz, considerando las medidas con potencial incidencia en las actuaciones de turismo.

Junto al Plan General, la ley de Turismo de esta comunidad autónom prevé la elaboración de los Marcos Estratégicos para la ordenació de los recursos y las actividades turísticas (MEORAT) que surgen de la conceptualización del territorio como recurso y soporte físico de actividad turística. Entre otros aspectos, dichos Marcos Estratégicos deben contener la evaluación de la incidencia ambiental del modelo turístico propuesto, incluyendo los efectos del cambio climáticoy su cherencia con el desarrollo sostenible.

Respecto al Plan General de Turismo Sostenible, lo esencial es que integra diferentes Programas de actuación, como el de coordinación administrativa y de cooperación público-privada en cuyo desarrollo hace una referencia explíita a la necesidad de establecer convenios con otros departamentos de la administración autonómica que incluirán "la protección y reparación de aquellos espacios naturales que puedan verse afectados por el cambio climático, caso de los situados en el ámbito litoral" Asimismo, el programa de apoyo a la calidady fomento de la sostenibilidad, incluye líneas para prevención y gestión de riesgos en el litoral como consecuencia del cambio climático. Por su parte, el Programa de formación para la profesionalización de los recursos humanos, incorpora entre los conocimientos a adquirir por empresarios y profesionales del sector la concienciación de la necesdad de apoyar el cambio a una economía de baja emisión de carbono adaptada al cambio climático, que haga un uso eficaz de los recursos y sea medioambientalmente sostenible.

Particularmente interesante resulta el análisis del Informe de Inform de Sostenibilidad Ambiental (Junta de Andalucía, 2014) del plan en cuestión, en cuanto se basa en el cumplimiento de las principales directrices adoptadas por el Consejo Europeo de Gotemburgo de 2001 en la "Estrategia de la Unión Europea a favor del desarrollo sostenible" (COM/2001/264 finaly COM/2005/658 final). Esta estrategia pone de manifiesto siete tendencias insostenibles que requieren una 
intervención, entre las cuales aparece el cambio climático y la energía. Para ello se enumeran toda una serie de objetivos, operativos y cuantificados, y medidas concretas a escala de la UE para alcanzarlos. Y el primer objetivo específico a largo plazo del plan consiste en luchar contra el cambio climático y sus efectos, respetando los compromisos del protocolo de Kioto y en el marco de la estrategia europea sobre el cambio climático.

Entre las medidas que propone el Informe de Sostenibilidad Ambie tal, se indica la necesidad de considerar explícitamente el camb climático en los planes para los que el Plan General de Turismo Sostenible es referenciay marco de actuación De este modo, los instumentos y acciones, a tenor del referido Informe, deben considerar en su formulación el cambio climático y adoptar medidas para que ello se traslade a los proyectos que los desarrollen. Y ello teniendo en cuenta las dos direcciones a través de las que incide el cambio climático en la actividad turistica. Una viene dada por los efectos que las act turísticas pueden ejercer en la emisión de gases de efecto invernadero; por ejemplo a través de la presión asociada al incremento del tráfico rodado en determir mo energético etc. La otra vertiente son las consecuencias que el cambio climático puede tener en tres aspectos: la demanda de actividades turísticas, en términos de cantidad y calidad; la variación del atractivo turístico de Andalucía, o de ciertas zonas turísticas andaluzas; $y$ la variación de la competencia, a causa del posible desplazamiento de la demanda hacia nuevas zonas cuyo atractivo puede mejorar por el cambio climático.

En general se trata de acciones que persiguen la diversificación de de actuación en la búsqueda de la calidad de los destinos, más que de medidas concretas de adaptación al cambio climático. La tabla adjunta resumen las acciones de adaptación previstas en los planes regionales de cambio climático del litoral mediterráneo español (vid. tabla 10).
Tabla 10. Medidas de adaptación del sector turístico al cambio climático contempladas en los Planes Autonómicos de Adaptación al cambio climático del litoral mediterráneo español.
ACCIONES DESTACADAS

\begin{tabular}{|c|c|}
\hline CATALUÑ̃A & $\begin{array}{l}\text { - Impulsar la desestacionalización de la oferta turística } \\
\text { (potenciar la estación bimodal: primavera y otoño) y de la } \\
\text { demanda (cambios en el calendario escolar). } \\
\text { - Incorporar los impactos previstos del cambio climático } \\
\text { en el Plan estratégico del turismo, así como las medidas de } \\
\text { adaptación propuestas. } \\
\text { - Impulsar el ahorro y la eficiencia en el uso del agua (sepa- } \\
\text { ración de aguas grises, depósitos de pluviales, etc.) y de la } \\
\text { energía. }\end{array}$ \\
\hline BALEARES & $\begin{array}{l}\text { - Implantación de políticas empresariales de uso eficiente } \\
\text { de la energía. } \\
\text { - Incorporación de un estudio de emisiones de } \mathrm{CO} 2 \text { y de } \\
\text { medidas correctoras en la solicitud de la licencia } \\
\text { integrada de actividades para los establecimientos comer- } \\
\text { ciales. } \\
\text { - Fomento de la utilización de dispositivos y mecanismos } \\
\text { de control eficientes para establecimientos turísticos de } \\
\text { alojamiento. } \\
\text { - Buenas prácticas en medio ambiente en el sector turísti- } \\
\text { co. } \\
\text { - Normativa para el ahorro de energía y disminución de } \\
\text { emisiones de gases de efecto invernadero en el sector } \\
\text { turistico de alojamiento. }\end{array}$ \\
\hline
\end{tabular}

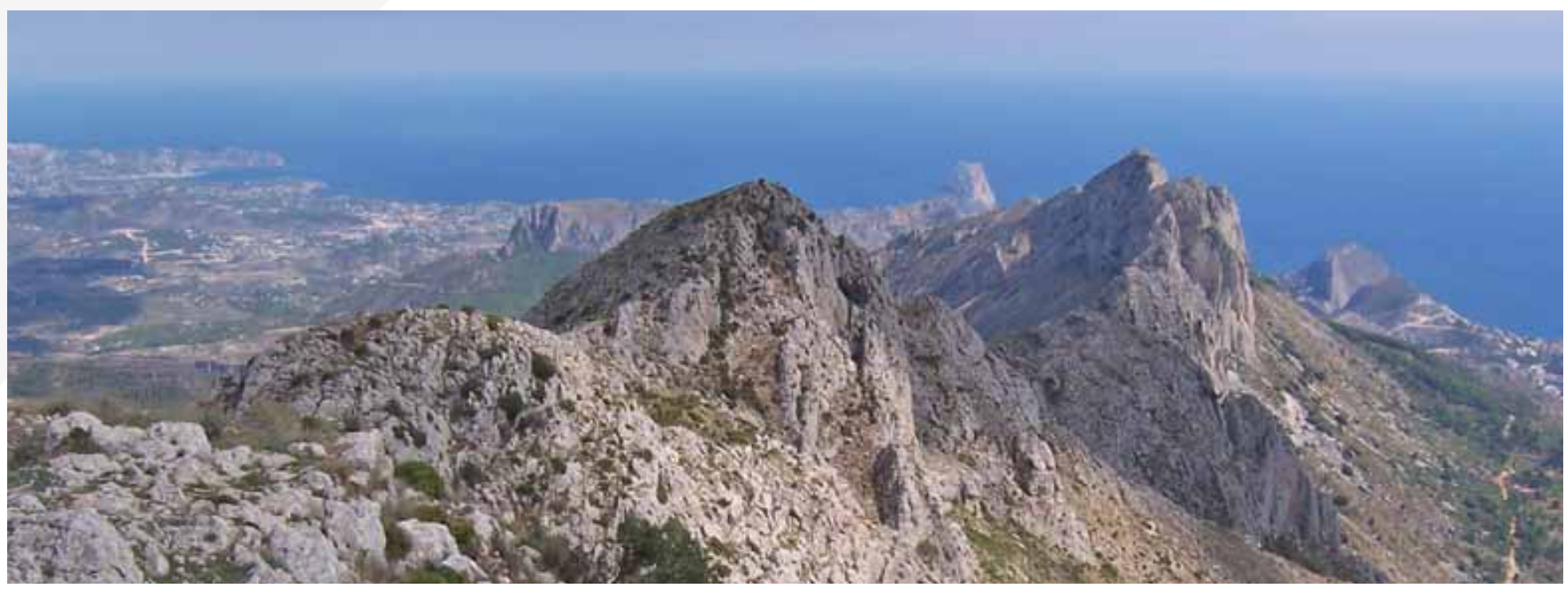


- Refuerzo de la sostenibilidad como eje de las estrategias de desarrollo turístico de la Comunitat Valenciana a corto medio y largo plazo.

- Apoyo al sector turístico para la implantación de sistemas de gestión medioambiental y la mejora de la eficiencia energética en empresas y entidades locales turisticas y

para el planeamiento y desarrollo sostenible de destinos urísticos.

- Inversión en infraestructuras y equipamientos sostenibles en empresas turísticas y entidades locales.

Fomento del consumo responsable en el sector turístico Fomentar el ahorro y la eficiencia energética en el sector:

Fomentar la utilización de vehículos de alquiler más eficientes, de menores emisiones de GEI.

- Plan para fomentar el uso de la microgeneración.

- Plan de sustitución de equipos de climatización por otros más eficientes: tecnología "inverter".

- Desarrollo de modelos ecoturísticos

- Promocionar los modelos de turismo rural, cultural y deportivo entre otros, que sean sostenibles y respetuosos con el medio en el que se desarrollan.

- Fomento de la red de itinerarios y senderos ecoturís-

- Desestacionalización de la oferta para evitar la concenración y la sobreexplotación de los recursos en determinadas épocas del año.

- Diversificación de la oferta turística.

- Aumento de la dotación de servicios de tipo social, cultural, sanitario, deportivo y comercial en zonas turísticas.

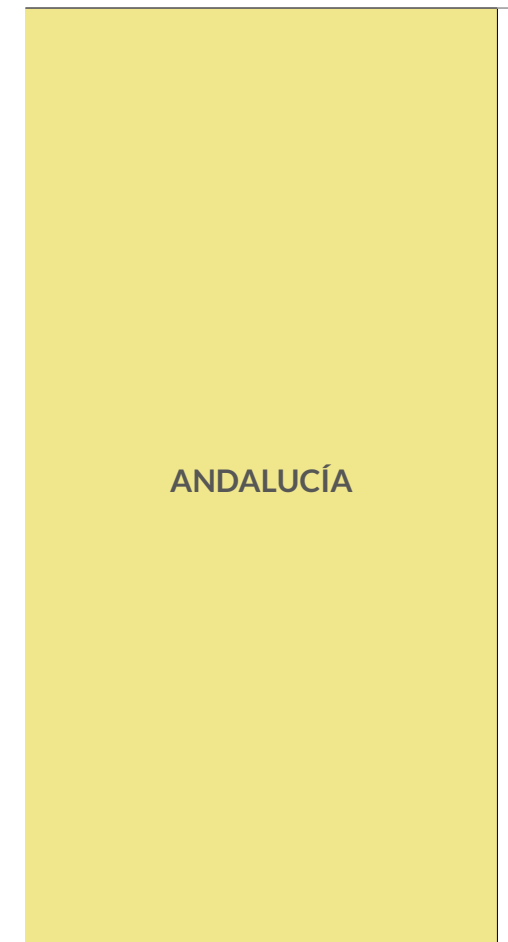

- Realizar planes de reconversión para la adaptación de los espacios de alta montaña a las nuevas condiciones climáticas.

- Realizar estudios de detalle sobre el retroceso de playas por aumento del nivel medio del mar y su incidencia en los destinos turísticos de sol y playa.

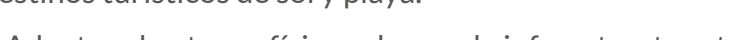
rística en las ciudades de atractivo monumental y cultural. - Adecuar progresivamente las edificaciones e infraestructuras turísticas a las nuevas condiciones del clima.

- Desarrollo de estudios de impactos y vulnerabilidad al

cambio climático sobre los diferentes espacios turísticos.

- Crear sistemas de indicadores que alerten sobre los

efectos del cambio climático en el turismo.

- Evaluación socioeconómica de los efectos del cambio

climático en el turismo y análisis de inversión futura.

Fuente: Planes Autonómicos de Adaptación al Cambio Climático de las CC.AA. Elaboración propia,a a partir de Olcina y Vera 
Al tratarse, en todos los casos, de documentos aprobados recientemente, en pocos casos se ha realizado una evaluación de seguimiento $y$, en todo caso, para el sector turístico, las medidas señaladas han tenido, hasta el momento presente, un grado de implantación bajo.

đlevadas a cabo en España en los últimos años se han desarrollado bien por propia iniciativa de los gobiernos municipales en muy pocos Dor pros. y auspiciada por el Ministerio de Medio Ambiente y la Federación Española de Municipios y Provincias (vid. figura 37.

su parte, tienen las acciones locales de adaptación al cambio climático y sus riesgos sextremos atmosfericos vinculados

Acciones de adaptación al cambio climático y a los extremos atmosféricos en municipios e instalaciones turísticas.

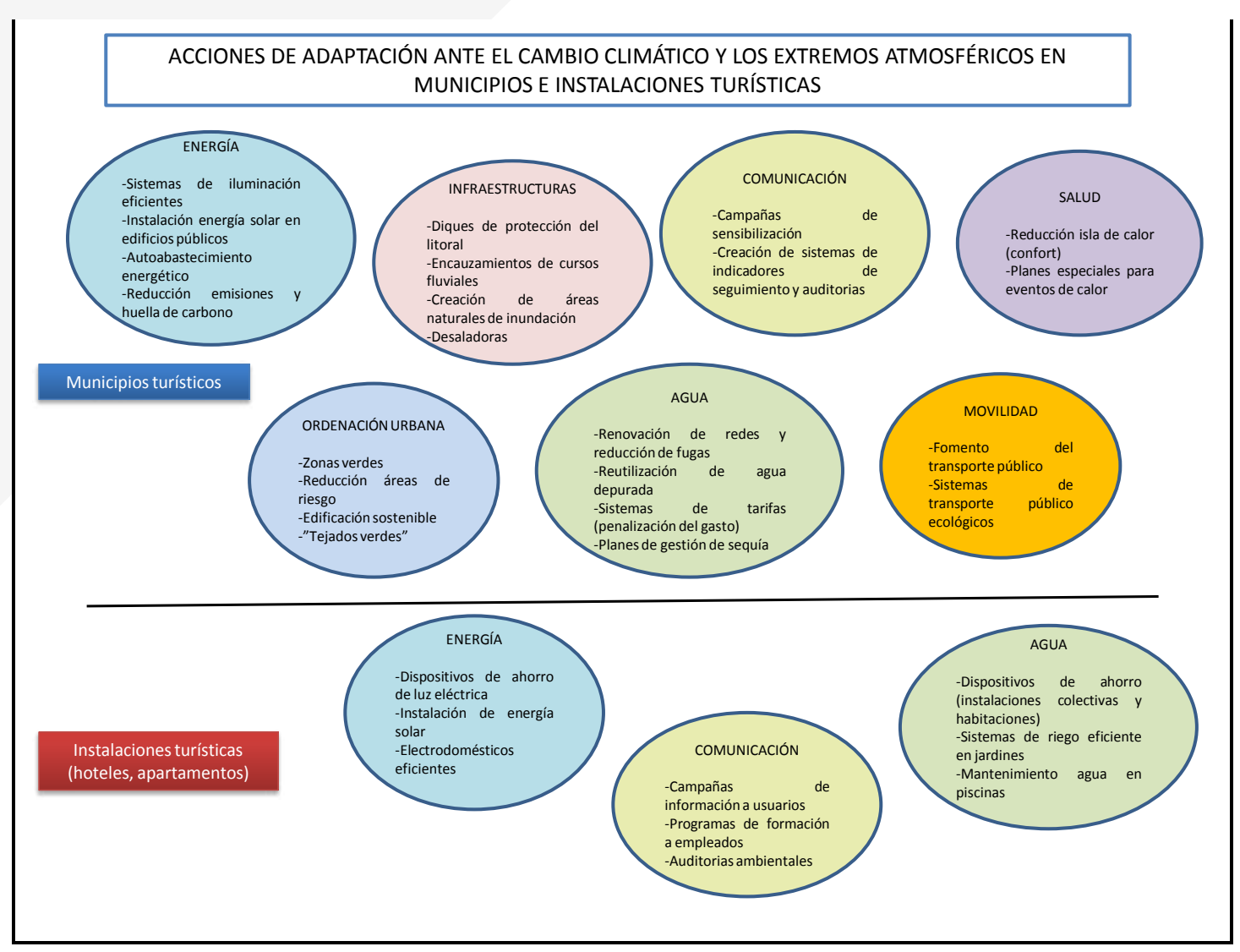

Debe señalarse, asimismo, que en 2011, el Ministerio de Medio Ambiente aprobóla Estrategia Española de Sostebilidad Urbanay Local, como adaptación al territorio español de la Estrategia Temática Europea de Medio Ambiente Urbano de 2006 (ETEMAU). El documento contiene una hoja de ruta de enorme interés para su aplicación en los municipios y ello debe suponer la puesta en marcha en los entes locales de una serie de planes sectoriales y de aprobación de ordenanzas relacionadas directamente con la sostenibilidad fundamentalmente ambiental de estos territorios. Asimismo, y con la referencia de la Ley

el Suelo aprobada en 2008, se pretende dar un impulso a la integración urbana En das de mitigación y adaptación del cambio climático que comprenden acciones relacionadas con la reducción de emisiones, energías limpias movilidad sostenible. La tabla adjunta resume las medidas contenidas los municipios (vid. tabla 11).

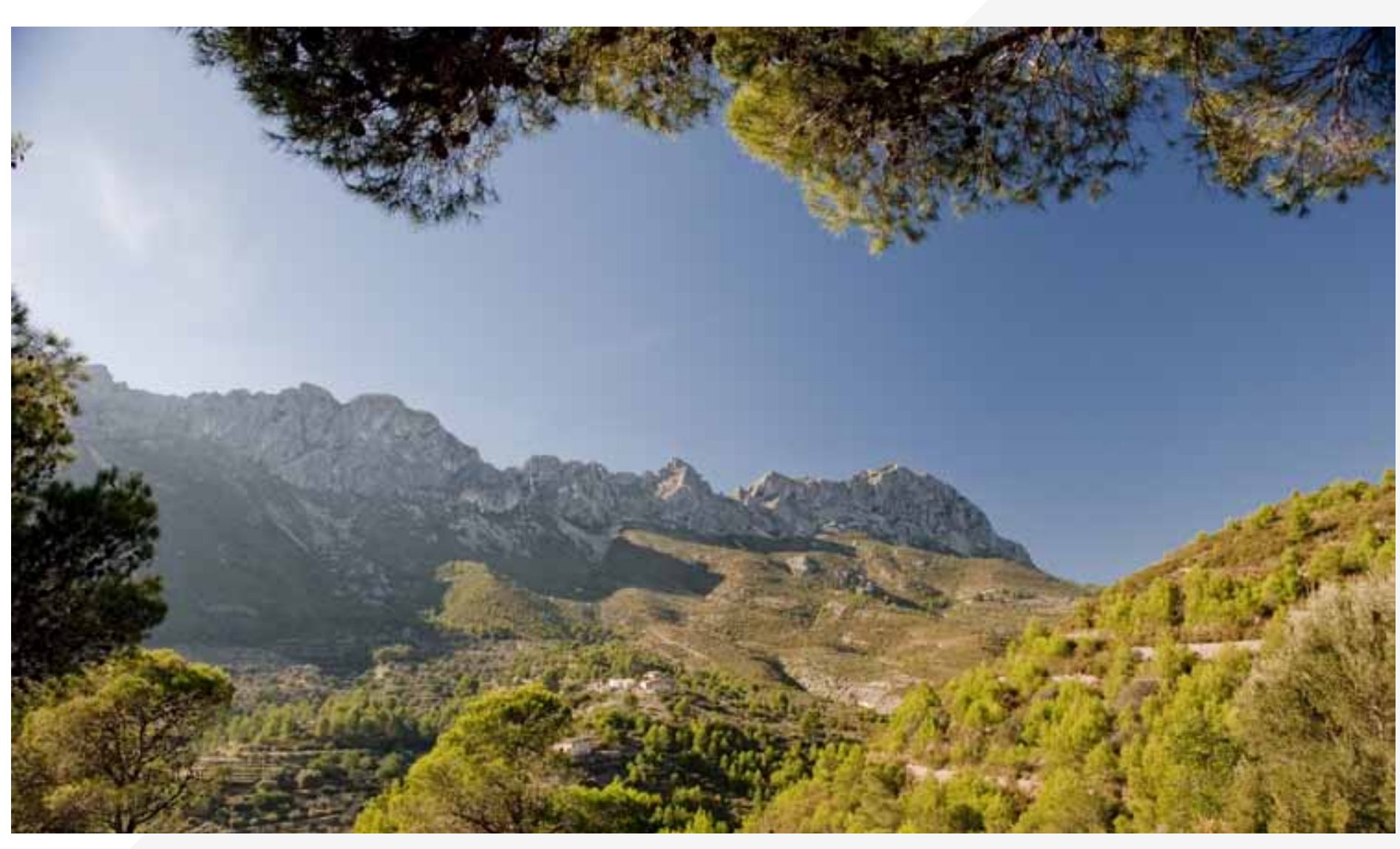




\begin{tabular}{|l|l|}
\hline AGUA & $\begin{array}{l}\text { - Reducir el consumo de agua en la edificación y fomentar } \\
\text { el reciclaje y uso selectivo de la misma. } \\
\text { - Minimizar el consumo energético del ciclo urbano del } \\
\text { agua }\end{array}$ \\
\hline MODELO URBANO & $\begin{array}{l}\text { - Desarrollar un modelo urbano y territorial maximizador } \\
\text { de la eficiencia energética, teniendo en cuenta, preser- } \\
\text { vando y potenciando los valores urbanos de la ciudad y los } \\
\text { naturales del territorio, y dando lugar a una red polinuclear } \\
\text { de ciudades compactas y complejas (con diversidad de } \\
\text { usos) conectadas mediante transporte público. } \\
\text { - Desarrollar un nuevo urbanismo que integre la energía } \\
\text { en la planificación, de modo que condicione las caracterís- } \\
\text { ticas de los edificios y el espacio público, haciendo de los } \\
\text { nuevos desarrollos sistemas eficientes que se acerquen a la } \\
\text { autosuficiencia energética. } \\
\text { - Reducir el consumo energético en la edificación. }\end{array}$ \\
\hline RESIDUOS & $\begin{array}{l}\text { - Medidas para mejorar el balance energético en la gestión } \\
\text { de residuos mediante el fomento de la recogida selectivay } \\
\text { el reciclaje. }\end{array}$ \\
\hline
\end{tabular}




\begin{tabular}{l|l}
\hline EVENTOS EXTREMOS & $\begin{array}{l}\text { - Reducir la escorrentía torrencial. } \\
\text { - Evitar o reducir los daños de las inundaciones en la edificación y } \\
\text { las infraestructuras. } \\
\text { - Aplicar Planes Especiales de Sequía (aprobados en marzo de } \\
\text { 2007) de acuerdo con la Ley 10/2001 del Plan Hidrológico Nacional } \\
\text { e implantación de Planes de Emergencia ante situaciones de sequía } \\
\text { en las ciudades de más de } 2000 \text { habitantes (Ley 10/2001 del Plan } \\
\text { Hidrológico) y en otros de menor tamaño o con sistemas mancomu- } \\
\text { nados de abastecimiento de aguas. } \\
\text { - Reducir tanto la generación de calor en el interior de los edificios, } \\
\text { como la penetración y absorción de radiación solar desde el exte- } \\
\text { rior. Desarrollar los sistemas naturales de ventilación y enfriamien- } \\
\text { to }\end{array}$ \\
\hline TURISMO & $\begin{array}{l}\text { - Impulsar un nuevo modelo turístico más competitivo y sostenible } \\
\text { a largo plazo, controlando la presión sobre el territorio, los recur- } \\
\text { sos naturales, el patrimonio cultural y el paisaje; diversificando los } \\
\text { modelos económicos locales y apostando por latransformación } \\
\text { cualitativa de la actividad turística. Revitalizar y reconvertir los de- } \\
\text { sarrollos turísticos ya existentes según este mismo modelo, donde } \\
\text { también se tengan en cuenta criterios saludables y sanitarios. } \\
\text { • Controlar la presión sobre el territorio para garantizar la preser- } \\
\text { vación del capital natural y del paisaje que son los fundamentos } \\
\text { del capital turístico, en base al análisis de la capacidad de carga del } \\
\text { medio físico, ecológico, social, económico y patrimonial, exami- } \\
\text { nando detenida- mente los efectos del desarrollo turístico sobre el } \\
\text { consumo de recursos, agua, energía, ocupación de suelo, paisaje, } \\
\text { calidad de vida, etc. } \\
\text { • Frenar la construcción de nuevas plazas turísticas en las zonas } \\
\text { congestionadas y estudiar la posibilidad de plantear procesos de } \\
\text { descongestión y reconversión urbanística y turística en determina- } \\
\text { dos casos, a escala local y supramunicipal. }\end{array}$ \\
\hline
\end{tabular}

Ciudades turísticas del litoral mediterráneo español como Barcelona, Calvià, Marbella han aprobado Planes o Estrategias locales de adaptación al cambio climático y mejora de la resiliencia urbana. Pero sorprende que no son muchos, todavía, los ejemplos que pueden encontrarse en los municipios turísticos de esta parte del territorio español. Contrasta esta situación con el impulso que ha merecido esta cuestión. por contra, en el País Vasco, donde numerosos municipios han elaborados planes específicos de acción, ordenenanzas municipales y han desarrollado ya medidas concretas en los últimos años (p.e. Bilbao, Balmaseda, Honsarribia, Areatza, Tolosa, Durango, Amurrio, etc.). E propio Gobierno Vasco ha desarollado un manual de planeamiento urbanístico (2012) donde insta a los municipios a aplicar medidas de acción y adaptación ante el cambio climático.

La Federación Española de Municipios y Provincias, por su parte, ha desarrollado en los últimos años diferentes iniciativas para fomentar la acción local en materia de luchay y adaptación al cambio climático A la creación de la mencionada Red de Ciudades Españolas por el Clima, ha seguido la elaboración desde 2009 de informes anuales de "Politicas Locales de lucha contra el Cambio Climático", la preparación de un documento informativo sobre "Vulnerabilidad al Cambio Climático a escala local" (2010)29 y la redacción de una "Guía para el desarrollo de normativa local en la lucha contra el cambio climático" (2012) $)^{30}$, con pautas para la redacción y puesta en marcha de ordenanzas munici- pales en los sectores relacionados con la mitigación y adaptación al cambio climático (energía, transporte, residuos, agua, vivienda, planeamiento urbano, participación, fiscalidad).

Desde 2006, y con una periodicidad bianual, esta Federación organiza una convocatoria para premiar las buenas prácticas en materia de adaptación al cambio climático. Esta convocatoria organiza los proyectos en diversos apartados (energía, movilidad, eco-innovación. educación y planificación territorial). En general, de la relación total de propuestas seleccionadas y de proyectos premiados en las cinco convocatorias desarrolladas se puede observar que las acciones dedicadas a cuestiones energéticas, tanto en edificios (instalación de energi solar) como en movilidad urbana (vehículos hibridos, bicicletas), y las orientadas a la sostenibilidad ambiental, en términos generales (mejora en el servicio de tratamiento de residuos sólidos urbanos, campañas de sensibilización), son las que más se han desarrollado, frente a los proyectos relacionados con la ordenación territorial que han tenido una consideración menor. La tabla adjunta muestra los proyectos llevados a cabo por municipios turísticos del litoral mediterráneo, y que han enido como finalidad el desarrollo de acciones relacionadas directamente con la actividad turística en las seis convocatorias realizadas hasta 2017: se comprueba que son escasas las actuaciones desarrolldas realmente con finalidad turistica, si bien esta convocatoria no está orientada a esta cuestión (vid. tabla 12) (31 $^{31}$ 
Tabla 12. Buenas prácticas de adaptación al cambio climático en municipios turísticos del litoral

\begin{tabular}{|c|c|c|}
\hline $\begin{array}{l}\text { - Creación observatorio energía de } \\
\text { Barcelona } \\
\text { - Creación Agencia Local Energía y } \\
\text { Cambio Climático de Murcia } \\
\text { - Implantación del Carsharing en } \\
\text { Barcelona }\end{array}$ & $\begin{array}{l}\text { - Vías amables del municipio de } \\
\text { Murcia } \\
\text { - Alumbrado eficiente de Calviá }\end{array}$ & $\begin{array}{l}\text { - Servicio público de alquiler de bici- } \\
\text { cletas de Murcia } \\
\text { - Plan de Infraestructuras Ciclistas } \\
\text { (PICA) de Alicante } \\
\text { - Creación de carriles-bici en Palma } \\
\text { de Mallorca } \\
\text { - Proyecto de movilidad sostenible } \\
\text { "Me han bajado los humos” de Palma } \\
\text { de Mallorca } \\
\text { - Proyecto eficiencia energética “De } \\
\text { la luz verde a la luz blanca” de Denia } \\
\text { - Mejora del alumbrado público de } \\
\text { lbiza } \\
\text { - Red de carga de vehículos eléctricos } \\
\text { en aparcamientos municipales de } \\
\text { Palma de Mallorca } \\
\text { - Recuperación de humedal a } 100 \text { m. } \\
\text { de la playa en Motril }\end{array}$ \\
\hline
\end{tabular}

\begin{tabular}{|c|c|c|}
\hline $\begin{array}{l}\text { - Plan director de ahorro energético } \\
\text { del Ayuntamiento de Marbella } \\
\text { - Determinaciones del plan general } \\
\text { de ordenación urbana vigente de } \\
\text { Marbella (2010) para la } \\
\text { Mejora del medio ambiente y la pro- } \\
\text { tección del entorno natural }\end{array}$ & $\begin{array}{l}\text { - Plan de Acción para la energía sos- } \\
\text { tenible de Lorca (2013-2020) } \\
\text { - Recuperación ambiental e integra- } \\
\text { ción urbanística del cordón dunar } \\
\text { litoral (Marbella) } \\
\text { - Educar contra el cambio climático } \\
\text { (Marbella) } \\
\text { - Creación de la "Fundació Obser- } \\
\text { vatori Valencià del Canvi Climatic" } \\
\text { (Ayuntamiento de Valencia) }\end{array}$ & $\begin{array}{l}\text { - Centro para la innovación en } \\
\text { energía y sostenibilidad -Living Lab- } \\
\text { Castellón } \\
\text { - Carril bico entre la Contraparada y } \\
\text { Beniel (Murcia) } \\
\text { - Programa Educación Ambiental } \\
\text { "Conocer+Cambiar= Residuos 0" } \\
\text { (Alhaurín de la Torre). } \\
\text { - Celebrem Amb La Natura (Caste- } \\
\text { llón) } \\
\text { - Castelló + Sostenible (Castellón) } \\
\text { - Huertos de Ocio Municipales } \\
\text { (Murcia) } \\
\text { - Ecoaula (Murcia) } \\
\text { - Escuelas Verdes (Murcia) } \\
\text { - Murcia, Ciudad Comprometida con } \\
\text { el Cambio Climático (Murcia) }\end{array}$ \\
\hline
\end{tabular}

Fuente: Red Española de Ciudades por el Clima 
Por último, la empresa turística también ha llevado a cabo estrategias y medidas para la adaptación al cambio climático que merecen destacarse (Olcina y Vera, 2016 a y b). Tanto tour-operadores como cadenas hoteleras han desarrollado desde los años noventa una serie de estrategias y medidas de adaptación al cambio climático que esta dando resultados concretos muy interesantes. Asi, el mayor grupo de tour operación europeo (TUI) con más de 30 millones de clientes, desarrolla una política sólida de adaptación al cambio climático desde principios de los años noventa del pasado siglo. En efecto, desde principios de 1990, la compañía TUI ha participado en proyectos diseñados específicamente para proteger el clima, con participación de investigadores, administración, empresa privada y sociedad civil. La estrategia climática de TUI se basa en la prevención y reducción de las emisiones

y la adaptación de los diferentes sectores de actividad de la empresa con medidas de eficiencia hacia aspectos ambientales y especificamente relacionados con el cambio climático. Para ello ha definido una serie de objetivos de sostenibilidad climática y ambiental:

- Apoyar e implementar políticas para reducir y evitar las emisiones de gases de efecto invernadero

- Optimizar los procesos operativos y aplicar tecnologías innovadoras para mejorar la eficiencia

- Comprometerse con objetivos de reducción específicos

- Promover el uso de energías renovables

- Elevar la conciencia de los consumidores y de los empleados para la protección activa del clima

- Cooperar con las organizaciones no gubernamentales, la administración y las instituciones de investigación.
La operadora turística lleva a cabo una evaluación sistemática de su huella ambiental (energí agua) a partir de la defnición de indicadores, ha puesto en marcha un servicio técnico de seguimiento de políticas de protección del clima y ha aprobado un Código de Conducta que incluye el compromiso con la protección del clima como uno de sus principios principales, además de realizar campañas de sensibilización de esta tema entre clientes y socios. Estas cuestiones son de aplicación come se ha mencionado, a sus diferentes sectores de actividad (transporte aéreo, hoteles, cruceros, vehículos de alquiler). Las acciones puestas en marcha por el tour-operador en la última década han sido reconocidas en 2011, por la organización "Carbon Disclosure Project", que persigue la transparencia de las empresas en materia de gestión ambienta y de puesta en marcha de políticas efectivas de reducción de emisiones de gases, de consumo de agua y de protección de espacios forestales.

En el caso concreto de España, EXCELTUR, la alianza para la excelencia turística, asociación formada por 25 de las más relevantes empresas que forman dicha cadena y que, en definitiva, es el lobby empresarial más importante de este país, ha sido pionera en afrontar nuevo retos para el sector empresarial turístico. Entre sus estudios y publicaciones, se encuentra MONITUR (Exceltur, 2011), ranking de competitividad 政 posición competitiva de las 17 comunidades, organizando los indicadores en pilares, uno de los cuales es la ordenación y condicionantes competitivos del espacio turístico. Este pilar integra variables como son la protección del territorio, densidad urbanística de los destinos compromiso ambiental, y a su vez se desglosa mediante indicadores como el tratamiento de residuos, reutilización de aguas, gestión ambiental de playas y achesión a programas de compromiso ambiental. No obstante Ilama la atención que ningún indicador haga referencia al cambio climático y a sus efectos previsibles.

Por su parte, grandes grupos hoteleros internacionalizados, como Melia, $\mathrm{NH}$ o Riu, están desarrollando su propias estrategias de reducción de consumo de energía y agua, en el marco de políticas generales de reducción de costes empresariales, que han supuesto la renovación de instalaciones eléctricas y de agua, con efectos palpables de disminución de consumo por plaza hotelera y día en estas dos variables ambientales. De manera que aunque insertas en concepciones de rentabilidad económica de la empresa, debe valorarse muy positivamente los resultados que se están obteniendo a escala de instalación hotelera, que suponen un ejemplo para cadenas hoteleras de menor dimensión o hoteles de titularidad familiar, de los que hay numerosos ejemplos en España y específicamente en su litoral mediterráneo (vid. tabla 13).

Tabla 13. Estrategias de reducción de agua y energía en grandes cadenas hoteleras
CADENA HOTELERA

\begin{tabular}{|c|c|c|}
\hline RIU Hotels and Resorts & $\begin{array}{c}\text { De } 389 \text { I/plaza/día (2013) a 371 I/ } \\
\text { plaza/día (2014) }\end{array}$ & $\begin{array}{c}\text { De 16,03 Kw/plaza/noche (2013) a } \\
15,31 \mathrm{Kw} / \text { plaza/noche (2014) }\end{array}$ \\
\hline Melia Group & $\begin{array}{l}\text { De } 500 \text { I/plaza/día (2013) a 490 I/ } \\
\text { plaza/día (2014) }\end{array}$ & $\begin{array}{c}\text { De 22,30 Kw/plaza/noche (2013) a } \\
21,34 \mathrm{Kw} / \text { plaza/noche (2014) }\end{array}$ \\
\hline HN Hotels & $\begin{array}{l}\text { De } 303 \text { I/plaza/día (2013) a } 300 \text { I/ } \\
\text { plaza/día (2014) }\end{array}$ & $\begin{array}{c}\text { De 55,52 Kw/habitación/noche } \\
\text { (2013) a 51,43 Kw/habitación/noche } \\
\text { (2014) }\end{array}$ \\
\hline
\end{tabular}

Euente: Memorias anuales derest 
Además de las medidas puestas en marcha por las grandes cadenas hoteleras es necesario destacar, por último, las actuaciones de adaptación que han llevado a cabo empresarios turísticos particulares en los últimos años. Básicamente se trata de actuaciones para el fomento del ahorro de energía y de agua en apartamentos $y$, sobre todo, en instalaciones hoteleras que se ha difundido al resto de intalaciones de menor tamaño en diversos destinos turísticos. Es el caso de la Costa Brava (Gabarda, Ribas y Daunis, 2015), de la Costa Daurada, de Mallorca, de Benidorm (Rico et al, 2013), del litoral de Murcia y de la Costa del Sol.

En estos casos, surge primero la necesidad de ahorrar agua, a partir de la década de los años ochenta del pasado siglo y a ello se ha unido la necesidad del ahorro de energía, en los últimos quince años debido al incremento de tarifas eléctricas y el aumento de porcentaje en el gasto de energia eléctrica presupuesto de explotación anual de una instalación hotelera. Suele haber, además, un evento importante de sequía ocurrido en los destinos turísticos, que motiva la realización de actuaciones por parte de la iniciativa privada y que complementan o, incluso, suplen las acciones desarrolladas por las administraciones públicas. Así ha ocurrido en Benidorm, tras la sequía de 1978, en e litoral catalán tras las sequías de 1990-95 y de 2008, en Baleares y Costa del Sol, por la sequía de 1990-95 y en el litoral de Murcia por las frecuentes sequías desde los años ochenta del pasado siglo (Martínez Ibarra, 2015).

Hay que tener en cuenta, asimismo, el papel que han tenido las ayudas a empresas del sector puestas en marcha por las administraciones, estatal y autonómica, en los últimos años en relación con el fomento de medidas generales de sostenibilidad y, específicas, de ahorro de energía y agua. Y asimismo, deben tenerse en cuenta las directrices económicas de las cadenas hoteleras o de particulares de mejora de resultados anuales de explotación en un sector cada vez más competi- tivo, y que han encontrado en la reducción de gastos de energía y agua un elemento de ahorro importante.

Una relación de medidas puesta en marcha por la planta hotelera de las áreas turísticas del litoral mediterráneo español en los últimos quince años contempla:

Instalación de grifería y sanitarios con dosificación de caudal en habitaciones

- Instalación de grifería eficiente en cocinas.

- Sistemas de presión en el suministro de agua de los hoteles.

- Información a los clientes con recomendaciones de ahorro de agua - Sistemas eficientes de riego de zonas ajardinadas (goteo, programa ción de riesgos).

- Mantenimiento de agua en piscinas todo el año, con tratamientos de depuración y cloración.

- Sistemas de ducha de pulsador en piscinas.

- Utilización de agua de pozos propios para rellenado de piscinas

(pozos de los años 70 y 80 .

- Utilización de electrodomésticos eficientes en cocinas y lavandería (lavaplatos, lavadoras).

- Sistemas combinados de ahorro de agua y energía (agua sanitaria con energía solar)

- Sistemas de "emergencia" para abastecimiento en hoteles (agua de pozos y unidades de desalinización propias en grandes hoteles).

En muchos casos, se han aprovechado procesos de renovación de las plantas hoteleras, $y$ la puesta en marcha de programas de ayudas estatales para llevar a cabo dicha renovación. Y el resultado ha sido una disminución en el consumo de agua y de energía eléctrica (Rico et al., 2013; Gabarda et al. 2015), que ha favorecido la reducción en los gastos anuales de explotación de los hoteles.
Es de notar que tanto organismos públicos (Diputaciones Provinciales) como asociaciones hoteleras en las áreas turísticas han desarrollado planes y estrategias orientadas a la reducción de consumos de agua y energía en el sector turístico, en el marco de políticas de adaptación al cambio climático. Debe tenerse en cuenta que la implantación de medidas de reducción de consumo de agua y la estrecha relación que ello tiene con el gasto energético anual de un establecimiento hotelero, puede llegar a suponer una disminución del $25 \%$ en la factura energética de un hotel; de ahí el interés en el desarrollo de este tipo de medidas por parte de las empresas hoteleras, sea cual sea su tamaño y titularidad.

Para impulsar medidas de ahorro de agua y energía, los hoteles han desarrollado, en los últimos, campañas de sensibilización sobre ahorro y uso sostenible del agua, dirigidas tanto a clientes como a trabajadores. S trata de campañas que, en algunos casos, comenzaron ya a finales del pasado siglo, pero que se han intensificado en la última década en relación con la mayor atención a las actuaciones de sostenibilidad. Se ha recurrido al empleo de carteles o adhesivos informativos en las zonas generales en las propias habitaciones. En la actualidad, esta es una medida común en buena parte de la planta hotelera del litoral mediterráneo español. Se anima por ejemplo a los clientes a utilizar las toallas más de un da y se informa de los beneficios que su acción voluntaria supone para el ahorro de agua y detergente, la disminución de la contaminación, y la reducción de emisiones de $\mathrm{CO} 2$ para frenar el cambio climático.
Por último, una línea de actuación futura deberá ser la reutilización de guas residuales en las propias instalaciones hoteleras. En la encues realizada en el presente estudio, se ha puesto de manifiesto la falta tota de acciones de los hoteles dentro de esta estrategia de ahorro de agua. En el informe sobre usos del agua en el área metropolitana de BarceIona (Domene, Sauri et al. 2004) se señalaba la implantación de redes de aguas grises para inodoros en hoteles como una posible medida hialaban ahorros de agua del $10 \%$ respecto al consumo total anual de un hotel, los autores aconsejaban la necesidad de estudiar bien la viabilidad de la inversión a realizar en función del tamaño de la instalación hotelera a reutilización del agua utilizada en lavabos y duchas de las habitaciones para los inodoros, a partir de la instalación de depósitos comunitarios para su tratamiento y posterior utilización en redes de aguas grises con destino a los inodoros supone, en efecto, una inversión costosa que debe valorarse a la hora de aplicar esta medida en un hotel. Otra posibilidad, de coste menor, es el aprovechamiento de agua de las duchas existentes en las piscinas de los hoteles para el rellenado diario que debe realizarse en las propias piscinas y que supondría inversiones asumibles en un hotel. 


\section{TURISMO Y CAMBIO CLIMÁTICO EN LA COMUNIDAD VALENCIANA:

A efectos de planificación y adaptación de los espacios
turísticos de la Comunidad Valenciana a los efectos del cambio climático, estos datos de proyección futura de variables atmosféricas, índices de confort y de temperatura de aguas marinas supon

La posibilidad de modificar el calendario de "temporada alta", muy centrada en la actualidad en julio y sobre todo agosto, que podrá prolongarse desde junio a septiembre, incluidos, además de considerar la estación primaveral junto con octubre muy aptos para las estancias a a 38) muestra la evolución de la temperatura me de los meses de verano en el conjunto de la Comunidad ser de en las dos Utimas décadas. Esta tendencia es, asimis manifiesta en la temperatura media de los primeros diez días del mes de octubre en la serie 1950-2017, lo que confirma la posibilidad mencionada de extender la temperada alta turística hacia los extremos (final de primavera y comienzos de otonol en el territorio valenciano para las diferentes modalidades turísticas $y$, de modo particular, para
de interior.
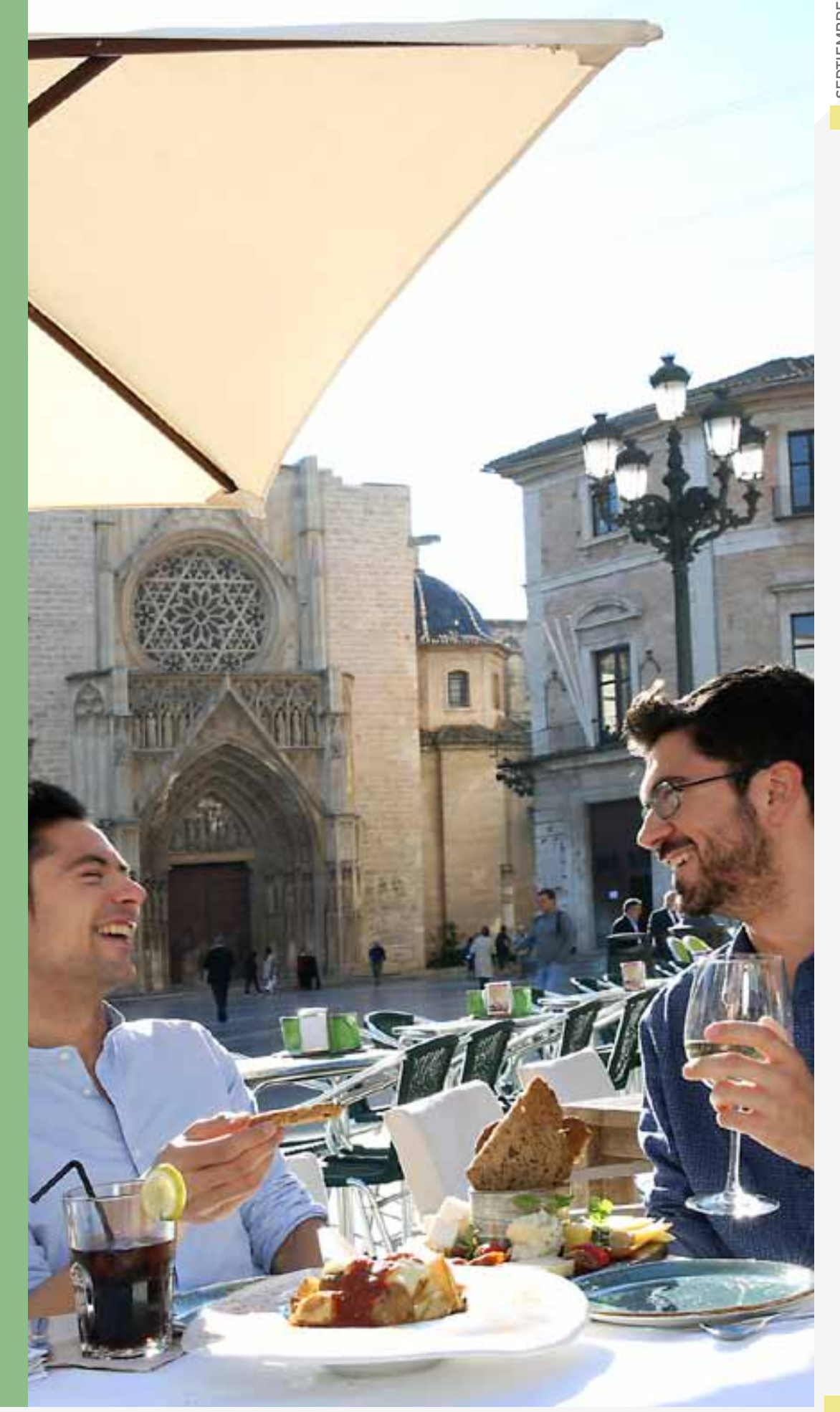


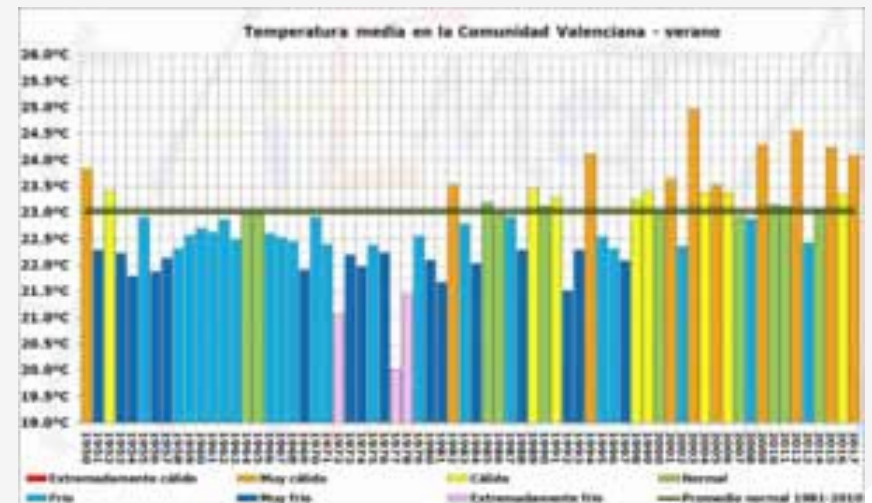
Fuente-AEMET Comunidad Vale

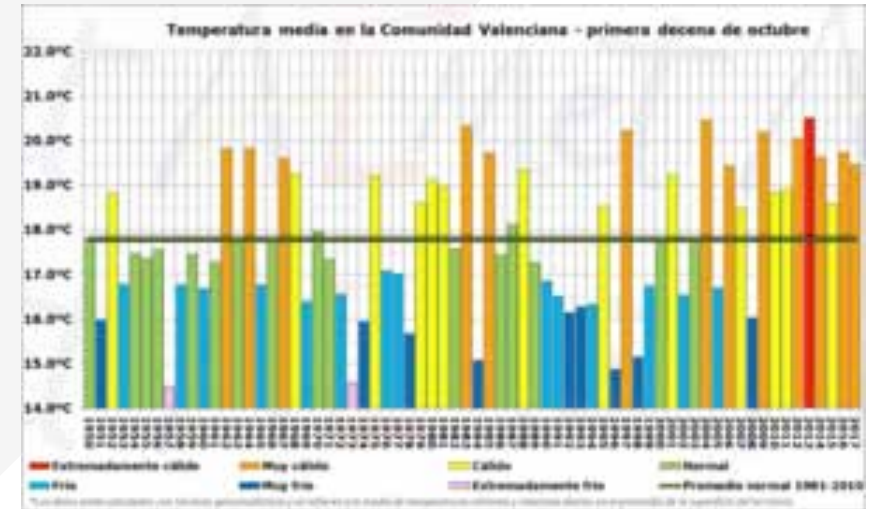

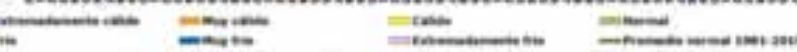

- La necesidad de acondicionamiento climático de los establecimientos turísticos, de las viviendas residenciales y de las tramas urbanas a una situación más habitual de altas temperaturas y elevada humedad, diurna y nocturna, a los efectos de compensar el disconfort térmico que se estima creciente en los espacios costeros, especialmente a partir de mediados del siglo actual.

- La obligación de tener bien diseñados los sistemas de abastecimiento de agua, a escala regional y local, en un área con natural escasez de recursos, donde la propia reducción de precipitaciones, el aumento de la irregularidad en su desarrollo y el incremento de la evaporación en embalses, originará una disminución de volúmenes de agua superficial disponible.
- La necesidad, asimismo, de modificar, en la escala local, los protocolos de protección civil y sanidad pública, puesto que se van a alterar los calendarios de riesgo frente a determinados peligros de causa clmática (tormentas y lluvias intensas por la presencia de aguas calidad en el Mediterráneo occidental durante un período del año mayor), asi como la frecuencia e intensidad de aparición de extremos atmosféricos (olas de calor y sus efectos en grupos de riesgo). En esta cuestión será necesario mejorar los sistemas de drenaje de precipitaciones intensas en las ciudades turísticas en aras a la reducción de sectores de riesgo de anegamiento e inundación.

La tabla adjunta resume el conjunto de propuestas y medidas a desarrollar en los próximos años en relación con los posibles efectos del cambio climático y de sus riesgos asociados en la actividad turística de la Comunidad Valenciana (vid 
Los modelos de cambio climático como se ha señalado no son pronósticos al estilo de la predicción meteorológica diaria. Marcan tendencias a medio y largo plazo, pero ahí estriba su valor. Si las tendencias que muestran resultan poco cambiantes con el paso del tiempo, como ocurre con los modelos climáticos incluidos en los diferentes informes de cambio climático realizados por el IPCC desde 1990, entonces la probabilidad de que se cumplan es elevada. Por ello, la próxima décad va a ser decisiva para confirmar las actuales hipótesis de trabajo del IPCC y mejorar, aún más, la modelización climática para alcanzar escalas de detalle. Ahora bien, la necesidad de mantener la investigación climática con el fin de ir confirmando todos los extremos de la hipótesis principal de trabajo (efecto invernadero de origen antrópico) no debe significar inacción de las administraciones públicas o de los agentes privados en las medidas de mitigación y adaptación que deben aplicarse en los territorios $\mathrm{y}$, especialmente, en la actividad turística del área mediterránea, que es una de las más vulnerables a los efectos de cambio climático señalados.

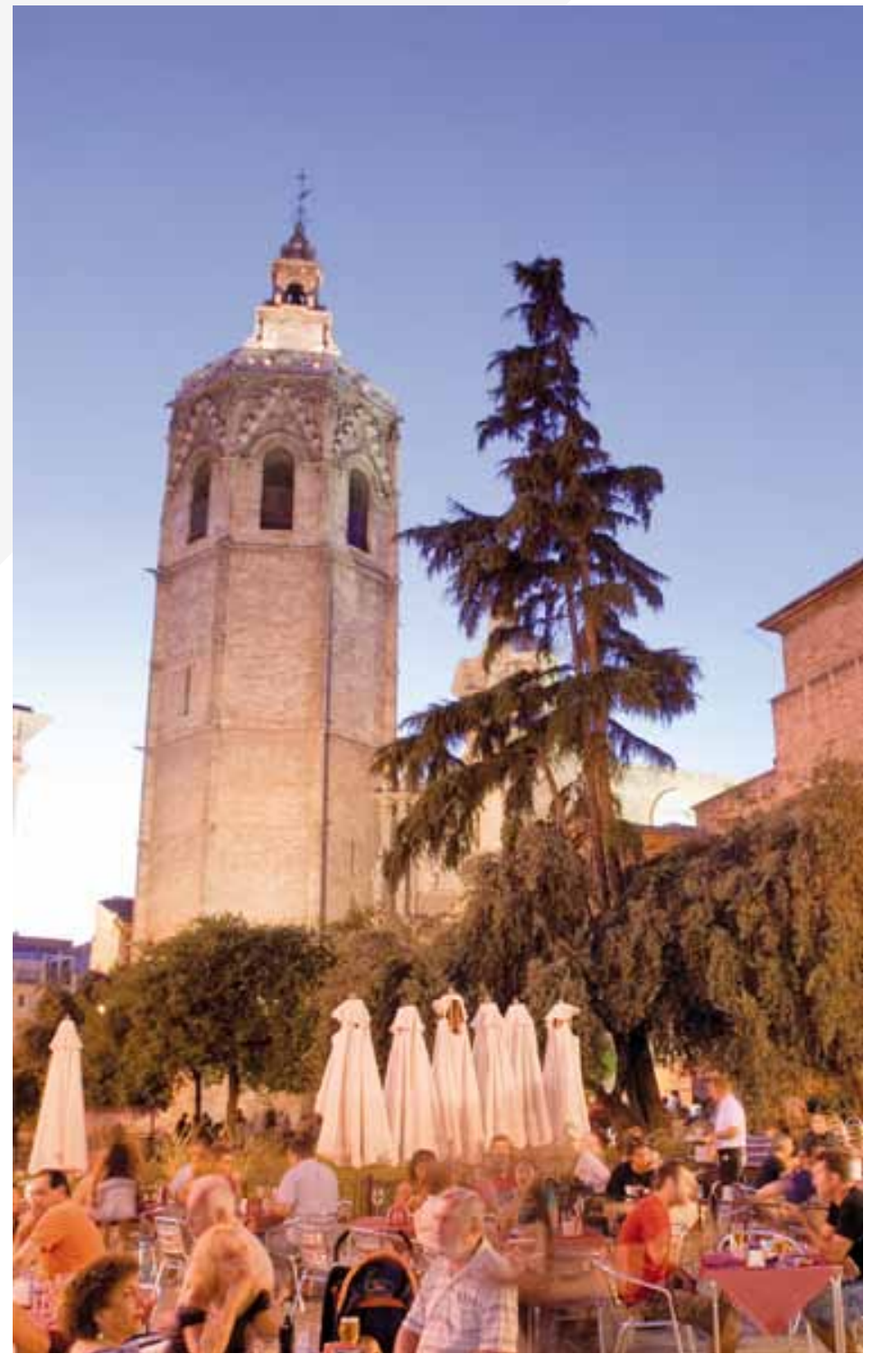

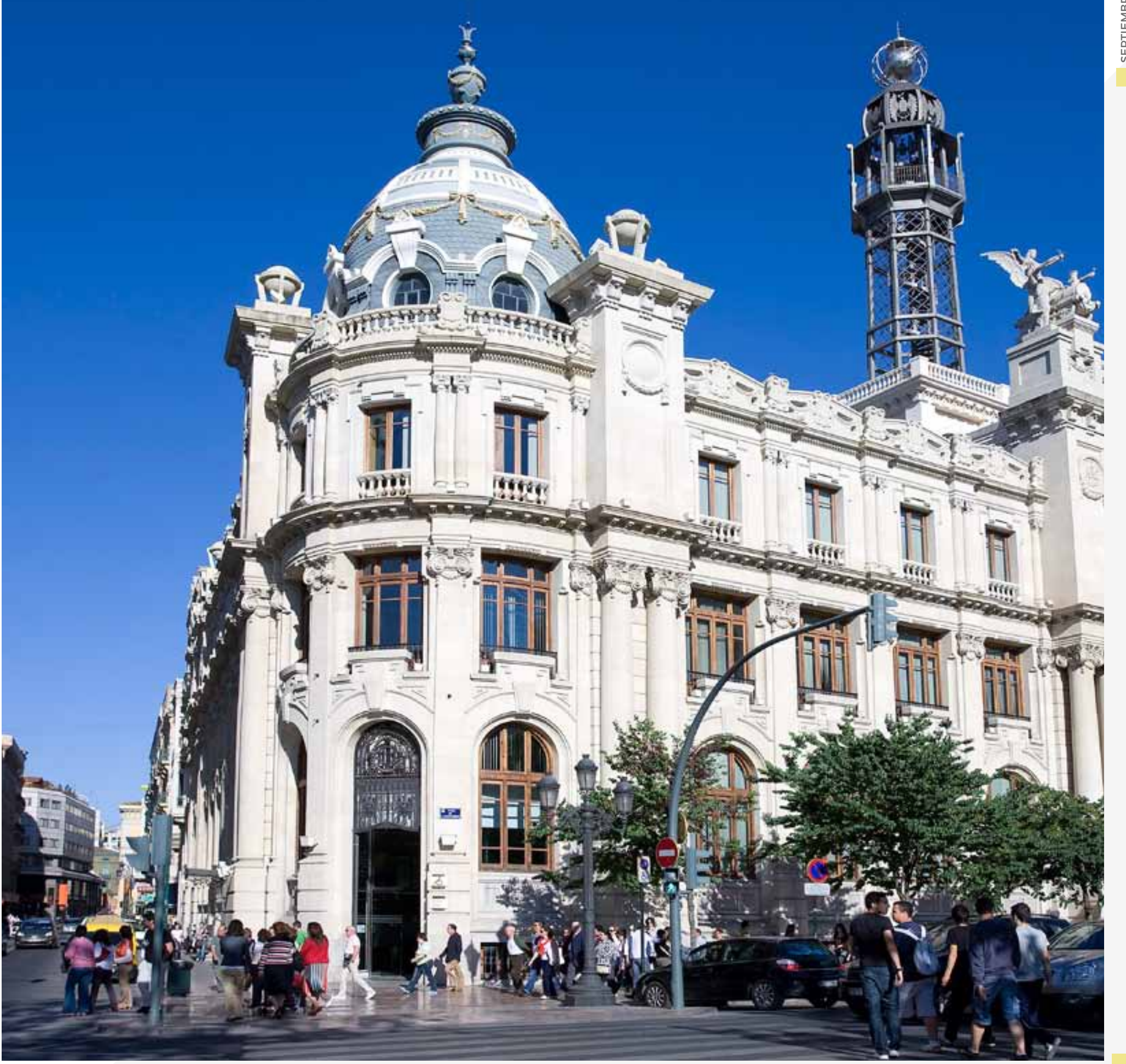




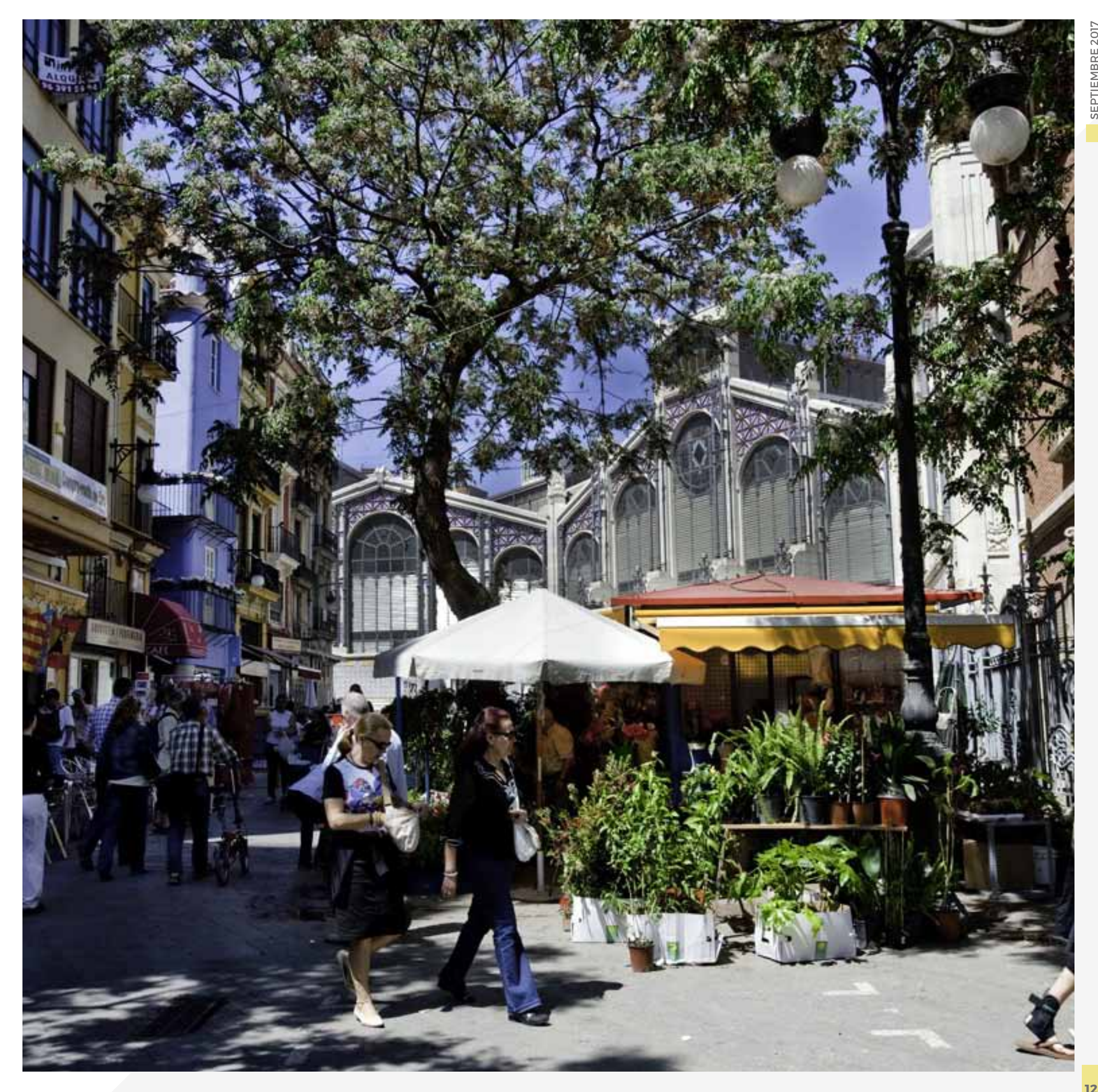


AEMA (2012) Los impactos del cambio climático en Europa: evaluación basada en indicadores. Informe conjunto de la AEMA, CCl y OMS. Oficina de Publicaciones de la CE y Ministerio de Medio Ambiente, Medio Rural y Marino, Madrid, 240

AEMET (2009) Generación de escenarios regionalizados de cambio climático en España. Available at http://www.aemet.es/documentos/ es/elclima/cambio_climat/escenarios/Informe_Escenarios.pdf. AMELUNG, B. and D. VINER (2006). "Mediterranean tourism: exploring the future with the tourism climatic index." Journal of Sustainable Tourism 14(4): 349-366.

AMELUNG, B.; NICHOLLS, S.; VINER, D. (2007) "Implications of global climate change for tourist flows and seasonality", Journal of Travel Research, 45, pp. 285-296.

ANTON CLAVÉ, S.; RULLAN SALAMANCA, O.; VERA REBOLLO, J.F. (2011) "Mass Tourism Development on the Mediterranean Coast", Tourism Geographies, 13:3, 495-501.

BAÑOS CASTINEEIRA, C.J.:VERA REBOLLO, J.F: DÍEZ SANTO, D. (2010) "El abastecimiento de agua en los espacios y destinos turísticos de Alicante y Murcia", Investigaciones Geográiccas, no 51, pp. 81-105. BARNETT J, and O'NEIL S. (2010) "Maladaptation", Global Environmental Change, 20, pp. 211-213.

BECKEN S and J HAY (2007). Tourism and climate change. Risks and opportunities. Clevedon, Buffalo, Toronto, Channel view publications. BODHANOWICZ, P. (2009) "Theory and Practice of Environmental Management and Monitoring in Hotel Chains". In GÖSSLING, S., HALL, C.M. and WEAVER, D. (eds) Sustainable Tourism Futures: Perspectives on Systems, Restructuring and Innovations. London. Routledge: 102130.

BOWS, A., B. ANDERSON, et al. (2009). "Air transport, climate change and tourism." Tourism and hospitality, Planning and development. 6(1) 7-20.

BROUDER, P. and LUNDMARK, L. (2011) “Climate change in North
Sweden: intra-regional perceptions of vulnerability among winteroriented tourism businesses", Journal of Sustainable Tourism 19 (8) pp. 919-933.

BRUNET, M. et al. (2007). Temporal and spatial temperature variability and change over Spain during 1850-2005. Journal of Geophysical Research: Atmospheres, $n^{\circ} 112$, D12117, doi: 10.1029/2006JD008249. BURRIEL, E. L. (2009) "Los límites del planeamiento urbanístico mun cipal. El ejemplo valenciano", Documents d'Anàlisi Geogràica, 54, pp. 33-54.

BURRIEL, E: L. (2008) “La "década prodigiosa”" del urbanismo españo (1997-2006)". Scripta Nova. Revista Electrónica de Geografía y Ciencias Sociales, vol. XII, núm. 270 (64). <http://www.ub.es/geocrit/sn/ sn-270/sn-270/sn-270-64.htm>

BUTCHER, J. (2003) The Moralisation of Tourism. Sun, Sand... and Saving the World? London. Routledge.

CALBO, J;; SANCHEZ-LORENZO, A.; CUNILLERA, J. y BARREDAESCODA, A. (2010) “Projeccions i escenaris de future", en LLEBOT, J.E. (Ed): Segon informe sobre el canvi climatic a Catalunya. Barcelona: Institut d'Estudis Catalans and Generalitat de Catalunya. ConsellAssessor per al Desenvolupament Sostenible de Catalunya, 183-239. CERON, J. P. and G. DUBOIS (2005). "Limits to tourism? A backcasting scenario for a sustainable tourism mobility in 2050" Symposium “The end of Tourism? Mobility and Local-global connections", Eastbourne CTPS

COROMINAS, J. (2008) "Los nuevos Planes Hidrológicos de las Cuencas Andaluzas". $1^{\circ}$ Seminario Nacional sobre "Los nuevos planes de Cuenca según la Directiva Marco del Asua” Fundación Botin Mudrid. Disponible en http://www.fundacionmbotin.org/seminarios-nacionales-ponencias_observatorio-del-agua_publicaciones.htm CUNILLERA, J., MAS, J., MANZANO, A., PRAT N., MUNNE, A., SAURI D. (eds.) (2009) Aigua i Canvi Climàtic. Barcelona: Agència Catalana de 'Aigua.
DODDS, R. (2007) Sustainable tourism and policy implementation: lessons from the case of Calviá. Spain. Current Issues in Tourism. 10 296-322.

DOMENE, E., SAURI, D., PARES, M. (2005) “Urbanization and Sustainable Resource Use: The case of garden watering in the Metropolitan Regio of Barcelona", Urban Geography, 26(6), 520-535.

DUBOIS AND CERON (2006) "Tourism and climate change: Proposals for a research agenda", Journal of Sustainable Tourism, 14 (4): 399-415. DUC PHAM, T., SIMMONS, D.G. and SPURR, R. (2010) “Climate Change Induced Economic Impacts on Tourism Destinations: The case of Australia". Journal of Sustainable Tourism, Vol. 8, Issue 3,pp. 449 - 473. ESPON Climate. (2011) Climate Change and Territorial Effects on Regions and Local Economies. Main Report. Available at: http://www. espon.eu/export/sites/default/Documents/Projects/AppliedResearch/ CLIMATE/ESPON_Climate_Final_Report-Part_B-MainReport.pdf. ESSEX, S., KENT, M., \& NEWNHAM, R. (2004) Tourism development in Mallorca: Is water supply a constraint? Journal of Sustainable Tourism $12(1), 4-28$

XCELTUR (2005) Impactos sobre el entorno, la economía y el empleo de los distintos modelos de desarrollo turístico del litoral mediterrán español, Baleares y Canarias. Resumen ejecutivo. Madrid: Deloitte y Area de Estudios e Investigaciones de Exceltur.

FUNDACIÓN BBVA (2006) Conciencia y conducta medioambiental en España. Unidad de Estudios de Opinión Pública, Madrid, 71 p. Disponible en http://www.fbbva.es/TLFU/dat/resultados_medio_ambiente.pdf FUNDACIÓN OPTI (2005) Estudio de prospectiva del sector turismo. Escenarios de demanda globaly tendencias tecnológicas. Madrid Fundación OPTI.

GARCIA, C. \& SERVERA, J. (2003) Impacts of tourism development on water demand and beach degradation on the island of Mallorca (Spain). Geografiska Annaler, 85 A (3-4), 287-300.

GIL OLCINA, A. (2010) “Optimización de recursos hídricos y armoniza- ción de sus usos: el Consorcio de Aguas de la Marina Baja", Investigaciones Geográficas, 51, 165- 183

GIL OLCINA, A. And RICO AMOROS,A.M. (2007) Políticas del Agua II. Mejora y ampliación de los riesgos de Levante. Murcia: ESAMUR. GOMEZ-MARTIN, B. (2006). "Climate potential and tourist demand in Catalonia (Spain) during the summer season", Climate Research(32): 75-87.

GOSSLING, S and HALL, C. M. (2006) "Uncertainties in predicting tourist fows under scenarios of climate change" Climate Change, 79, pp. 163173.

GÖSSLING, S. (2002) “Global Environmental Consequences of Tourism” Global Environmental Change, 12(4): 283-302

GÖSSLING, S. and C.M. HALL (eds) (2005) Tourism and Global Environmental Change. Ecological, social, economic and political interrrelationships. London, Routledge.

GÖSSLING, S. and PEETERS, P.M. (2007). "It does not harm the environment!" An analysis of industry discourses on tourism air travel and the environment" Journal of Sustainable Tourism 15(4), pp. 402-417.

GOSSLING, S., SCOTT, D., HALL, CM ; CERON, JP; DUBOIS, G (2012) Consumer Behaviour and Demand response of tourist to climate change", Annals of Tourism Research, 39, 1: 36-58

GÖSSLING, S., J. BRODERICK, et al. (2007). "Voluntary carbon offsetting schemes for aviation : efficiency and credibility " Journal of Sustainable tourism. 15(3): 223-248.

GOSSLING, S., P. PEETERS, et al. (2012). "Tourism and water use:

Supply, demand and security. An international review." Tourism management(33): 1-15.

GÖSSLING, S. PEETERS, P. and SCOTT, D. (2008) "Consequences of Climate Policy for International Tourist Arrivals in Developing Countries". Third World Quarterly 29(5), pp. 873-901.

GÖSSLING,S., P. PEETERS, C. M. HALL, J-P CERON, G. DUBOIS, L. LEHMANN ANDD SCOTT (2012) “Tourism and wateruse:Supply, Demand 
and Security. An international review", Tourism Management, 33, 1-15. HALL, C.M. and HIGHAM, J. (eds.) (2005) Tourism, recreation and climate change: International perspectives. Clevedon UK: Channel View Publications

HAMILTON, L.C. and KEIMB, B.D. (2009) "Regional variation in perceptions about climate change", International Journal of Climatology 29, pp. 2348-2352

HEIN. L.. M.J. METZGER and MORENO, A. (2009) "Potential impacts of climate change on tourism; a case study for Spain Current Opinion", Environmental Sustainability, 1, pp. 170-178.

HOF, A. \& SCHMITT, T. (2011) Urban and tourist land use patterns and water consumption: evidence from Mallorca, Balearic Islands, Land Use Policy, 28, 792-804

INSTITUTO NACIONAL DE ESTADÍSTICA (2010) Banco de datos sobre el sector turístico español. Available at http://www.ine.es/ inebmenu/mnu_hosteleria.htm

INSTITUTO NACIONAL DE ESTADÍSTICA (2010) Encuesta de ocupación hotelera. http://www.ine.es/jaxi/menu.do?type=pcaxis\&path $=\% 2 \mathrm{Ft} 11 \% 2 \mathrm{Fe} 162$ eoh $\&$ file=inebase $\& \mathrm{~L}=0$ Last accessed 2 nd August 2010

JRC (2009) The PESETA project. Impact on climate change in Europe. European Commission. Disponible en http://peseta.jrc.ec.europa.eu/ mperatura del mar Balear a partir de imágenes de satélite. Universidad de Valencia, 158 pp.

MARCH, H. and SAURI, D. (2009) "What lies behind domestic water use? A review essay on the drivers of domestic water consumption Boletin de la Asociación de Geógrafos Españoles, 50, 297- 314 MIECZKOWSKI, Z. T. (1985)., The tourism climatic index: a method of evaluating world climates for tourism. The Canadian geographer, $n^{\circ} 29$ p. 220-33.
MIRO PEREZ, J.J. (2014) Downscaling estadistico de series climáticas mediante redes neuronales: Reconstrucción en alta resolución de a temperatura diaria para la Comunidad Valenciana Interpolacion espacial y análisis de tendencias (1948-2011). Tesis Doctoral. Instituto Interuniversitario de Geografía de la Universidad de Alicante, Fundación Centro de Estudios Ambientales del Mediterráneo, y Departamento de Geografía de la Universidad de Valencia. 523p. Doi: 10.13140/RG.2.1.2059.1523.

MIRÓ, J. J., ESTRELA, Ma J.y MILLÁN, M. (2006) “Summer Temperature Trends in a Mediterranean Area (Valencia Region)". Internationa Journal of Climatology, $n^{\circ} 26$, p. 1051-1073, doi: 10.1002/joc.1297. MIRÓ, J. J., ESTRELA, M² J. y OLCINA CANTOS, J. (2015), Statistical downscaling and attribution of air temperature change patterns in the Valencia region (1948-2011). Almospheric Research, $n^{\circ} 156, p .189$ 212, doi:10.1016/j.atmosres.2015.01.003 MIRÓ PÉREZ, J.J; ESTRELA NAVARRO, Ma J.; OLCINA CANTOS, J. (2016) "Reconstrucción de la señal térmica local en la Comunidad Valenciana entre 1948 y 2011 a partir de un downscaling estadístico mediante una red neuronal artificial: detección de patrones locales de cambio", Boletín de la Asociación de Geógrafos Españoles, $n^{\circ} 70$, 113-147.

MIRÓ, J.J., CASELLES, V.y ESTRELA, M.J. (2017). Multiple imputation of rainfall missing data in the lberian Mediterranean context. Atmospheric Research, $\mathrm{n}^{\circ}$ 197, p.313-330, https://doi.org/10.1016/1 atmosres.2017.07.016

OBSERVATORIO DE LA SOSTENIBILIDAD DE ESPAÑA (2006) Cambios de ocupación del suelo en España. Implicaciones para la sostenib-

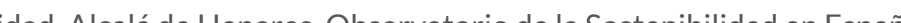
de Medio Ambiente.

OBSERVATORIO DE LA SOSTENIBILIDAD DE ESPAÑA (2012) Atlas de la sostenibilidad en España. Alcalá de Henares. Observatorio de la Sostenibilidad en España, Ministerio de Medio Ambiente.

LLCINA CANTOS, J. (2009) "Cambio climático y riesgos climáticos en España", Investigaciones Geográficas, 49. Instituto Universitario de Geografía, Universidad de Alicante, pp. 197-220.

OLCINA CANTOS, J. (2012) "Turismo y cambio climático: una actividad vulnerable que debe adaptarse", Investigaciones Turisticas, 4, pp. 1-34. ICINA CANTOS, Jy MOLTÓ MANTERO, E (2010) "Recursos de agu no convencionales en España. Estado de la cuestión, 2010" Investigaciones Geográficas, 51. Instituto Universitario de Geografía, Universidad de Alicante, pp. 131-163.

OLCINA CANTOS, J.; VERA-REBOLLO, J.F. (2016a) "Adaptación del

sector turístico alcambio clinático en Españ ta importancide acciones a escala local y en empresas turísticas", Anales de Geografía de la Universidad Complutense, $n^{\circ} 36$ (2), 331-349. OLCINA CANTOS, J.; VERA-REBOLLO, J.F. (2016b) "Climate change and tourism policy in Spain: Diagnosis in the Spanish mediterranean coast', Cuadernos de Turismo de la Universidad de Murcia $0^{\circ} 38$ 565-571. OLCINA CANTOS, J.; BAÑOS CASTIÑEIRA, C.; RICO AMORÓS, A. M. (2016) "Medidas de adaptación al riesgo de sequía en el sector hotelero de Benidorm (Alicante, España)", Revista de Geografía Norte Grande, $\mathrm{n}^{\circ}$ 65, 129-153.

PALMER, T \& RIERA, A. (2003) Tourism and environmental taxes with secial reference to the 'Balearic ecotax', Tourism Management, 24, 665 674

PASTOR, F., VALIENTE, J.A.y ESTRELA, Ma J. (2015) Sea surface temperature and torrential rains in the Valencia region: modelling the role of recharge areas. Natural Hazards and Earth System Sciences, $\mathrm{n}^{\circ} 15$, p.1677-1693, doi:10.5194/nhess-15-1677-2015

PASTOR, F., VALIENTE,J.A., PALAU, J.L. (2017). “Sea surface temperature in the Mediterranean climatology, trends and spatial patterns" poster presented in 10th Hymex Workshop in Barcelona (4-7 July 2017), http:// www.ceam.es/VERSUS/publications.html

PEETERS, P. and G. DUBOIS (2010). “Exploring tourism travel under climate change mitigation constraints." Journal of Transport Geography 18: 447-457.

PEETERS, P., GÖSSLING, S. and BECKEN, S. (2006) "Innovation towards tourism sustainability: climate change and aviation" International Journal of Innovation and Sustainable Development 1(3), pp. 184-200. PEETERS, P., S. GÖSSLING, et al. (2007). “Innovation towards tourism sustainability: climate change and aviation." International journal of innovation and sustainable development 1(3): 184-200

PEETERS, P. SZIMBA, E. and DUIJNISVELD, M. (2007) “Major Environmental Impacts of European Tourist Transport"., Journal of Transport Geography 15, pp. 83-93.

QUEREDA SALA, J. et al. (2001) Nuestro porvenir climático, ¿Un escenario de aridez?. Universitat Jaume I, Castellón, 224 p.

QUEREDA SALA, J.; MONTON CHIVA, E. y ESCRIG BARBERA, J. (2009) Evaluación del cambio climático y de su impacto sobre los recursos hídricos en la cuenca del Júcar. Generalitat Valenciana, Valencia, 165 pp. RICO AMORÓS, A.M. (2007) “Tipologías de consumo de agua en abastecimientos urbano-turísticos de la Comunidad Valenciana", Investigaciones Geográficas, $n^{\circ} 42$, pp. 5-34.

RICO-AMOROS, A., OLCINA-CANTOS,J. AND SAURI, D. (2009) “Tourist Land Use Patterns and Water Demand. Evidence from the Western Mediterranean", Land Use Policy, 26, 493-501.

RODRÍGUEZ MÉNDEZ, M. y DOMÍNGUEZ GARCÍA, M.D. (2011)

"Cambio climático, turismo y políticas regulatorias", Revista de Análisis Turistico no 11. AECIT, Madrid, pp. 35-44

ROSELLO, J. (2011) “España, Turismo y cambio climático", Economistas nº 
127, Madrid, en pp. 28-34.

SAURÍ, D. AND LLURDEÉS, J.C. (2010) “El Turisme”, a J.E. Llebot (ed): Se-

gon Informe sobre el Canvi Climàtic a Catalunya. Barcelona: Generalitat de Catalunya, CADS.

SAURÍ D OLCINA J MARCH, H. MARTÍN-VIDE, J, VERA, F, PADILLA E. and SERRA-LLOBET, A. (2011) "Case Study Mediterranean Coast of Spain", in ESPON Climate: Climate Change and Territorial Effects on

Regions and Local Economies. Applied research project 2012/1/4. Final Report. Annex 4. Disponible en: www.espon.eu/export/sites/default/ Documents/Projects/AppliedResearch/CLIMATE/ESPON_Climate_Final_Report_Annex4_Spain_Case_Study.pdf.

SCOTT, D. (2006) "Climate change and sustainable tourism in the 21s century" in Cukier 'Hed) Tourism Research. Policy Planning and Prospects. Waterloo. Department of Geography, University of Waterloo, pp. $175-248$

SCOTT, D. and LEMIEUX, C. (2009). Weather and Climate Information for Tourism .Geneva and Madrid. WMO and UNWTO.

SCOTT, D. C.M HALL, and GÖSSLING, S. (2011) Climate change and tourism: Impacts, adaptation and mitigation. London, Routledge.

SCOTT, D., P. PEETERS, et al. (2010). "Can tourism deliver its "aspirational" greenhouse gas emission reduction tagets?" Journal of Sustainab Tourism 18(3): 393-408.

SCOTT,D. and BECKEN,S.(2010) "Adapting to climate change and climat policy: progress, problems and potentials", Journal of Sustainable Tourism, vol. 18, n 3, pp. 283-296.

STERN, N. (2006) The Economics of Climate Change: The Stern Review. Cambridge.Cambridge University Press.

SUSTAINABLE TOURISM COOPERATIVE RESEARCH CENTRE (2009) The Impacts of Climate Change on Australian Tourism Destinations: developing adaptation and response strategies - Summary. Sustainable Tourism Cooperative Research Centre, Gold Coast, Qld.

TẢBARA, J.D. (2010) "Percepció I comunicación del canvi climàtic a Cataya. Barcelona, Generalitat de Catalunya i Institut d'Estudis Catalans, pp. 977-1010.

TORTELLA, B.D. \& TIRADO, D. (2011) Hotel water consumption at a seasonal mass tourist destination. the case of the island of Mallorca Journ of Environmental Management, 92, pp. 2568-2579.

TURTON, S., HADWEN, W. and WILSON, R. (Eds.) (2009) The Impacts of Climate Change on Australian Tourism Destinations: developing adaptation and response strategies - A Scoping Study. Sustainable Tourism Cooperative Research Centre, Gold Coast, Qld.

UNWTO, UNEP and WMO (2007) Climate Change and Tourism. Responding to Global Challenges. Advanced Summary. Report Prepared for the Second Conference on Climate Change and Tourism, Davos, Switzerland.

UNWTO, UNEP, et al. (2008). Climate change and tourism. Responding to global challenges. Madrid, UNWTO.

VERA REBOLLO, J. F. (1985), “Las condiciones climáticas y marítimas como factores de localización del turismo histórico alicantino", Investiga ciones Geográficas n 3, pp. 161-178,

VERA REBOLLO, J.F. (1987) Turismo y urbanización en el litoral ali-

cantino. Instituto de estudios Juan Gil Albert, Diputación Provincial de Alicante.

VERA REBOLLO, J. F. (2006) "Agua y modelos de desarrollo turístico: la necesidad de nuevos criterios para la gestión de los recursos", Boletín de la Asociación de Geógrafos Españoles, n 42, pp. 155-178.

VERA REBOLLO. J.F. (coord.) LÓPEZ PALOMEQUE, F. MARCHENA
GÓMEZ, M. y ANTÓN CLAVE, S. (2011) Análisis Territorial del Turismo y planificación de destinos turísticos, Valencia, Tirant Lo Blanch, 473 p. VERA REBOLLO, J.F. and IVARS, J.A. (2004) 'Measuring Sustainability in a Mass Tourist Destination: Pressures, Perceptions and Policy Response in Torrevieja, Spain', Journal of Sustainable Tourism, 11, 2\&3, 181-203. VERA REBOLLO, J.F. and IVARS, J.A. (2009) "Spread of Low-Cost Carriers: Tourism and Regional Policy Effects in Spain", Regional Studies, vol. 43, 4, 559-570.

VERA REBOLLO, J.F. Y BAÑOS, C.J. (2010) "Renovación y reestructuración de los destinos turísticos consolidados del litoral: las prácticas recreativas en la evolución del espacio turístico", Boletín de la Asociación de Geógrafos Españoles, nº 53, pp. 329-353.

VERA REBOLLO, J.F. Y RODRIGUEZ SÁNCHEZ, I. (eds.) (2012) Renovación y reestructuración de destinos turísticos en áreas costeras, Valencia, Publicaciones de la Universitat de València, $429 \mathrm{p}$

WORLD TRAVEL AND TOURISM COUNCIL (2009) Leading the Challenge on Climate Change. London. World Travel \& Tourism Counci.

YEOMAN, I. (2008) Tomorrow's tourist. Scenarios \& Trends. Amsterdam Elsevier Science. 
ACTIVIDAD TURÍSTICA Y CAMBIO CLIMÁTICO EN LA COMUNIDAD VALENCIANA

Diagnóstico y propuestas

anValenciona

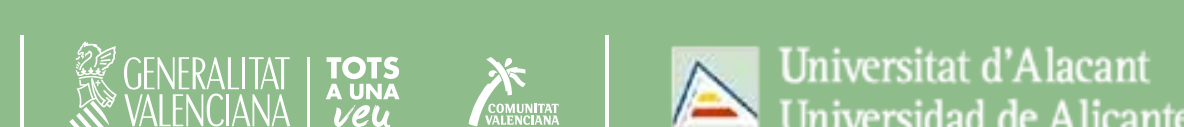

Universidad de Alicante

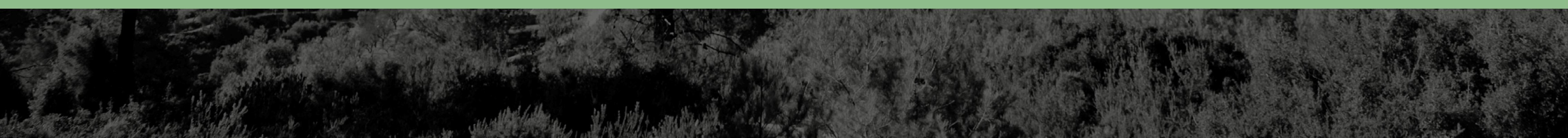

